USE OF INTRAVENOUS LIDOCAINE TO TREAT DEXMEDETOMIDINE
INDUCED BRADYCARDIA IN SEDATED AND ANESTHETIZED DOGS

by

Tainor Tisotti

A Thesis
presented to
The University of Guelph

In partial fulfillment of requirements

for the degree of

Doctor of Veterinary Science

in

Clinical Studies

Guelph, Ontario, Canada

(C) Tainor Tisotti, September, 2020 


\section{ABSTRACT \\ USE OF INTRAVENOUS LIDOCAINE TO TREAT DEXMEDETOMIDINE INDUCED BRADYCARDIA IN SEDATED AND ANESTHETIZED DOGS}

Tainor Tisotti

University of Guelph, 2020
Advisor:

Alexander Valverde

This thesis evaluated the use of intravenous lidocaine to treat the bradycardia associated with the administration of the sedative dexmedetomidine in canine anesthetic protocols. Research Beagle dogs were assigned to three different groups in a randomized crossover design that involved the administration of intravenous dexmedetomidine in different modalities of the anesthetic protocol. In two groups, dexmedetomidine was administered to dogs while awake and in the third group while anesthetized with isoflurane. After receiving dexmedetomidine, dogs were given intravenous lidocaine as a bolus 30 minutes later, followed by a second bolus and a constant rate infusion 20 minutes after the first bolus, in one of the awake groups and the anesthetized group. The other awake group received the lidocaine bolus and constant rate infusion 5 minutes after the dexmedetomidine.

Intravenous lidocaine increased heart rate in awake and anesthetized dogs pretreated with intravenous dexmedetomidine. Additional benefits from lidocaine administration included an increase in cardiac index and a decrease in systemic vascular resistance. 


\section{DEDICATION}

In Memoriam of my grandparents

Ieda Hainzenreder and João de Mesquita. 


\section{ACKNOWLEDGEMENTS}

Many people have contributed in the last years to help me reach my professional goals.

Foremost, I would like to thank my supervisor, Dr. Alexander Valverde, for opening the doors for me, for being resolute, tireless and for his guidance during my program. I would also like to thank all the anesthesia faculties I had the opportunity to work with and absorb some of their knowledge, but specially to Drs. Andrea Sanchez, Carolyn Kerr and Melissa Sinclair for the personal and professional support along these three years. To my committee advisors, Drs. Lynne O’Sullivan, Brad Hanna and Luis Arroyo. Additionally, I would like to thank Dr. Andrea Sanchez and Dr. Luis Gaitero for their friendship and support.

I would like to thank my resident mates for their help when needed, specially to Rodrigo Aguilera for his friendship and support. Additionally, I am grateful to all OVC personnel that have been helpful and kind during these three years, particularly to the anesthesia technicians, specially to Carolyn Sidenberg, who has become a friend.

I wish to show my gratitude to Gibrann Castillo, not only for being an excellent colleague, but specially for becoming my best friend in Canada, and making these past years go by easier. Also, I would like to thank Dr. Xiu Ting for her friendship, Michelle Colpits for her friendship and shedding some light on what Canada is, and to my Portuguese speaking friends, Camila Cantarelli, Luiza Zakia and Rita Serrenho.

I would not have reached this point without the help and support from many people in Brazil throughout my academic and professional life, but I would like to single out Dr. Cláudio Natalini, who gave me opportunities as a student, introduced me to the world of 
veterinary anesthesia and became a friend. I would like to extend it to Dr. Priscila Serpa, for her support and knowledge shared with me. Additionally, I am grateful to my parents Arno Tisotti and Helita de Mesquita, my parents-in-law Benoni Pires and Débora Pires, my sister-in-law Thayná Pires, all my many family members and friends spread across the continent, specially to Rafael Ruggeri, Bruno Teixeira, Günther Greiwe, Rafael Kretzer and Leonardo Bonneau, for being supportive, understanding and bringing joy to my days. Finally, I would like to show my appreciation to the most important person on this journey, my wife Ananda Pires for all the support and patience in the last years. We have endured almost four residencies and a change of country, which has physically parted us for some extension of the path, but that has strengthened our relationship. Thank you for your unconditional love. 


\section{TABLE OF CONTENTS}

ABSTRACT

DEDICATION

ACKNOWLEDGEMENTS _ _ _

TABLE OF CONTENTS

DECLARATION OF WORK PERFORMED X

LIST OF FIGURES $\quad x i$

LIST OF TABLES $\ldots \ldots \ldots \ldots$

LIST OF ABBREVIATIONS _ _ _ X

\section{CHAPTER 1:}

\section{GENERAL LITERATURE REVIEW}

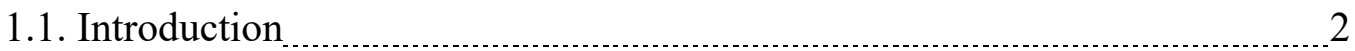

1.2. Electric Activity of the Heart

1.2.1. Action Potential of Heart Cells

1.2.1.1. Sinoatrial Node $\ldots \ldots$

1.2.1.2. Atria 6

1.2.1.3. Atrioventricular Node $\quad 7$

1.2.1.4. His-Purkinje System $\ldots$

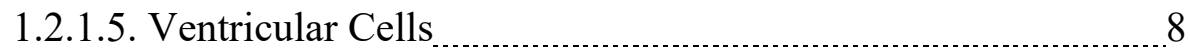

1.2.2. Action Potential of Muscle Cells _.............................................. 9

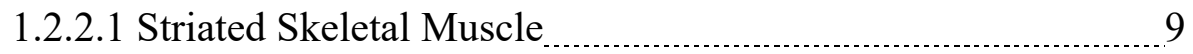

1.2.2.2 Smooth Muscle 
1.2.4. Arrhythmias

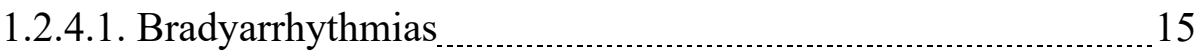

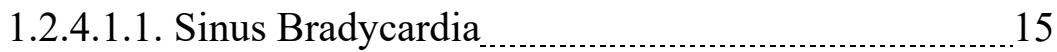

1.2.4.1.2. Atrioventricular Block 16

1.2.4.1.3. Sinus Node Dysfunction and Sick Sinus Syndrome

1.2.4.1.4. Atrioventricular dissociation

1.3. Antiarrhythmic drugs

1.3.1. Classification, Mechanism, and Sites of Action 19

1.3.2. Lidocaine $\quad 24$

1.3.2.1. Effects on Cardiac Electrical Activity ................................... 24

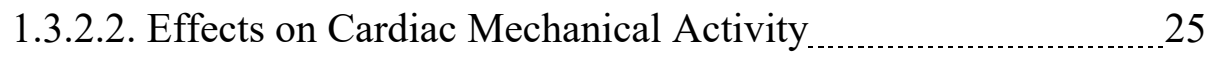

1.4. Heart as a Pump $\ldots \ldots$

1.4.1. Cardiac Cycle

1.4.2. Cardiac Output Determinants _ 28

1.5. Sedatives and Tranquilizers in Small Animals 29

1.5.1. Dexmedetomidine 32

1.5.1.1. Effects on Cardiac Electrical Activity ................................... 34

1.5.1.2. Effects on Cardiac Mechanical Activity ................................... 35

1.6. Effects of General Anesthesia on Cardiac Function $\ldots$

1.6.1. Isoflurane 37 
1.7. Drugs to Treat Bradyarrhythmias

1.7.1. Anticholinergics

1.7.2. Sympathomimetics

1.7.3. Lidocaine

1.8. Dexmedetomidine Antagonists

1.8.1. Atipamezole

1.8.2. Vatinoxan

1.9. Rationale, Hypothesis, and Objectives 46

1.10. References 48

\section{CHAPTER 2:}

\section{USE OF INTRAVENOUS LIDOCAINE TO TREAT DEXMEDETOMIDINE- INDUCED BRADYCARDIA IN SEDATED AND ISOFLURANE-ANESTHETIZED DOGS}

2.1. Summary 69

2.2. Introduction 71

2.3. Materials and Methods

2.3.2. Study Design 74

2.3.3. Anesthesia and Instrumentation 74

2.3.4. Cardiorespiratory Measurements .76

2.3.5. Recovery from Sedation/Anesthesia 77

2.3.6. Data Analysis 78 
2.4.1. Effects of Lidocaine 30 Minutes After Dexmedetomidine in Sedated Dogs (SED1) 80

2.4.2. Effects of Lidocaine 5 Minutes After Dexmedetomidine in Sedated Dogs (SED2) 81

2.4.3. Effects of Lidocaine 30 minutes After Dexmedetomidine in IsofluraneAnesthetized Dogs (ISO) 81

2.5. Discussion 83

2.6. References 90

2.7. Appendix 1 99

2.8 Appendix 2 100

\section{CHAPTER 3:}

\section{GENERAL DISCUSSION AND FINAL CONCLUSIONS}

3.1 General Discussion

3.2 Final Conclusions

3.3 References 


\section{DECLARATION OF WORK PERFORMED}

I declare that the work reported in this thesis was performed by myself and the contributing authors as stated.

The authors' contribution is as follows:

Tainor Tisotti: Study design, experimental study, anesthetic monitoring and data collection, statistical analysis, and thesis preparation. Alexander Valverde: Student advisor, study design and funding application, experimental study, data collection, statistical analysis, and thesis revision. Brad Hanna: Advisory committee member, study design, and thesis revision. Lynne O'Sullivan: Advisory committee member, study design, and thesis revision. Luis Arroyo: Advisory committee member, study design, and thesis revision. Ashley Hopkins: Assistance with experimental study, data collection, and thesis revision. 


\section{LIST OF FIGURES}

FIGURE

Page

Figure 1.1

Action potential configurations in different regions of the mammalian heart

\section{Figure 1.2}

Individual currents responsible for depolarization of a pacemaker cell in the SA node. The outward current iKAch helps stabilize resting potential; when this current is increased by parasympathetic stimulation, heart rate slows.... 5

\section{Figure 1.3}

Surface electrocardiogram in lead II of a normal cardiac action potential being conducted through the atria and ventricles

\section{Figure 2.1}

(a) Heart rate (HR), (b) mean arterial pressure (MAP), (c) cardiac index (CI) and

(d) systemic vascular resistance index (SVRI) in conscious dogs administered IV dexmedetomidine (D; $10 \mu \mathrm{g} \mathrm{kg}^{-1}$ ), followed by an IV lidocaine bolus (L; $2 \mathrm{mg} \mathrm{kg}$

${ }^{1}$ ) after 30 minutes, and a second lidocaine bolus and constant rate infusion 20 minutes later (L-CRI, $2 \mathrm{mg} \mathrm{kg}^{-1}+50 \mu \mathrm{g} \mathrm{kg}^{-1}$ minute ${ }^{-1}$ for 30 minutes), followed by a washout period (W) of 30 minutes (group SED1). Data expressed as mean \pm standard deviation. *Significantly different from $\mathrm{D}(p<0.05)$. Horizontal line 
indicates all values during that period of assessment were significantly different from $\mathrm{D}$ 102

\section{Figure 2.2}

(a) Heart rate (HR), (b) mean arterial pressure (MAP), (c) cardiac index (CI) and (d) systemic vascular resistance index (SVRI) in conscious dogs administered IV dexmedetomidine (D; $10 \mu \mathrm{g} \mathrm{kg}^{-1}$ ), followed by an IV lidocaine bolus and constant rate infusion 5 minutes later (L-CRI, $2 \mathrm{mg} \mathrm{kg}^{-1}+50 \mu \mathrm{g} \mathrm{kg}^{-1}$ minute ${ }^{-1}$ for 30 minutes), followed by a washout period (W) of 30 minutes (group SED2). Data expressed as mean \pm standard deviation. * Significantly different from $\mathrm{D}(p<0.05)$. Horizontal line indicates all values during that period of assessment were significantly different from $\mathrm{D}$ 103

\section{Figure 2.3}

(a) Heart rate (HR), (b) mean arterial pressure (MAP), (c) cardiac index (CI) and (d) systemic vascular resistance index (SVRI) in isoflurane-anesthetized dogs administered IV dexmedetomidine (D; $10 \mu \mathrm{g} \mathrm{kg}^{-1}$ ), followed by an IV lidocaine bolus (L; $2 \mathrm{mg} \mathrm{kg}^{-1}$ ) after 30 minutes, and a second lidocaine bolus and constant rate infusion 20 minutes later (L-CRI, $2 \mathrm{mg} \mathrm{kg}^{-1}+100 \mu \mathrm{g} \mathrm{kg}^{-1}$ minute ${ }^{-1}$, for 30 minutes) followed by a washout period (W) of 30 minutes (group ISO). Data expressed as Mean \pm standard deviation. *Significantly different from $\mathrm{D}(p<0.05)$ Horizontal line indicates all values during that period of assessment were significantly different from $\mathrm{D}$ 


\section{LIST OF TABLES}

TABLE

Page

\section{Table 2.1}

Temperature and cardiorespiratory variables in conscious dogs administered IV dexmedetomidine $\left(10 \mu \mathrm{gg}^{-1}\right)$, followed by an IV lidocaine bolus $\left(2 \mathrm{mg} \mathrm{kg}^{-1}\right)$ after 30 minutes, and a second lidocaine bolus and constant rate infusion (CRI) 20 minutes later $\left(2 \mathrm{mg} \mathrm{kg}^{-1}+50 \mu \mathrm{g} \mathrm{kg}^{-1}\right.$ minute $^{-1}$ for 30 minutes $)$, followed by a washout period of 30 minutes (group SED1) 105

\section{Table 2.2}

Temperature and cardiorespiratory variables in conscious dogs administered IV dexmedetomidine $\left(10 \mu \mathrm{g} \mathrm{kg}^{-1}\right)$, followed by an IV lidocaine bolus $\left(2 \mathrm{mg} \mathrm{kg}^{-1}\right)$ and constant rate infusion (CRI) 5 minutes later $\left(2 \mathrm{mg} \mathrm{kg}^{-1}+50 \mu \mathrm{g} \mathrm{kg}^{-1}\right.$ minute $^{-1}$ for 30 minutes), followed by a washout period of 30 minutes (group SED2) 107

\section{Table 2.3}

Temperature and cardiorespiratory variables in isoflurane-anesthetized dogs administered IV dexmedetomidine (10 $\left.\mathrm{g} \mathrm{kg}^{-1}\right)$, followed by an IV lidocaine bolus ( $2 \mathrm{mg} \mathrm{kg}^{-1}$ ) after 30 minutes, and a second lidocaine bolus and constant rate infusion (CRI) 20 minutes later $\left(2 \mathrm{mg} \mathrm{kg}^{-1}+100 \mu \mathrm{g} \mathrm{kg}^{-1}\right.$ minute ${ }^{-1}$ for 30 minutes), followed by a washout period without of 30 minutes (group ISO). 109 


\section{LIST OF ABBREVIATIONS}

ACh Acetylcholine

AChE Acetylcholinesterase

AN Atrionodal

ASA American Society of Anesthesiologists

AV Atrioventricular

CNS Central nervous system

$\mathrm{ETCO}_{2} \quad$ End tidal carbon dioxide

ETIso End tidal isoflurane

$i \quad$ Current

$i_{\mathrm{K}} \quad$ Potassium current

$i_{\mathrm{KAch}} \quad$ Potassium current dependent on acetylcholine

$i_{\mathrm{Kr}} \quad$ Delayed rectifier (rapidly activating component)

$i_{\mathrm{Ks}} \quad$ Delayed rectifier (slowly activating component)

$i_{\mathrm{KCa}} \quad$ Calcium activated potassium current

$i_{\text {to1 }} \quad$ Transient outward current

IM Intramuscular

IV Intravenous

$\mathrm{K}^{+} \quad$ Potassium

LC Locus coeruleus

MAC Minimum alveolar concentration

$\mathrm{mm} \quad$ Millimeter

ms Millisecond 


$\begin{array}{ll}\mathrm{mV} & \text { Millivolts } \\ \mathrm{N} & \text { Nodal } \\ \mathrm{Na}^{+} & \text {Sodium } \\ \mathrm{NH} & \text { Nodal-His } \\ \mathrm{nm} & \text { Nanometer } \\ \mathrm{SA} & \text { Sinoatrial } \\ \mathrm{SN} & \text { Sinus node } \\ \mu \mathrm{m} & \text { Micrometer } \\ \mathrm{VPC} & \text { Ventricular premature complex }\end{array}$


CHAPTER 1

GENERAL LITERATURE REVIEW 


\subsection{INTRODUCTION}

Dexmedetomidine is one of the most commonly used drugs in dogs to provide sedation and analgesia. Both properties are ideal for simple procedures such as diagnostic imaging, premedication before invasive surgery, and handling of aggressive animals.

Dexmedetomidine belongs to the class of alpha-2 agonists, also showing agonist effects on alpha-1 receptors, but of less magnitude, as the selectivity for the former is greater. The activation of central alpha- 2 receptors result in sedation and analgesia, whereas the activation of peripheral alpha-1 and -2 receptors leads to vasoconstriction and hypertension. This effect elicits an activation of baroreceptors, mediating a reflex-vagal response that results in bradycardia. The increase in vascular resistance and bradycardia can be dramatic in dogs, resulting in a significant decrease in cardiac output, which can be detrimental in some patients.

Lidocaine is a local anesthetic, used frequently for locoregional blocks, but also intravenously to provide analgesia, decrease the minimum alveolar concentration (MAC) of inhalational anesthetics drugs, as an anti-inflammatory, prokinetic effects, and as an antiarrhythmic. The antiarrhythmic actions of lidocaine in veterinary and human medicine is more commonly applied to ventricular arrhythmias such as ventricular premature complexes. However, earlier studies performed in the late 1960's in dogs also showed the effectiveness of lidocaine in treating arrhythmias of supraventricular origin, due to specific vagolytic effects.

The use of lidocaine to treat bradycardia in dogs has not been assessed. The effects of dexmedetomidine are specifically related to a vagal reflex response and lidocaine could prove useful in this scenario. 


\subsection{ELECTRIC ACTIVITY OF THE HEART}

The heart works as a pump to maintain homeostatic functions of cells by delivering nutrients and oxygenated blood and removing waste products. This pumping action is the result of an elaborate and synchronized electro-mechanical mechanism. The mammalian heart may be divided into six different regions according to the predominant cell type: sinoatrial nodal cell, atrial cell, atrioventricular nodal cell, Bundle of His, Purkinje system and ventricular cell. Each one of these regions exhibits specific transmembrane properties (Figure 1.1; Shih 1994).
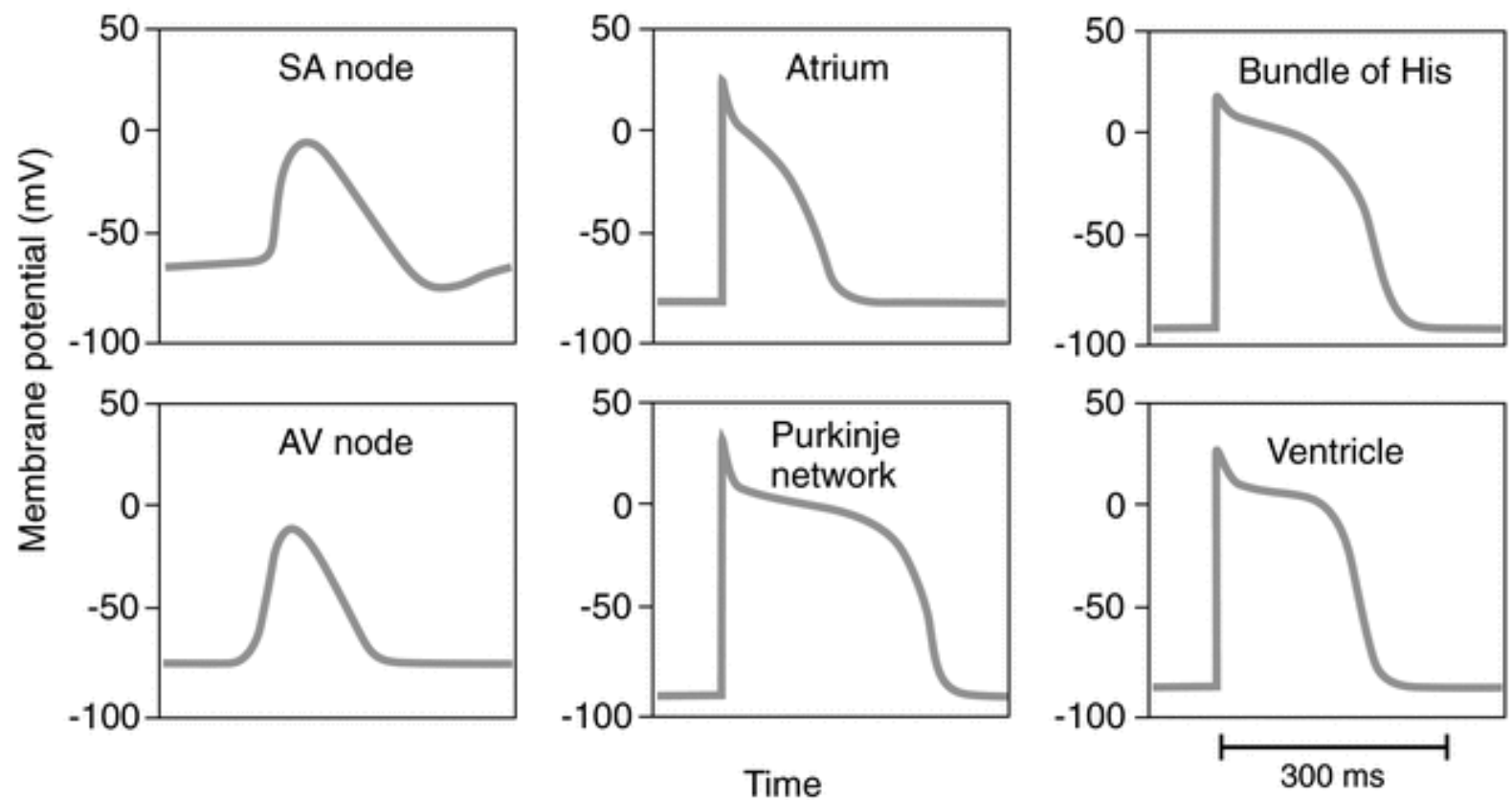

Figure 1.1 Action potential configurations in different regions of the mammalian heart (From Katz 2011a). 


\subsubsection{Action Potential of Heart Cells}

\subsubsection{Sinoatrial Node}

The sinoatrial node (SA node) of vertebrates, also known as sinus node ( $\mathrm{SN})$, is a region of cells organized in a spindle-crescent shape, localized at the junction of the cranial vena cava with the free wall of the right atrium. The cells of the SA node have almost no contractile muscle filaments and are about 3 to $5 \mu \mathrm{m}$ in diameter (Hall 2016a). The node in both dogs and humans lies less than $1 \mathrm{~mm}$ below the epicardium, being nourished by a central artery, originating from the right coronary artery in $90 \%$ of dogs and $50 \%$ of humans (James 1962).

The fibers of the SA node are capable of self-excitation, making it the main source of rate control of the entire heart (Hall 2016a). In a normal situation, all the other regions of the heart are activated after and due to the spontaneous activation of the SA node; it is the natural pacemaker of the heart (Katz 2011a).

The resting membrane potential in the SA nodal cell is about -50 to -60 millivolts $(\mathrm{mV})$, the lowest compared to the other cells of the heart (Shih 1994; Figures 1.1 and 1.2). At this resting potential, most of the fast sodium channels have become inactivated due to closure of the gates on the inner side of the cell, which occurs after a few milliseconds once this voltage is reached. As a result, only slow sodium-calcium channels can open and generate the action potential, which is slower to develop compared to other regions of the heart (Hall 2016a). 

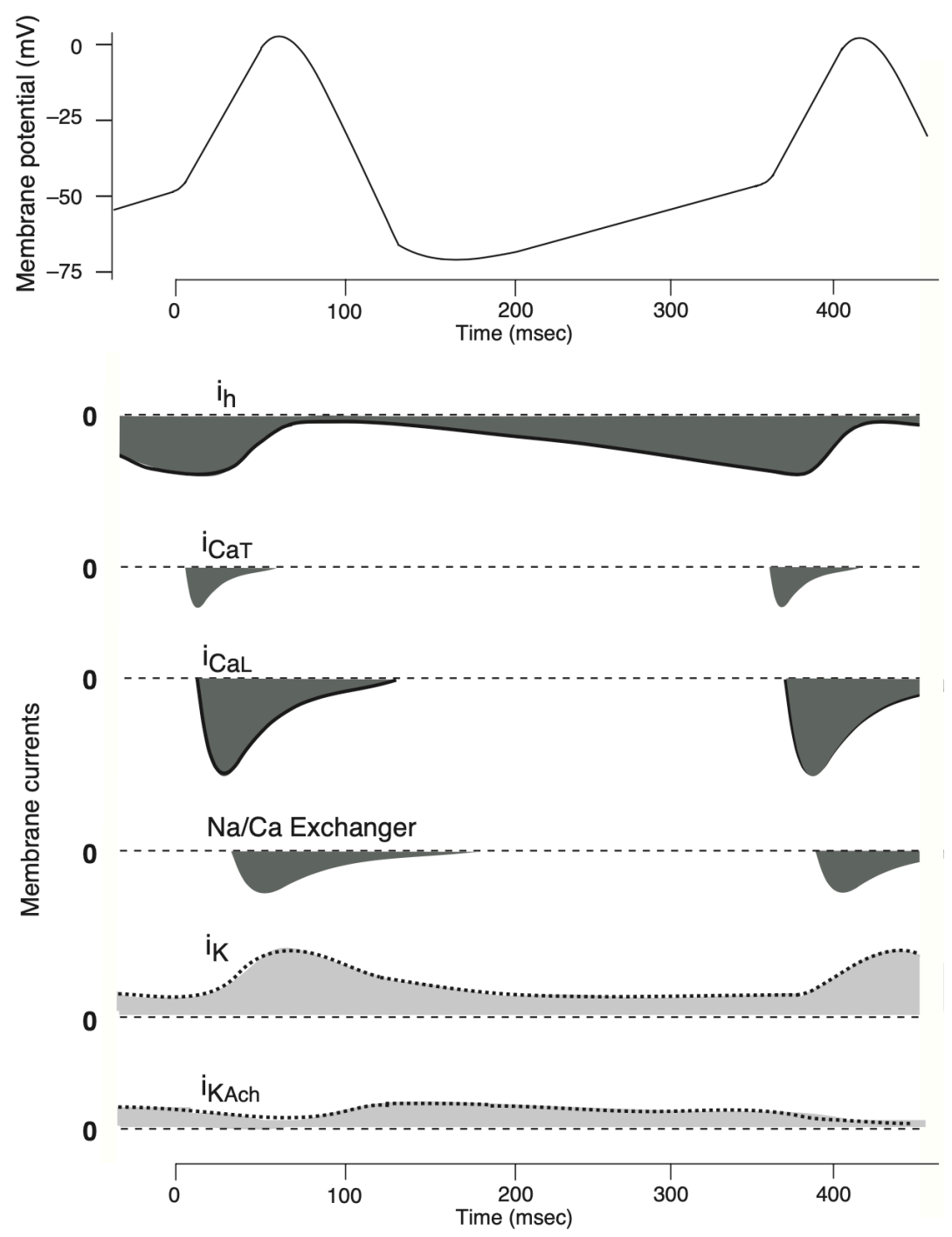

Figure 1.2 Individual currents responsible for depolarization of a pacemaker cell in the SA node. The outward current $i_{\mathrm{KACh}}$ helps stabilize resting potential; when this current is increased by parasympathetic stimulation, heart rate slows (From Katz 2011a).

The pacemaker activity is controlled by four inward currents $\left(i_{f}, i_{\mathrm{CaT}}, \mathrm{i}_{\mathrm{CaL}}, \mathrm{Na}^{+} / \mathrm{Ca}^{2+}\right.$ exchanger) and two outward potassium currents $\left(i_{\mathrm{K}}, i_{\mathrm{KACh}}\right)$. The first step is the opening of nonspecific cation channels resulting in a depolarizing current referred as $i_{f}$ - "funny" due to its unusual characteristics, also represented as $i_{\mathrm{h}}$ (hyperpolarization activated), which leads to 
depolarization of the SA node cells, and consequently opening of T- and L-type calcium channels, in this order, once the threshold is reached, which is $-40 \mathrm{mV}$ for T-type. Both calcium currents will increase the depolarizing current, as well as increase the inward flux of sodium by the $\mathrm{Na}^{+} / \mathrm{Ca}^{2+}$ exchanger, which will switch $3 \mathrm{Na}^{+}$ions for each $\mathrm{Ca}^{2+}$ that leaves the cell. The depolarization then starts to be antagonized by two different $\mathrm{K}^{+}$currents leaving the cell. One is $i_{\mathrm{K}}$, which by leaving the cell stops the action potential. An elevation in this current shortens the action potential duration, which increases the frequency of depolarizations from the pacemaker. The other current responsible for repolarization is mediated by $i_{\mathrm{KAch}}$, which are potassium channels that are opened by acetylcholine and purinergic agonists. It can also slow heart rate by counteracting the $i_{\mathrm{f}}$ inward current (Katz 2011a).

\subsubsection{Atria}

The terminal portion of the SA node fibers are directly connected to surrounding atrial muscle fibers, causing the pacemaker activity of the sinus node to spread through all atrial cells to the atrioventricular (AV) node and then to the rest of the heart. The velocity of conduction is not homogeneous within the atria as it is composed of different bands and internodal pathways; for example, the internodal pathways have specialized conduction fibers, making the conduction velocity faster than other regions of the atrium, and are even more rapid than the Purkinje fibers of the ventricles (Hall 2016b).

Atrial cells are similar to ventricular cells, but the action potential in the atria is shorter compared to both ventricular and Purkinje fibers. Similar to what happens in the ventricles, fast $\mathrm{Na}^{+}$channels are present in the atrial cells, opening briefly at the beginning of the action potential 
and then becoming inactivated. Once the action potential has started, atrial slow $\mathrm{Ca}^{2+}$ channels open and $\mathrm{K}^{+}$channels close, as in the ventricles (Katz 2011a; Klein 2013a).

\subsubsection{Atrioventricular Node}

In the dog's heart, the AV node is located in between the base of the right medial atrial wall and crest of the interventricular septum, measuring around $2.5 \mathrm{~mm}$ in length by $1.5 \mathrm{~mm}$ in width and depth at its broadest region (Racker 1989). The AV node plays the role of connecting the atria to the ventricles in terms of electrical activity, being the only pathway to conduct the action potential that started in the SA node, to depolarize the ventricles in the normal heart, as the atria are connected to the ventricles by a non-conductive layer (Sundnes et al. 2006). The stimulus coming from the SA node will encounter cells in the AV node slowly depolarizing towards the threshold, which makes the AV node reach the threshold quicker and propagate the potential to the His-bundle and then ventricles (Klein 2013a). The AV node is responsible for delaying the action potential coming from the atria, preventing the cardiac impulse from traveling too fast to the ventricles, which allows the atria to empty their blood content into the ventricles before ventricular systole takes place (Hall 2016b).

The AV node is functionally divided into three different regions; one proximal to the atria called atrionodal (AN), a middle portion named nodal $(\mathrm{N})$ and the last portion that is in contact with the AV bundle named nodal-His $(\mathrm{NH})$. All of them show different electrical activity; the lowest resting potential is in the $\mathrm{N}$ region, whereas the shortest action potential is in the $\mathrm{AN}$ region, and the pacemaker activity is faster in the NH region (Katz 2011a). Similar to what happens in the SA node, the AV node also possesses pacemaker activity capable of spontaneous depolarization but significantly slower action potentials than the SA node. The AV node depolarizes at a rate of 
30-60 beats/min in a dog, compared to $80-90$ beats/min for the SA node, and in some special circumstances the AV node pacemaker activity becomes essential for survival if the SA node is inactive, since the cardiac output generated by the AV node is compatible with life in a resting situation (Klein 2013a; Santilli et al. 2018).

\subsubsection{His-Purkinje system}

The cells of this system have fast conduction and very large, rapidly rising action potentials. The resting potential is around -80 to $-90 \mathrm{mV}$, going up to $+25 \mathrm{mV}$ at the peak of the

depolarization (Figure 1). The long duration of the action potential provides a safety mechanism against re-entrant arrhythmias, avoiding impulses going from the His-Purkinje to the myocardium, from reactivating the former (Katz 2011a).

Four inward currents are responsible for depolarizing the system: an initial fast $i_{\mathrm{Na}}$, followed by a small transient $i_{\mathrm{CaT}}$ and a larger more prolonged $i_{\mathrm{CaL}}$, and finally a hyperpolarizing current $i_{\mathrm{h}}$. Repolarization occurs due to rectifier potassium currents $\left(i_{\mathrm{to}}, i_{\mathrm{Kr}}, i_{\mathrm{Ks}}\right.$ and $\left.i_{\mathrm{KCa}}\right)$ and an outward chloride current $i_{\text {to2 }}$ (Katz 2011a).

\subsubsection{Ventricular Cells}

When the electric stimulus reaches the final portion of the Purkinje fibers it is transmitted to the ventricular muscle mass by the muscle fibers themselves, and the transmission velocity is around six times slower than that in the Purkinje fibers (Hall 2016b). Action potentials in the ventricles are smaller and rise more slowly when compared to the Purkinje fibers, and the duration is shorter than that of the His-Purkinje system, helping prevent reentrant arrhythmias, as impulses 
in the myocardial cells do not reactivate the His-Purkinje system that is still depolarizing (Katz 2011a).

The action potential duration is not homogeneous throughout the layers of the ventricle. The myocardial cells have the longest action potential, compared to endocardial and epicardial cells, and it is due to the uneven distribution of repolarizing $i_{\text {to1 }}$ and $i_{\mathrm{Ks}}$ channels (Katz 2011a).

\subsubsection{Action Potential of Muscle Cells}

Across all cells in the body there is a resting electrical potential, called the resting membrane potential, which exists due to a difference between the electrical charges on the two sides of the membrane (Hall 2016a; Alberts et al. 2018).

An action potential is only generated or propagated when the electrical stimulus reaches a minimum threshold, being the lowest membrane potential value for the cell to have enough sodium and/or calcium channels open (Katz 2011a).

\subsubsection{Striated Skeletal Muscle}

Around $40 \%$ of the mammalian body is skeletal muscle, whereas smooth and cardiac muscle make another 10\% (Hall 2016c). Myocytes of the skeletal muscle are elongated cells ranging from 10 to $110 \mu \mathrm{m}$ in diameter and up to $50 \mathrm{~cm}$ in length, and when viewed in longitudinal section, they have a transverse striated appearance like the cardiac myocyte, which is due to the organization of thin and thick myofilaments and $\mathrm{Z}$ discs inside each myofibril (Eurell 2006). Unlike heart muscle cells, skeletal muscle cells are multinucleated, as they originate from the fusion of myoblasts during fetal development (Bear et al. 2016). Contraction of the skeletal myocyte is dependent on nerve supply; if the connection between the nerves and the muscle cells 
is interrupted, no contraction will occur, as opposed to smooth and cardiac muscle that have an intrinsic ability to contract in the absence of nerve supply (Mitchell \& Peel 2009). Skeletal myocytes don't show the characteristics of a syncytium as do heart cells, so each skeletal fiber is innervated by a single motor neuron in order to contract (Beitz \& Fletcher 2006; Klein 2013b). The motor plate in the myocyte is similar to other chemical synapses and consists of a presynaptic side called synaptic bouton, which stores chemical neurotransmitters in vesicles, a synaptic cleft, which is a small space filled with extracellular fluid of around $50 \mathrm{~nm}$ between the axon terminal and the fiber, and a postsynaptic side that includes the muscle cell with a series of invaginations and receptors (Klein 2013c).

The process of depolarization starts with the release of acetylcholine ( $\mathrm{ACh}$ ) from the nerve into the synaptic cleft and binding for about $1 \mathrm{~ms}$ to nicotinic receptors in the muscle fiber. This will increase $\mathrm{Na}^{+}$inward currents, allowing each channel to transmit between 15,000 and 30,000 $\mathrm{Na}^{+}$ions during this $1 \mathrm{~ms}$. The action potential is then propagated by $\mathrm{Na}^{+}$and proceeds in all directions of the fiber, beginning in the $\mathrm{T}$ tubules. These structures work as a communication link between the sarcolemma and the myofibril. When the $\mathrm{T}$ tubules depolarize, they also depolarize the sarcoplasmic reticulum, which will release $\mathrm{Ca}^{2+}$ ions into the cytosol, allowing contraction to begin, and also making the contraction synchronized as all myofibrils in the same fiber will contract at the same time (Klein 2013b; Reece 2015; Hall 2016d). The released ACh only remains in the cleft for a few milliseconds and then most of it is hydrolyzed by the enzyme acetylcholinesterase (AChE) into acetic acid and choline, and a small amount diffuses out of the synaptic cleft. This process is important to prevent re-excitation after the muscle has recovered from the initial contraction (Hall 2015d). 
The resting potential in a striated skeletal muscle cell is similar to that of neurons, around -80 to -90 millivolts. In neurons, the most important ion maintaining the resting potential is $\mathrm{K}^{+}$, whereas for the skeletal muscle it is $\mathrm{Cl}^{-}$. Once $\mathrm{Na}^{+}$channels are opened by $\mathrm{ACh}$, depolarization starts, and after reaching the threshold at around $-30 \mathrm{mV}$, the membrane is rapidly depolarized, reaching an electrical peak of 30 , but sometimes as much as 50 to $75 \mathrm{mV}$. Once the peak has been reached, the repolarization process begins with the inactivation of the $\mathrm{Na}^{+}$channels and the opening of $\mathrm{K}^{+}$channels. The outward flux of $\mathrm{K}^{+}$returns the membrane potential back to the resting values. The whole action potential in the muscle cell lasts for 1 to $5 \mathrm{~ms}$, five times longer than large myelinated fibers, whereas velocity ranges from 3 to $5 \mathrm{~m} / \mathrm{sec}$, about 13 times slower than the large myelinated fibers that excite the skeletal muscle (Hopkins 2006; Hall 2016b).

\subsubsection{Smooth Muscle}

Like the cardiac cell, the smooth muscle fiber is smaller than skeletal muscle, ranging from 1 to $5 \mu \mathrm{m}$ in diameter (around 30 times narrower) and only 20 to $500 \mu \mathrm{m}$ in length (hundreds of times shorter), and can be divided into two major types. The first one is the multi-unit smooth muscle, where contraction is dependent on nervous stimuli, and each fiber can contract independently. The ciliary muscle of the eye and piloerector muscle of the hairs are some examples. The other type is the unitary smooth muscle, that contracts as a whole, since the structure is similar to a syncytium, and a major share of contraction is exerted by non-nervous stimuli. An example is the musculature of the arteries. Innervation to smooth muscle fibers is provided by the autonomic nervous system, and most contractions are prolonged tonic, sometimes lasting for hours, whereas skeletal fibers contract and relax quickly. Like skeletal fibers, smooth muscle has 
actin and myosin as part of the contractile apparatus, in a different arrangement, but lack troponin and T tubules (Klein 2013b; Hall 2016e).

Unlike the skeletal muscle action potential that starts with ACh binding to receptors, the smooth muscle action potential begins with either ACh or norepinephrine released into the cleft. A single fiber can be innervated by more than one neuron and can be either excited or inhibited by it. Once the neurotransmitter binds the receptor, an inward current of $\mathrm{Ca}^{2+}$ is responsible for initiating the depolarization, which will prompt the release of more $\mathrm{Ca}^{2+}$ from the sarcoplasmic reticulum, spreading and speeding up the action potential. As $\mathrm{Na}^{+}$channels are absent in the sarcolemma, this ion does not take part in the action potential of smooth muscle, as it does in skeletal and cardiac muscle (Berridge 2008; Klein 2013b).

\subsubsection{Normal Conduction}

The SA and AV nodes, AV bundle, bundle branches and the Purkinje fibers are known as the specialized conduction system of the heart, which is composed of specialized muscle fibers, and not nerves, making each heartbeat follow a specific pattern (Klein 2013a). The depolarization of each area generates a specific electrical activity, which is captured by the electrocardiogram (Figure 1.3). 

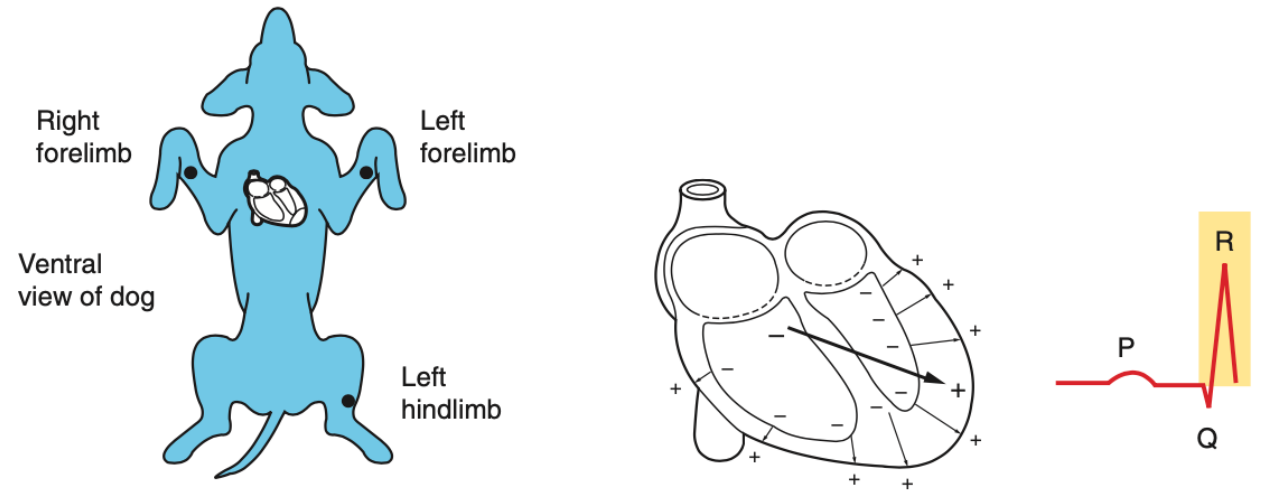

\section{Ventricular depolarization}
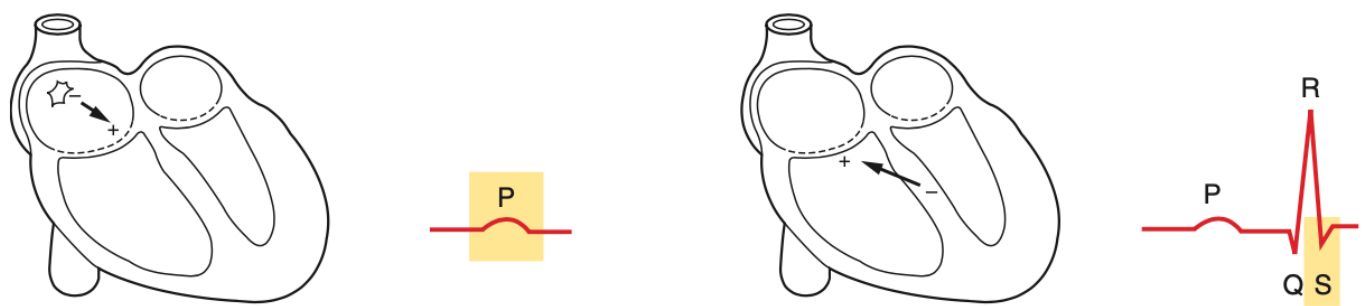

A Atrial depolarization

D Late ventricular depolarization
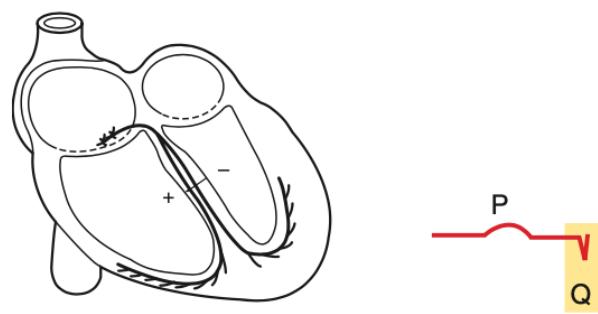

B Early ventricular depolarization
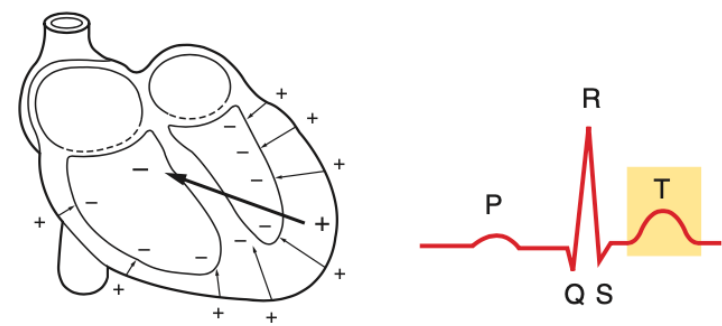

E Ventricular repolarization

Figure 1.3 Surface electrocardiogram in lead II of a normal cardiac action potential being conducted through the atria and ventricles (From Klein 2013a).

\subsubsection{Arrhythmias}

Variations of the cardiac rhythm from normal sinus rhythm, besides those changes in rhythm according to physiological requirements, define the presence of cardiac arrhythmias. The underlying mechanism of arrhythmia can be subdivided in two general major groups: abnormalities of impulse formation (abnormal automaticity) and abnormalities of impulse 
propagation (blocks or re-entry, or a combination of both processes) (Gilmour \& Moïse 2015; Mavropoulou 2018).

Impulses originating from areas other than the cells present in the SA node can have different underlying causes. It can be the result of (1) subsidiary pacemakers, where cells other than the SA node have the ability to discharge spontaneously, and in the absence of stimulus coming from the SA node or if the rate is too low; these cells may reach the threshold and produce an abnormal beat that enables the heart to keep some cardiac output to the body. It can also result from (2) reduced automaticity, when the SA node fires at a lower rate than normal, which can be due to electrolyte abnormalities or elevated vagal tone. With (3) enhanced normal automaticity, the SA node fires at a rate higher than the normal range causing tachycardia, and may be due to electrolyte abnormalities (hypokalemia) or hypoxemia. In (4) abnormal automaticity, cells that don't normally have pacemaker activity, like ventricular myocardial cells, start to depolarize spontaneously, which can happen in regions of infarction that alters cell membrane function. With (5) triggered activity premature depolarization of the cell occurs before complete repolarization, which can be subclassified as early afterdepolarizations when it happens during stages 2 or 3 of the action potential, or delayed afterdepolarization when it happens during early stage 4 (Mavropoulou 2018).

Abnormal impulse conduction has two major classifications, one type involves a delay or impulse conduction block, which may lead to bradyarrhythmias, such as atrioventricular block, but can happen during tachycardia. The other type involves re-entry mechanisms that may cause tachyarrhythmias. Re-entry may happen around an anatomical structure, being called anatomical re-entry, or can occur in adjacent fibers that present different electrophysiological properties, named functional re-entry (Mavropoulou 2018). 


\subsubsection{Bradyarrhythmias}

The term bradyarrhythmia is used when there is a rhythm disorder with a ventricular rate that is below the lower limit range for the species and animal's size. Pathological bradyarrhythmias may be caused by primary cardiac disease in the conduction system or a consequence of systemic illness. Some bradyarrhythmias may be hemodynamically stable, but others will lead to syncope and have the potential to be life threatening (Santilli et al. 2018; Willis 2018).

\subsection{Sinus Bradycardia}

This rhythm has its origin in the SA node, being defined as a slower rate than the sinus rhythm, below 60 beats per minute (bpm) in adult dogs and $140 \mathrm{bpm}$ in cats, maintaining the other characteristics of the latter, and being classified in three major groups: physiologic, pathologic or pharmacologic. Physiologic bradycardia is benign and can be seen during periods of rest due to increased parasympathetic tone. It can be accompanied by first degree AV block or wandering pacemaker. Pathological sinus bradycardia is the result of diseases affecting the SA node and atrial myocardium. Examples are sick sinus syndrome, atrial standstill and sinus arrest. Finally, pharmacologic sinus bradycardia is related to the use of drugs such as $\beta$-blockers to treat other arrhythmias, or anesthetic drugs like opioids and alpha-2 agonists. Both pathologic and pharmacologic causes can be life-threatening (Santilli et al. 2018; Willis 2018). 


\subsection{Atrioventricular block}

Atrioventricular blocks are conduction disorders and range from a reduction in conduction velocity to intermittent or complete block of impulse propagation. It is subdivided into first-, second- and third-degree AV block. First-degree AV block is characterized by a lengthening of the PR interval to $>130 \mathrm{~ms}$ in dogs, being only a delay in conduction rather than a complete block. The subsequent QRS complex is normal in morphology. Second-degree AV block is an intermittent obstruction of the normal atrioventricular conduction, characterized by $\mathrm{P}$ waves that are not followed by QRS complexes, which are normal in morphology. Lengthening of the PR interval may be progressive before the block (Mobitz type I) or may be constant with the block happening randomly (Mobitz type II). Third-degree AV block is a complete obstruction at the AV node, where $\mathrm{P}$ waves are visible, but no QRS complex results from it. Instead, the ventricles depolarize at a lower rate originating from a junctional or ventricular escape rhythm (Santilli et al. 2018; Willis 2018).

\subsection{Sinus Node Dysfunction and Sick Sinus Syndrome}

Sinus node dysfunction identifies a number of rhythm disorders secondary to a malfunction of sinus node automaticity and sino-atrial conduction. The three types are sinus pause, sinus node block and sino-atrial arrest. Sinus pause is a delay to start an impulse of up to 4-6 seconds, followed by a normal sinus beat. In sinus node block, there is depolarization from the pacemaker cells, but no propagation of the stimulus reaches the myocardium cells. Sinus block can be subdivided in first-degree (impulse to transmission is delayed, not recognized on ECG), second-degree (lengthening of the period between impulse origin and transmission, eventually leading to complete failure in transmission, that can be progressive - type I - or sudden - type II) and third- 
degree (no transmission is generated from the SA node, so no P waves are detected on the ECG, with long pauses that may lead to junctional or ventricular escape beats). The definition of sinus arrest in veterinary medicine is based on human medicine, where a block lasting longer than three P-P intervals is considered sinus arrest, which causes more detrimental hemodynamic effect than the previous two arrhythmias. Sick sinus syndrome is the presence of sinus node dysfunction along with clinical signs such as exercise intolerance and syncope (Santilli et al. 2018; Willis 2018).

\subsection{Atrioventricular Dissociation}

This can be described by the presence of two rhythms, one coming from the SA node and another one coming independently from the ventricles. The ECG is characterized by the presence of $\mathrm{P}$ waves that are not associated with QRS complexes (Oliveira 2018). AV dissociation is not considered a primary arrhythmia but a consequence of another underlying rhythm disturbance that may be slowing of SA node, acceleration of a latent pacemaker, AV blocks or a combination of these three factors (Olgin \& Zipes 2019). Atrioventricular dissociation with nearly equal atrial and ventricular rates can be seen (termed isorhythmic) (Perego et al. 2012); however, the ventricular rate is usually faster (Olshansky et al. 2016).

\subsection{Escape Beats}

A ventricular beat that happens after a pause, or later than the $\mathrm{R}$ wave is supposed to happen, is called an escape beat (Mavropoulou 2018). An escape beat, or rhythm, is a ventricular compensatory mechanism for lack of firing of stimulus from the atria, or conduction abnormalities from the SA node to the ventricles, where the ventricle assumes "control" in order to maintain some cardiac output. It can be a consequence of a myriad of arrhythmias, most notably sick sinus 
syndrome, third-degree AV block and sinus bradycardia (Moïse et al. 1996; Willis 2018). Whereas a sinus rhythm can be around $130 \mathrm{bpm}$ in dogs, a ventricular escape rhythm will most likely be significantly lower than that in healthy dogs, being as low as $40 \mathrm{bpm}$. (Hope et al. 1976). The other situation in which a ventricular beat is responsible for the cardiac output is when a ventricular complex happens before the next $\mathrm{R}$ wave is supposed to and is called a ventricular premature complex (VPC), but in this case it occurs early, compared to the underlying rhythm and usually has a faster rhythm. This arrhythmia is related to underlying diseases such as neoplasia, cardiomyopathies and gastric dilation volvulus or administration of drugs such as dopamine and digoxin (Santilli et al. 2018).

\subsection{ANTIARRHYTHMIC DRUGS}

An arrhythmia can result in abnormal cardiovascular function. Some arrhythmias are benign and do not require specific treatment as they don't produce significant clinical effects whereas others may lead to lethargy, syncope or degenerate into a more malignant arrhythmia like ventricular fibrillation causing cardiac arrest and sudden death (Kraus et al. 2008). For the latter, antiarrhythmic drugs may be used solely or combined with other techniques with the objective of ameliorating clinical signs and prolonging survival. The benefits of treating acute arrhythmias is usually obvious, meanwhile evaluating the efficacy of chronic treatment of arrhythmias can be more challenging, particularly in asymptomatic arrhythmias, where survival may even be decreased when adding a drug (Silva 2018). 


\subsubsection{Classification, Mechanism, and Sites of Action}

The Vaughan Williams classification system - from homonymous author - was introduced in 1970 and is the most widespread method used in both veterinary and human medicine to classify drugs used for antiarrhythmic therapy. Drugs are divided in four different classes, numbered after roman numerals I, II, III or IV, according to four basic ways an abnormal heart rhythm can be treated or prevented, and not so much related to the drug chemical or physical structure and property, as several of them possess more than one of the four mechanisms of action. With the advent of new drugs, subclasses were added for class I, being known as IA, IB and IC (Vaughan Williams 1975; Cobbe 1987; Silva 2018). More recently the system was revised, and more classes added, from 0 to VII, as well as new subclasses (Lei et al. 2018). The different drug classes and subclasses will be discussed further in this text.

Most of the drugs available to treat arrhythmias are classified according to whether they have blocking actions primarily on sodium, potassium, or calcium channels, and if they block other receptors. The Vaughan Williams classification has its limitations as it is based on electrophysiologic effects of arbitrary concentrations of drugs, normally tested in laboratory preparations of healthy cardiac tissues. In patients these drugs may produce different responses depending on factors such as tissue type, heart rate, degree of acute or chronic disease and concentration, to mention few (Miller et al. 2018). Some drugs intended for antiarrhythmic use are not included in this system, like digoxin, anticholinergics, vagolytics and sympathomimetics, giving more space for debate about the importance of the classification (Vaughan Williams 1992; Meurs \& Riviere 2018)

Another system to classify antiarrhythmic drugs was suggested in 1990, being called the Sicilian Gambit - from the chess movement - that is more complex and intended to review and 
complement the system mentioned previously. Given that this system didn't get much acceptance in veterinary cardiology, only the Vaughan Williams is further discussed (Rosen \& Schwartz 1991; Silva 2018).

Class I - Drugs of this class block fast sodium channels in the cell membrane, slowing phase 0 of the action potential and with that decreasing the velocity of conduction, in both atrial and ventricular myocardial cells and Purkinje fibers. Some drugs of this class will also block potassium channels at certain plasmatic concentrations. Class I is further divided into IA, IB and IC and differ particularly in the way they affect repolarization (Meurs \& Riviere 2018; Miller et al. 2018; Silva 2018). Sodium channel is voltage dependent and can assume three main conformational states: open, inactivated and resting, depending on the membrane potential. At resting potential, the majority of the channels are in resting state. As the action potential initiates, they go through a period of open state, allowing $\mathrm{Na}^{+}$inflow and depolarization is maintained. Once repolarization has started, the channels go into inactivated state, halting the influx of $\mathrm{Na}^{+}$, returning slowly to the resting state (Schulman \& Strichartz 2011).

Class $\boldsymbol{I} \boldsymbol{A}$ - Examples of drugs of this class are quinidine, procainamide and disopyramide. Like other class I drugs, they will decrease the rate of rise during depolarization upstroke (Vmax of phase 0 ) and differently from class IB and IC, IA prolongs the action potential by also slowing repolarization (phases 2 and 3), causing an increase in action potential duration and prolonging the refractory period. Compared to IB and IC, IA drugs have an intermediate onset and offset kinetics in blocking sodium channels, of about 4 to 8 seconds (Miller et al 2018; Silva 2018). Drugs in this class also show an indirect vagolytic effect, increasing heart rate and enhancing the conduction at the atrioventricular node (Silva 2018). Indications of use are ventricular and supraventricular tachyarrhythmias, mainly ventricular tachycardia and atrial fibrillation (Chandler et al. 2006; Fries 
\& Saunders 2012; Silva 2018). Cessation of atrial fibrillation is through increases in wavelength at short cycle lengths, slower atrial activation and increase in the size of reentry circuits, decreasing the number of circuits in the atria (Fries \& Saunders 2012). In recent years, drugs of this class have lost clinical importance due to availability of safer drugs. One exception is the current use of quinidine to treat atrial fibrillation in horses in places where transvenous electrical cardioversion is not available (Silva 2018; Takahashi et al. 2018).

Class $\boldsymbol{I B}$ - Examples of drugs in this class are lidocaine and mexiletine, and differently from classes IA and IC, they will shorten the action potential duration in healthy tissues. They have fast onset and offset kinetics and bind more avidly to channels that are in the open or inactivated states (Miller et al. 2018; Silva 2018).

Class IC - Drugs of this class include flecainide and propafenone, which markedly prolong and reduce phase 0 of the action potential, slow conduction velocity, particularly in the His-Purkinje fibres, and cause minimal effect on the refractory period. These drugs show slow onset and offset kinetics, and dissociation from the sodium channels is slow, with the time constant (time for concentration of a drug to reach $37 \%$ of its original value) being about 10 to 30 seconds (Roberts \& Freshwater-Turner 2007; Miller et al. 2018; Silva 2018).

Class II - Drugs in this class act by blocking $\beta$-adrenergic receptors, inhibiting binding of catecholamines to the receptor, and some of the most commonly used clinically are propranolol, esmolol, atenolol metoprolol and sotalol (both class II and III drug) (Silva 2018). At around 10 times the concentration necessary for blocking $\beta$ receptors, these drugs also show a direct membrane-stabilizing effect, depressing sodium channels in Purkinje fibers in a manner similar to 
local anesthetics. However, this mechanism has little importance due to the amount of drug in the plasma needed for it to take place (Miller et al. 2018).

$\beta$-adrenergic antagonism will decrease the magnitude of the calcium current, decrease the amount of repolarizing potassium current, decrease pacemaker currents and thereby decrease heart rate, decrease stored calcium in the sarcoplasmic reticulum, and inhibit afterdepolarizationmediated automaticity. All of these actions will contribute to the prevention or treatment of arrhythmias (Knollmann \& Roden 2017). $\beta$-blockers can be subdivided according to the subtype of receptors they inhibit. Drugs like propranolol and nadolol are nonselective $\beta_{1} / \beta_{2}$-blockers; metoprolol, esmolol and atenolol are selective $\beta_{1}$-blockers; carvedilol and labetalol are nonselective $\beta$ blockers with $\alpha_{1}$ blocking action; and pindolol and acebutolol are non-selective $\beta$ blockers with sympathomimetic activity (Cheng 2009; Knollmann \& Roden 2017).

Several factors play a role in how efficacious the $\beta$-blockade is, like level of adrenergic stimulation, density and sensitivity of $\beta$-receptors, and type of receptors that are blocked by a specific drug. The clinical consequence is that the plasmatic levels may not correlate well with the extent of receptor blockade (Silva 2018). $\beta$-blockers have a myriad of uses in veterinary medicine. Other than for arrhythmias, indications of these drugs include systemic hypertension (Taylor et al. 2017), subaortic stenosis (Eason et al. 2014), pulmonic stenosis (Francis et al. 2011), hypertrophic cardiomyopathy (Jackson et al. 2015) and thyrotoxicosis (Trepanier 2006).

Class III - Drugs in this class inhibit repolarizing potassium currents, extending the action potential duration, which delays repolarization time and prolongs the refractory period in all cardiac fibers, which for some drugs can reflect in the ECG as lengthening of the QT interval (Miller et al. 2018; Silva 2018). The most common drugs used in veterinary medicine belonging 
to this class are sotalol and amiodarone, though they are not pure class III, possessing electrophysiological properties of other classes as well (Silva 2018). Amiodarone produces peripheral vasodilation, decreases heart rate and inotropism, and it can be used in a myriad of supraventricular and ventricular arrhythmias, such as atrial flutter or fibrillation and junctional tachycardia (Miller et al. 2018).

Class IV - These are drugs that block the voltage gated calcium channel, decreasing the inflow of this cation across cell membranes of different tissues in the body. Regarding its use as an antiarrhythmic, efficacy is mostly due to its actions on the heart, mediated through blockade of Ltype channels (Silva 2018). Calcium triggers contraction in all types of muscle cells. The decreased inflow of $\mathrm{Ca}^{2+}$ in vascular smooth muscle causes relaxation and vasodilation, whereas in cardiac myocytes the consequence will be a negative inotropic effect (Eschenhagen 2017). Three chemical classes exist: dihydropyridines, in which amlodipine is the most commonly used, has more effect on vascular smooth muscle cells, causing little electrophysiological effect. The other two classes are phenylalkylamine, with verapamil as example, and benzothiazepine, with diltiazem as example. These two drugs produce greater effects on cardiomyocytes, decreasing automaticity of the SA node and conduction of the AV node (Eschenhagen 2017; Silva 2018). These two drugs decrease the plateau height of the action potential, slightly shorten the muscle action potential, and prolong the Purkinje fiber action potential (Miller et al. 2018). Clinical indications are mainly for rate control in supraventricular tachyarrhythmias such as atrial fibrillation, and to slow the ventricular response rate (Silva 2018). 


\subsubsection{Lidocaine}

Lidocaine was the first amino-amide local anesthetic to be used clinically in the 1940's and quickly its use became (and still is) widespread due to its intermediate potency, fast onset, low toxicity and applicability through different routes (Ruetsch et al. 2001). Lidocaine binds to a receptor within the $\mathrm{Na}^{+}$channel, inhibiting the inflow of this electrolyte into the cell. In a sensory neuron, this effect will halt the action potential, thus providing analgesia (Catterall \& Mackie 2018). This same mechanism is responsible for the antiarrhythmic effects of lidocaine, as explained in the section above.

\subsubsection{Effects on Cardiac Electrical Activity}

As with other drugs belonging to class IB antiarrhythmics, lidocaine depresses the fast inward current of $\mathrm{Na}^{+}$in phase 0 of the action potential, slowing conduction, shortening the action potential period, and may also increase the effective refractory period in higher doses (Campbell 1983; Vaughan Williams 1984). Lidocaine increases conduction times between different parts of the heart in dogs, an effect that is dose-dependent and minimal at clinical doses. The longest delay occurs from the SA node to the His bundle, with an average $15 \mathrm{~ms}$ delay (Lieberman et al. 1968). However, heart rate is not significantly affected by administration of a lidocaine bolus or CRI in anesthetized dogs with normal rhythm (Liu et al. 1982; Nunes de Moraes et al. 1998)

Lidocaine is not recommended in cases of AV block and escape rhythms due to the possibility of slowing the rate of escape beats and causing asystole, as lidocaine can slow AV node and Purkinje fibers conduction even in a healthy heart, especially in patients with a lower location of the block in the His bundle (Sugimoto et al. 1968; Aravindakshan et al. 1977). However, 
clinically it is not possible to identify where the block originates from without an intraventricular ECG.

\subsubsection{Effects on Cardiac Mechanical Activity}

Lidocaine depresses the contractile force of the ventricles in a dose-dependent fashion, but the effect is minimal at clinical doses used to treat arrhythmias (Lieberman et al. 1968). A single IV bolus of $1.5 \mathrm{mg} / \mathrm{kg}$ administered to humans decreased stroke volume and increased vascular resistance, but neither was of significance, whereas heart rate was unaltered (Klein et al. 1968). In anesthetized dogs, lidocaine administered IV up to $3 \mathrm{mg} / \mathrm{kg}$ causes minimal changes in vascular resistance and mean arterial pressure (Liu et al. 1982). Heart rate and stroke volume are not significantly affected at doses up to $10 \mathrm{mg} / \mathrm{kg}$ (Liu et al. 1982). During infusions of up to 200 $\mu \mathrm{g} / \mathrm{kg} / \mathrm{min}$, no significant changes were seen in cardiac index and mean arterial pressure (Nunes de Moraes et al. 1998).

\subsection{HEART AS A PUMP}

The heart is a hollow muscular organ that over the lifetime of an animal will work in different conditions in order to deliver blood to the rest of the body. The heart is able to function independently, but at the same time its performance will be affected by many humeral and neuronal factors released peripherally (Riedesel 2015).

Cardiac cells are histologically classified as cardiac muscle and differ from those of skeletal and smooth muscle. Like skeletal muscle the cardiac muscle is striated and cylindrical, whereas the smooth muscle cells are fusiform and nonstriated. While skeletal muscle cells are multinucleated and have longer fibers, both cardiac and smooth muscle cells are mononucleated 
and have shorter fibers. Functionally, skeletal myocyte contraction will happen under conscious control, being also known as voluntary muscle, whereas cardiac and smooth cells lack this ability, responding to autonomic stimulus only. Cardiac cells have a unique characteristic among muscular cells in that they possess intercalated disks, which are specialized cell junctions. These structures connect the cells end-to-end and form gap junctions, allowing the action potential to spread faster and in a synchronized manner, when compared to other muscle cells, due to free transport of electrolytes in this syncytium, contributing to the heart's distinct physiology. (Eurell 2006; Mitchell \& Peel 2009).

The beating heart differs from the contraction of the skeletal muscle that is characterized by changes in tension and length, in that it produces pressure and ejects a volume of blood, making the description of the work of the heart to be defined as a relationship between changes in volume and pressure (Katz 2011b). It is possible to interpret the heart as two separate pumps (right, pumping blood through the pulmonary circulation, and left, pumping blood through the systemic circulation), that work in synchrony in a cycle, first relaxing and allowing blood to come in, and then ejecting blood through contraction (Klein 2013d).

\subsubsection{Cardiac Cycle}

The events that occur at the beginning of one heartbeat until the beginning of the next beat are known as the cardiac cycle, which is initiated by spontaneous fire of an action potential from the sinus node, located in the right atrium, close to the entrance of the vena cave. The stimulus then spreads through the atria to the atrioventricular node, and from there to the bundle branch and ventricles. The atria will act as primer pumps for the ventricles, which in turn will pump the blood to the body's vascular system. The cycle can be depicted as alternate periods of diastole, where 
the chamber is relaxed and allows the blood coming from the periphery to fill it, followed by systole, where there is contraction of the chamber to pump the pre-loaded blood to the systemic and pulmonary circulation. The total duration of this biphasic activity is the reciprocal of heart rate; if the rate is 120 beats/min, the whole cycle will take 0.5 seconds/beat. Increases in heart rate will lead to a shorter period of relaxation/contraction, whereas decreases in heart rate will allow for longer times of systole/diastole. Clinically the latter usually represents an increase in the ventricular blood volume at the end of the relaxation phase. (Hall 2016a)

During the first phase of ventricular diastole, the ventricular muscle relaxes causing a decline of left ventricular pressures from close to aortic pressures to values close to left atrial pressure. Until this point the mitral and tricuspid valves remain closed, not allowing any filling of the ventricles, and the drop in ventricular pressures draws the blood from the great arteries back toward the heart, closing the aortic and pulmonary valves. From this point until opening of the AV valves there is a period characterized as isovolumetric relaxation, as there is neither filling nor emptying of the ventricle. The closure of the semilunar valves marks the beginning of ventricular diastole. When the gradient of pressure is lower inside the ventricles compared to the atria, both atrioventricular valves open, allowing blood to flow into the ventricles. Initially, there is a rapid ventricular filling, followed by a reduced ventricular filling (diastasis). These two phases combined are responsible for around $80 \%$ of the total ventricular volume. Diastasis occurs until an action potential from the sinoatrial node initiates atrial systole (contraction) providing the remaining $20 \%$ of end-diastolic volume. The clinical impact of this ratio is that the heart is able to pump around $80-90 \%$ of its potential in a resting animal, even if the atria are not functional such as in atrial fibrillation. However, this may not be the same during exercise where cardiac output is 
increased, as the lack of the $20 \%$ active participation from the atria may be detrimental. (Klein 2013d; Hall 2016e).

At the end of atrial systole begins atrial relaxation, where atrial internal pressure falls slightly. After that, the ventricles start to contract, increasing its pressures quickly, producing a blood backflow towards the atria that closes the atrioventricular valves. This marks the end of ventricular diastole and the beginning of ventricular systole. At this point, the volume in the ventricles remains constant, as the AV valves are closed, and the built-up of pressure is not enough to open the semilunar valves. This period is called isovolumetric contraction, where the muscle tension is increased but with little shortening of the muscle fibers. The pressure continues to rise towards the end of systole, pushing the aortic and pulmonary valves open when the pressure inside the ventricles is greater than that in the aorta and pulmonary artery respectively (about $80 \mathrm{mmHg}$ in the left ventricle, and $8 \mathrm{mmHg}$ for right ventricle. As both valves open, there is an outflow of blood to the pulmonary and systemic circulation, firstly in a rapid ejection phase, followed by a reduced ejection phase. The pressure within the ventricles starts to fall, and the backflow of blood from the arteries closes the semilunar valves again. The next phase is marked by another isovolumetric relaxation, followed by opening of the AV valves and the beginning of a new cycle (Klein 2013d; Hall 2016e).

\subsubsection{Cardiac Output Determinants}

Cardiac output $(\mathrm{CO})$ is the amount of blood ejected from the ventricles per minute, and will be directly affected by the rate at which the heart is beating (HR) and the stroke volume (SV), which is the volume of blood ejected by each contraction; therefore $\mathrm{CO}=\mathrm{HR} \times \mathrm{SV}$. These two 
variables are affected by intrinsic and extrinsic mechanisms, altering HR and SV by changing force, velocity, duration and extent of contraction (Kline et al. 2015).

Cardiac output is directly proportional to HR (chronotropism) when other variables are kept constant, so doubling the HR could potentially double the CO (Riedesel 2015). This is not always the case, as above a certain range of $\mathrm{HR}$, the diastolic filling time is decreased and consequently so is end diastolic volume and cardiac output (Miller et al. 1962).

Stroke volume can be affected by different mechanisms. Preload is the amount of blood returning to the heart during diastole, so the more volume the heart has stored to pump, the greater the stroke volume will be. Another factor related to the diastolic volume is the Frank-Starling mechanism. Increasing the volume up to a certain limit will increase the contraction force, as the muscle fibers function similar to a spring, accumulating more energy with increased distention, and releasing more intracellular $\mathrm{Ca}^{2+}$ (Klein 2013d; Riedesel 2015; Hall 2016e). Afterload is the resistance the ventricles need to overcome to pump blood to the periphery, and for the left ventricle is mostly determined by aortic vascular resistance. The higher the afterload, the lower will be the CO. (Riedesel 2015). Increasing contractility (inotropism) of the heart muscle will increase stroke volume when preload and afterload are constant, and decrease the ventricular end systolic volume. Inotropism is mostly regulated by the sympathetic nervous system (Riedesel 2015).

\subsection{SEDATIVES AND TRANQUILIZERS IN SMALL ANIMALS}

Small animal patients undergo procedures that may be painful, stressful or that cause them anxiety. The use of drugs that will provide sedation or tranquilization may be needed in these circumstances and to facilitate the cooperation of the patient for catheter placement, positioning for imaging techniques or even physical exam (Karas 1999; Levy et al. 2017). Sedation is often 
preferred over general anesthesia for procedures that can be completed without complete unconsciousness of the patient. One of the main advantages of sedation over general anesthesia is the lower mortality rate. For example, in dogs the rates are $0.07 \%$ versus $0.18 \%$, in cats $0.12 \%$ versus $0.26 \%$, and in rabbits $0.7 \%$ versus $1.48 \%$ (Brodbelt et al. 2008).

The difference between sedatives and tranquilizers is not a clear concept, and it may vary across species and doses. For example, cattle need ten times less of the alpha-2 agonist xylazine to achieve a similar clinical effect to horses, and phenothiazines such as acepromazine cause reliable tranquilization in dogs but not in pigs. In short, tranquilizers induce a restful state, whereas sedatives will cause more profound effects, reducing the response to external stimuli (Rankin 2015).

Some of the drugs used for sedation will concomitantly provide analgesia, which becomes relevant in patients exhibiting pain or in which pain will arise as a result of surgical or diagnostic procedures. Pain can lead to detrimental effects to the patient through sympathetic stimulation and, if left untreated for a long period of time, the constant noxious stimulus to the spinal cord may lead to hyperexcitability (wind-up). At this point the challenge to adequately inhibit pain becomes more difficult (Dowing \& Gaynor 2015).

The most common sedatives/tranquilizers used in dogs include phenothiazines (acepromazine), benzodiazepines, opioids and alpha-2 $\left(\alpha_{2}\right)$ agonists. Their cardiovascular effects vary among the different sedatives; the most common changes observed for acepromazine include a decrease in arterial blood pressure as a consequence of blockade of alpha-1 $\left(\alpha_{1}\right)$ adrenergic receptors, leading to vasodilation (Ludders et al. 1983), which becomes more intense during inhalant anesthesia (Grasso 2015). After premedication with acepromazine, dogs require higher doses of dopamine to increase pressures (Monteiro et al. 2007), and the effects of a bolus of dextran 
or lactated ringer's and an ephedrine CRI were minimized by acepromazine in dogs (Sinclair \& Dyson 2000), whereas it didn't influence the rate of dobutamine to keep normal pressures in horses (Monteiro et al. 2011). It produces sedation through inhibition of central dopaminergic receptors, mainly at the D2 subtype, which are pre- and postsynaptic G-protein coupled receptors that when blocked decrease the calcium and potassium conductance. The blocking effect on $\alpha_{1}$-adrenergic, muscarinic and histamine (H1) receptors may also contribute in part to the sedative role (Rankin 2015; Posner 2018). One of the advantages of using acepromazine as part of the tranquilization protocol is its antiemetic effect, decreasing the incidence of vomiting in dogs receiving opioids for premedication, when given at least 15 minutes prior (Valverde et al. 2004).

Opioids are used in order to provide analgesia and sedation. The sedative effects are dose dependent, and vary between species, as cats and horse may show excitement, whereas in dogs and pigs this is less likely. Respiratory depression is not as severe as in humans compared to domestic species, but is still present in a dose-dependent fashion (KuKanich \& Wiese 2015). Opioids may lead to a vagally mediated bradycardia (Randich et al. 1993), but cardiac output is usually maintained due to an increase in stroke volume if the decrease in HR is mild (KuKanich \& Wiese 2015).

The primary inhibitory neurotransmitter in the central nervous system is $\gamma$-aminobutyric acid (GABA), which increases the conductance of chloride once it stimulates its receptor, hyperpolarizing the neuron. Benzodiazepines enhance the effect of GABA on the receptor subtype $\mathrm{GABA}_{\mathrm{A}}$, which also have other binding sites for drugs such as alcohol and barbiturates, explaining the synergistic effect of these drugs when combined (Goodchild 1993; Posner 2018). The presence or absence and distribution of different receptor subtypes may explain the different clinical actions seen across species, and between drugs of this class (Sigel \& Ernst 2018). Diazepam and 
Midazolam are the most common drugs belonging to this class used in veterinary anesthesia, with very little detrimental effects on the cardiovascular system (Jones et al. 1979; Rankin 2015), but they can result in paradoxical excitement and restlessness when not used with another sedative in some domestic species, including dogs (Simon et al. 2014).

Alpha-2 agonists, including dexmedetomidine, have more profound cardiovascular effects than the aforementioned sedatives and their effects are discussed below.

\subsubsection{Dexmedetomidine}

Dexmedetomidine is the most commonly used $\alpha_{2}$-adrenergic agonist in small animals for its sedative and analgesic effects. Dexmedetomidine is the R-isomer of medetomidine, which is a racemic mixture of dexmedetomidine and levomedetomidine, and is the active isomer of the mixture. Levomedetidine does not provide sedation and at high doses may exacerbate the adverse cardiovascular effects associated with $\alpha_{2}$ agonists (Kuusela et al. 2001). Dexmedetomidine is two times as potent as the racemic mixture, and 40 times when compared to xylazine (Wellington et al. 2013). Regarding receptor selectivity of $\alpha_{2}$ : $\alpha_{1}$, dexmedetomidine is the most selective of the drugs used clinically, with a ratio of 1620:1, compared to 160:1 for Xylazine, 220:1 for clonidine and 260:1 for detomidine (Virtanen et al. 1988).

Alpha-2 agonists activate pre- and postsynaptic alpha receptors (Posner 2018). Alpha receptors are divided into $\alpha_{1} \mathrm{~A}$ and $\mathrm{B}$, and $\alpha_{2} \mathrm{~A}, \mathrm{~B}$ and $\mathrm{C}$, and are coupled to different classes of $\mathrm{G}$ protein (Bylund 1988). Initially, the proposed classification was based on localization: $\alpha$ receptors localized postsynaptically, in the effector organ, were named $\alpha_{1}$, whereas $\alpha$ found presynaptically and involved in the release of norepinephrine were named $\alpha_{2}$ (Langer 1974). 
However, $\alpha_{2}$ receptors have also been found postsynaptically, making this way of classification confusing and less popular (Boyd 2000).

The effects on the cardiovascular system can be categorized as biphasic. During the initial phase, there is bradycardia mediated by activation of presynaptic $\alpha_{2}$ receptors and by vagal reflex due to peripheral vasoconstriction. In a later phase, a decrease in vascular resistance compared to the first phase and lingering bradycardia may be seen, maintained by central stimulation of receptors and lack of norepinephrine outflow. (Pagel et al. 1998; Posner 2018).

The sedation provided by dexmedetomidine is believed to be mostly a result of the action on $\alpha_{2}$ A receptor, localized on the locus coeruleus (LC). This is a tiny neuronal nucleus in the pons, under the floor of the fourth ventricle, being the largest noradrenergic cell body aggregation in the brain, and an important site for the control of vigilance (Schwinn \& Schwenn 1992). The LC may also play a role in pain modulation through descending and ascending pathways (Llorca-Torralba et al. 2016). Direct vagal stimulation results from activation of alpha-2 receptors in the dorsal motor nucleus of the vagus nerve, the nucleus ambiguous and the nucleus tractus solitarius (Robertson \& Leslie 1985; Tobias \& Chrysostomou 2013).

Analgesia results from activation of pre- and post-synaptic $\alpha_{2}$ A, B and C receptors, at the supraspinal and spinal level, which results in inhibition of neurotransmitter release from the primary afferent fibers to second order neurons, such as substance P, affecting pre- and postsynaptic modulation of nociceptive signals occurring in the dorsal horn, altering descending modulatory systems from the brainstem, or ascending modulation of nociceptive signals in the diencephalon and limbic areas (Murrell \& Hellebrekers 2005; Valverde 2010). 


\subsubsection{Effects on cardiac electrical activity}

Mediated by central action in the LC, dexmedetomidine inhibits sympathetic activity by decreasing the release of norepinephrine, causing sedation and bradycardia. The decrease in heart rate is also a consequence of increased vagal stimulus by triggering a baroreceptor reflex due to increase in peripheral vascular resistance and direct central vagal stimulation (Tobias \& Chrysostomou 2013; Cepiel et al. 2018). Dexmedetomidine also has a negative dromotropic effect (i.e., decreases rate of conduction through AV node) and increases the atrial effective refractory period in humans (Ergul et al. 2015). Some researchers compare the effect of $\alpha_{2}$-agonist on the conduction system to those of $\beta$-antagonists and vagal maneuver (Tobias \& Chrysostomou 2013). Similar effects are expected to happen to domestic mammals, but the research is still limited.

In pigs receiving dexmedetomidine, bradycardia was the most common arrhythmia noted, and the only conduction parameter affected was the effective refractory period of the right ventricle, which was only significantly increased when the heart rate was stimulated to reach 130 bpm (Cepiel et al. 2018). Apart from bradycardia, the most common arrhythmias in dogs receiving dexmedetomidine include ventricular premature complexes (seldom) and second-degree AV blocks (more often). These are more common after premedication and at the recovery phase. Bradycardia may last for hours if animals are kept under anesthesia and heart rate increases only once they are awake (Kuusela et al. 2002). The resulting depressing effects on conduction and bradycardia can be so intense that they lead to asystole or pulseless electrical activity in some cases (Gerlach \& Murphy 2009; Chen et al. 2012). On the other hand, dexmedetomidine increases the dose of epinephrine necessary to develop arrhythmias in halothane-anesthetized dogs (Hayashi et al. 1991). 


\subsubsection{Effects on cardiac mechanical activity}

Dexmedetomidine has no direct effects on the heart tissue, and the depressed cardiac function results from peripheral and CNS effects (Housmans 1990; Flacke et al. 1992). Clinical doses of dexmedetodimine infusion in dogs can lead to an increase in vascular resistance of up to $70 \%$, which in turns decreases the heart rate up to $55 \%$. The resultant effect of bradycardia and increased vascular resistance will negatively affect cardiac output, which can be decreased up to $56 \%$ (Pascoe 2015).

The cardiovascular effects of dexmedetomidine in horses and cats are not as significant as in dogs, mostly because the change in heart rate is minimal, and vascular resistance does not show the same level of increase (Bettschart-Wolfensberger et al. 2005; Pypendop et al. 2017; MartinFlores et al. 2018).

\subsection{EFFECTS OF GENERAL ANESTHESIA ON CARDIAC FUNCTION}

Broadly speaking, most drugs used clinically to provide general anesthesia in domestic animals lead to cardiovascular depression, through decreases in cardiac output, vascular resistance or both (Mazzafero \& Wagner 2001). Injectable anesthetics such as barbiturates, propofol and alfaxalone are used mostly for induction, but can also be applied for maintenance of general anesthesia. These drugs bind and activate $\mathrm{GABA}_{\mathrm{A}}$ receptors, decreasing the rate of dissociation of the neurotransmitter GABA, increasing chloride conductance, which results in hyperpolarization of the neuron. In the cardiovascular system this mechanism leads to a decrease in myocardial contractility translating into decreased stroke volume and vascular resistance. The end result of both effects is hypotension, which may be somehow compensated in some species by an increase in heart rate, that is usually short lived. One exception of these drugs worth mentioning is the 
induction drug etomidate, which provides a more stable cardiovascular function, but it is not available in some countries, and has other adverse effects such as poor muscle relaxation, adrenal gland suppression and hemolysis, precluding its use in many patients (Berry 2015).

Another class of drugs used widely for general anesthesia maintenance in veterinary medicine, but that can also be used as an induction agent, are inhalant anesthetics. They are unique among anesthetics due to the fact that are administered and mostly removed from the body through the lungs, provide a fast adjustment in anesthetic depth and their concentration can be easily measured continuously. Inhalant anesthetics produce amnesia and immobility through not completely known mechanisms, which may include action on several receptors, like GABA $\mathrm{A}_{\mathrm{A}}$ and NMDA, both in the spinal cord and brain. All inhalant anesthetics lead to cardiovascular depression, which is dose- and drug-dependent. Cardiac output can be preserved due to reduction in systemic vascular resistance, but usually a decrease is seen from direct depression in myocardial contractility and stroke volume. Cardiac output is also affected by heart rate, which varies according to drugs and species, but in dogs is usually maintained constant by halothane, sevoflurane, desflurane and isoflurane. Arterial blood pressure decreases in a dose-dependent fashion regardless of the species being studied. In humans the main cause seems to be related to a decrease in vascular resistance, whereas in some veterinary species myocardial depression and low stroke volume may play a more significant role. Some of the older inhalants, namely halothane and cyclopropane, predispose the myocardium to arrhythmias by sensitizing it to catecholamines, an effect that is not so evident in modern inhalants like isoflurane and sevoflurane (Steffey et al. 2015; Brosnan \& Steffey 2018). 


\subsubsection{Isoflurane}

Isoflurane is a halogenated ether, in widespread use for humans since the 1980 's, currently being the most used inhalant anesthetic in veterinary medicine in several countries (Brosnan \& Steffey 2018). Isoflurane affects the arterial blood pressure in dogs in a dose-dependent fashion, with even clinical doses of 1.2 times the minimum alveolar concentration (MAC) causing it to drop significantly. These changes get worse as the concentration increases, but up to 2 MAC the mean pressure is usually maintained above $60 \mathrm{mmHg}$ in healthy subjects. Cardiac output is maintained similar to awake state until 1.4 MAC, by means of an increase in heart rate as a compensatory mechanism, given that at 1.2 MAC the stroke volume is already affected by almost 40\% (Merin et al. 1991; Pagel et al. 1991). The effect of isoflurane on the baroreceptor reflex to vagal and sympathetic stimulus in dogs is dose-dependent. At 2 MAC the response seems to be completely blunted, whereas at $1 \mathrm{MAC}$ baroreflexes are well maintained. The response in heart rate is greater when the change is an increase in arterial blood pressure (towards decreasing heart rate), than a decrease in arterial blood pressure (towards increasing heart rate) (Seagard et al. 1983).

\subsection{DRUGS TO TREAT BRADYARRHYTHMIAS}

Arrhythmias in which the heart rate is below the reference level for a specific species are called bradyarrhythmias. Sinus bradycardia may result from systemic problems like hypothermia, hypothyroidism and increased vagal tone (Santilli et al. 2018). Cardiac output is the product of heart rate and stroke volume, therefore, within physiological limits, the faster the heart rate is, the greater the cardiac output will be and vice versa (Vincent 2008). An excessively fast heart rate leads to a decreased stroke volume due to reduced ventricular filling time, and so cardiac output will not necessarily improve (Noble et al. 1966). On the other side, the stroke volume will not be 
able to compensate for a severe bradycardia, as the ventricles have a limited filling volume, and so cardiac output, and consequently peripheral perfusion will be negatively affected (Valverde et al. 2006; Klein 2013d).

The treatment for low heart rates may be achieved by either decreasing the vagal tone (vagolytics) or stimulating the sympathetic system through $\beta$-adrenergic activation in the sinus node. (Meurs \& Riviere 2018).

\subsubsection{Anticholinergics}

The use of anticholinergic drugs is common in veterinary medicine to treat or prevent perianesthetic bradycardia, to decrease airway secretions, to dilate the pupils, to block vagal reflexes from surgical manipulation or manipulation of visceral organs, in conjunction with inhibitors of the anticholinesterase enzyme (neostigmine, edrophonium) for reversal of neuromuscular blocking drugs, and during cardiopulmonary resuscitation (Doyle \& Mark 1990; Aniskevich et al. 2011; Lerche 2015; Wilson \& Shih 2015).

Anticholinergics act specifically on muscarinic, rather than nicotinic receptors, and can also be referred as antimuscarinics or muscarinic receptor antagonists. Among the different subtypes of muscarinic receptors, they don't show any specificity, but the physiological effects are dose- and drug-dependent (McMurphy et al. 2018)

Muscarinic receptors can be subdivided in five types, M1-M5, according to the chronological sequence that they were cloned. Like other receptors, their distribution and prevalence vary among species and even though there are great morphological similarities for the same subtype in mammals, different pharmacological responses may occur. Muscarinic receptors are G-protein coupled, and their agonism by ACh leads to a decrease in cAMP and activation of 
acetylcholine-mediated $\mathrm{K}^{+}$channels $\left(\mathrm{K}_{\mathrm{Ach}}\right)$ that increase $\mathrm{K}^{+}$efflux, hyperpolarizing the cell, leading to negative chronotropy, as seen during increased vagal tone (Caulfield \& Birdsall 1998; Katz 2011a)

This class of drugs will lead to an increase in heart rate by interacting with the muscarinic receptor, blocking $\mathrm{ACh}$ from binding to and activating the receptor. This will then mitigate the parasympathetic response that otherwise would be fully achieved through acetylcholine. (McMurphy et al. 2018). This may lead to a paradoxical bradycardia, decreasing the heart rate initially and even causing escape beats or atrioventricular blocks, before increasing it. This is believed to be due to an initial vagal stimulus in the central nervous system, which is then overcome by blockade of peripheral muscarinic receptors (Richards et al. 1989). Another mechanism involved is the antagonism at the muscarinic $\mathrm{M}_{1}$ receptor subtype in sympathetic ganglia, and at pre-synaptic $\mathrm{M}_{2}$ receptors on parasympathetic nerve endings. Both receptors work as negative feedback to control acetylcholine release and once blocked will only allow for more acetylcholine to reach the SA node (Meyer \& Sommers 1988). This is a general explanation as the receptor subtypes may differ between species. Humans seem to have only $\mathrm{M}_{2}$ receptors in the heart, whereas $M_{2}, M_{3}$ and $M_{4}$ receptors have been identified in the dog's heart (Shi et al. 1999; Oberhauser et al. 2001). It is assumed that low-dose atropine is more likely to induce paradoxical bradycardia, slowing the SA node firing rate, and also seems to increase the rate of impulse conduction at the AV node. This is not always the case, and the opposite effect has been reported in humans, with an increased sinus discharge rate along with a decrease in AV node conduction (Chin 2005). Systemically, these drugs will decrease the amount of salivary and airway secretion making it more viscous, reduce gastrointestinal motility and may increase gastric $\mathrm{pH}$ (Pendleton et al. 1986; McMurphy 2018). 
Atropine is a racemic mixture, the L-isomer being the one responsible for most of the drug's clinical effect. The molecule is a lipid-soluble tertiary amine, and easily crosses the bloodbrain and blood-placenta barriers (Proakis \& Harris 1978; Lerche 2015)

Glycopyrrolate is a synthetic antimuscarinic agent, four times as potent as atropine and with longer lasting effects. The drug has poor penetration of the blood-brain and blood-placenta barriers due to the presence of a quaternary ammonium, causing less or no antimuscarinic CNS effects such as cycloplegia, sedation or mydriasis (Lerche 2015; McMurphy et al. 2018).

Due to their antimuscarinic effects and increase in heart rate, both drugs have been considered and investigated as treatment or prevention options for $\alpha_{2}$-induced bradycardia, with overall poor outcomes. Glycopyrrolate given IM 15 min prior to romifidine resulted in higher heart rates and arterial blood pressure values compared to romifidine alone in healthy dogs, however they also showed AV blocks, not observed in the romifidine group (Lemke 2001). Unfortunately, cardiac output was not evaluated in this study. In studies evaluating echocardiographic and hemodynamic alterations in dogs receiving medetomidine with and without glycopyrrolate under isoflurane anesthesia, the group receiving glycopyrrolate had worse LV systolic function indices, increased SVR and arterial blood pressures, with no improvements in cardiac output or oxygen delivery (Moraes et al. 2004a; Moraes et al. 2004b). Another study compared the effects of administering glycopyrrolate 20 minutes prior or concomitantly with romifidine in awake healthy dogs, and also determined that the inclusion of glycopyrrolate resulted in marked increases in heart rate and arterial blood pressure, including arrhythmias when administered concomitantly (Sinclair et al. 2002). The use of glycopyrrolate 20 minutes before romifidine was deemed a more viable option (Sinclair et al. 2002). 


\subsubsection{Sympathomimetics}

Sympathomimetic use is intended to treat hypotension caused by vasodilation (vasopressor), myocardial depression (inotropes) or a combination of both (drugs with mixed effects) (Duke-Novakovski \& Carr 2015). Since the cardiovascular effects of $\alpha_{2}$ agonists include an increase in arterial blood pressure followed by bradycardia, these agents have not been investigated as a treatment option. Potentially, drugs with chronotropic and vasodilatory effects could be useful in treating the bradycardia and increase in vascular resistance from $\alpha_{2}$ agonists. Dobutamine and isoproterenol are positive chronotropic drugs and also decrease vascular resistance, however their effects have not been investigated to counteract the bradycardia and increase in vascular resistance caused by $\alpha_{2}$ agonists. Dopamine increases heart rate, but may also increase vascular resistance at higher doses, which could be detrimental to patients that have received dexmedetomidine (Imai 1978; Rosati et al. 2007; Murrel 2015). Horses are frequently administered sympathomimetic treatment with dobutamine under anesthesia after receiving $\alpha_{2}$ agonists as premedication, but the purpose of this therapy is to treat hypotension that results from inhalant anesthesia which offsets the effects on $\alpha_{2}$ agonists on vascular resistance (Yamashita et al. 2002).

\subsubsection{Lidocaine}

Traditionally, lidocaine has been indicated for arrhythmias originating in the ventricles and was regarded as ineffective for supraventricular ones (Miller et al. 2018). Some studies have shown conflicting results, demonstrating that lidocaine can be an effective treatment for some arrhythmias with supraventricular origin, in both human and veterinary species. Such examples are atrial fibrillation (Josephson et al. 1976; Moïse et al. 2005) and supraventricular tachycardia (Johnson 
et al. 2006). These studies show that lidocaine may be useful to convert supraventricular arrhythmias with a vagal origin, supported by a study from Lieberman et al. (1968), where lidocaine seemed to partially block the effects of an electrical stimulus to the vagus nerve, increasing the heart rate. In the SA node and atrial tissue there are ligand-gated acetylcholineactivated inward rectifier potassium currents $\left(i_{\mathrm{KAch}}\right)$, which mediate a hyperpolarizing response of the cells as a result of parasympathetic stimulus. The hyperpolarizing effect caused by opening of $i_{\text {KAch }}$ will reduce excitability by making the resting potential more negative. In the SA node, this will slow the pacemaker activity, and in the atria will shorten the action potential, contributing to the negative inotropic effect seen during the vagal response (Katz 2011a). It has been shown in vitro that lidocaine blocks rectifying $\mathrm{K}^{+}$channels in myocardial cells, and more specifically $i_{\mathrm{KATP}}$ channels, which are activated by ADP (Josephson 1988; Olschewski et al. 1996). It is possible that lidocaine exerts its parasympatholytic effect through the blockage of $i_{\text {KAch }}$ channels.

In the clinical setting, dogs receiving dexmedetomidine as premedication, and administered lidocaine intravenously for a MAC-sparing effect during inhalant anesthesia, were observed to have an increase in heart rate within a few minutes, which is supported by the studies mentioned previously, as part of the bradycardia induced by $\alpha_{2}$ agonists is mediated through a vagal response as a consequence of increased systemic vascular resistance.

\subsection{Dexmedetomidine Antagonists}

Several drugs with $\alpha$-adrenergic receptor antagonism activity are available and used for different clinical reasons in human and veterinary medicine. Phenoxybenzamine is a non-selective and non-competitive alpha-adrenergic blocker that was traditionally used to decrease the urethral pressure and resistance in dogs and cats with urethral obstruction, but nowadays is intended for 
systemic arterial blood pressure control before adrenalectomy surgery in dogs with pheochromocytoma (Marks et al. 1996; Fischer et al. 2003; Herrera et al. 2008). Prazosin is a selective $\alpha_{1}$ adrenergic antagonist that has taken the role of phenoxybenzamine to aid the treatment of urethral obstruction in companion animals and has also been used as an antihypertensive agent for pheochromocytoma (Fischer et al. 2003; Murrell 2015).

Other alpha-adrenergic antagonists are more selective for $\alpha_{2}$ receptors, such as yohimbine, tolazoline and atipamezole, and for that reason are used as reversal agents for $\alpha_{2}$ agonists (McMurphy et al. 2018). In the last decades, peripherally acting $\alpha_{2}$ antagonists, without the capability of crossing the blood-brain-barrier, have been studied, with the potential to reverse the undesired systemic side effects of agonists, but still keeping the desired central effects like sedation and analgesia (Clineschmidt et al. 1987).

\subsubsection{Atipamezole}

Atipamezole possesses a higher selectivity for $\alpha_{2}$ receptors compared to $\alpha_{1}$, than other alpha-adrenergic antagonists such as yohimbine and tolazoline. Atipamezole's $\alpha_{2}$ : $\alpha_{1}$ - selectivity ratio is around $8,300-8,525$, making it the best option for reversal of dexmedetomidine, a drug that is also highly selective for $\alpha_{2}$ receptors (1620:1) (Virtanen et al. 1989; Schwartz \& Clarck 1998; Posner 2018), and reverses the sedation provided by medetomidine faster than yohimbine in lambs (Ko \& McGrath 1995).

Atipamezole is only approved for use in dogs, to be given by the intramuscular route, to reverse the effects of dexmedetomidine or medetomidine (Posner 2018), but has also been used in other species, including horses and ponies to reverse the sedative effects of medetomidine infusions (Bettschart-Wolfensberger et al. 1999) and in calves to reverse the cardiovascular effects 
of xylazine and medetomidine (Rioja et al. 2008). Intramuscular atipamezole reverses the cardiovascular and sedative effects of detomidine gel given buccally to dogs, improving heart rate cardiac output and normalizing vascular resistance (Kasten et al. 2018). Atipamezole IM reversed the sedative and analgesic effects of a single bolus of IV dexmedetomidine, but the heart rate did not reach pre-sedation levels, even though an increase was observed (Granholm et al. 2007).

Atipamezole antagonizes the central effects provided by $\alpha_{2}$ agonists, such as sedation and analgesia, because it readily crosses the blood-brain-barrier. Studies in rats receiving medetomidine or dexmedetomidine have shown cessation of analgesia after the administration of centrally acting $\alpha_{2}$ antagonists (Pertovaara et al. 1990; Fisher et al. 1991). This limits the use of this drug if only the cardiovascular effects were to be reversed and analgesia and sedation were to be preserved. Reversal of the cardiovascular effects may not be achieved with atipamezole, and administration of an antagonist can be harmful to arterial blood pressure. Anesthetized cats receiving two different doses of atipamezole after a bolus of dexmedetomidine showed no increase in heart rate and cardiac output, and a decrease in arterial blood pressure, causing hypotension (Zatroch et al. 2019).

\subsubsection{Vatinoxan}

Vatioxan, also known as MK-467 or L-659,066, is an alpha-2 antagonist that does not seem to readily cross the blood-brain-barrier. The brain/plasma concentration ratio in rats and marmosets varies between 0.038 and 0.07 depending on dose and administration route (Clineschmidt et al. 1987; Vainionpää et al. 2013). The brain/plasma ratio of vatinoxan in dogs is around 0.02, and spinal/plasma ratio is very similar, varying between 0.01 and 0.02 . Pharmacodynamic studies in

dogs have shown similar effects to that in rats and marmosets, as the degree of sedation is not 
altered in dogs receiving only dexmedetomidine or dexmedetomidine and vatinoxan concomitantly, whereas heart rate was lower in the first group (Clineschmidt et al. 1987; Honkavaara et al. 2008; Honkavaara et al. 2020).

A study in dogs showed that vatinoxan administered by itself leads to a decrease in systemic vascular resistance and an increase in heart rate and cardiac output, but no apparent effects on the central nervous system were observed (Pagel et al. 1998). Furthermore, vatinoxan prevents decreases in plasma insulin concentrations and consequently maintains plasma glucose at steady levels, whereas glucose concentration significantly increases in dogs receiving dexmedetomidine without vatinoxan (Restitutti 2012).

In cats anesthetized with isoflurane and a constant rate infusion of dexmedetomidine, vatinoxan administration resulted in a higher MAC value than a control group receiving saline instead of vatinoxan (Pypendop et al. 2019). This raises questions regarding the drug's capability to cross the blood-brain-barrier in domestic species, requiring further pharmacokinetic studies to determine its concentration in plasma and CNS. 


\subsection{Rationale, Hypothesis, and Objectives}

The bradycardia that results from dexmedetomidine administration is due to a baroreceptor response from the increase in vascular resistance caused by the stimulation of alpha receptors. The reduction in heart rate results in a proportional decrease in cardiac output, despite the increase in arterial blood pressure. The ideal therapy modality should include an increase in heart rate without a detrimental increase in cardiac work that compromises efficiency and cardiac output. Unfortunately, the use of anticholinergics markedly increases heart rate but further decreases cardiac output and increases mean arterial pressure, because vascular resistance remains elevated. The alternative then, has been to reverse the cardiac actions of dexmedetomidine with its specific antagonist, atipamezole; however, this also reverses the sedative and analgesic effects.

In our clinical practice, we have observed that when lidocaine is used intravenously intraoperatively to provide analgesia and a significant reduction in the MAC of inhalational anesthetics, an increase in heart rate occurs in patients that were administered dexmedetomidine as part of their premedication, and this increase was of moderate magnitude and mean arterial pressure was better regulated. The usefulness of lidocaine to treat the dexmedetomidine induced bradycardia have not been investigated.

There were two main objectives in the current research. The primary objective was to assess cardiorespiratory function in sedated and anesthetized dogs that have received dexmedetomidine and then treated with IV lidocaine. A secondary objective was to determine if there are differences in the response to lidocaine between sedated and isoflurane-anesthetized dogs administered dexmedetomidine since vascular resistance is lower in anesthetized dogs, which may have less effect on vagal tone. We hypothesized that administration of lidocaine to counteract the bradycardia from dexmedetomidine in dogs under sedation or isoflurane anesthesia can improve 
cardiac output by increasing heart rate without affecting systemic vascular resistance and/or blood pressure. 


\subsection{References}

Alberts B, Johnson A, Lewis J, Morgan D, Raff M, Roberts K, Walter P. Membrane Transport of Small Molecules and the Electrical Properties of Membranes. In: Molecular Biology of The Cell (6 ${ }^{\text {th }}$ edn.). Alberts B, Johnson A, Lewis J, Morgan D, Raff M, Roberts K, Walter P (eds.). Garland Science, New York, USA. 2015; pp. 597-640.

Aniskevich ST, Leone BJ, Brull SJ. Sugammadex: a novel approach to reversal of neuromuscular blockade. Expert Rev Neurother 2011; 11:185-198.

Aravindakshan V, Kuo CS, Gette LS. Effect of lidocaine on escape rate in patients with complete atrioventricular block. Am J Cardiol 1977; 40:177-183.

Bear MF, Connors BW, Paradiso MA. Spinal control of movement. In: Neuroscience - Exploring the Brain (4 ${ }^{\text {th }}$ edn.). Bear MF, Connors BW, Paradiso MA (eds.). Wolters Kluwer, USA. 2016; pp. 453-482.

Beitz AJ, Fletcher TF. Nervous tissue. In: Dellmann's Textbook of Veterinary Histology (6 ${ }^{\text {th }}$ edn.). Eurell JA, Frappier BL (eds.). Blackwell, Ames, USA. 2006; pp. 91-116.

Berridge MJ. Smooth muscle cell calcium activation mechanisms. J Physiol 2008; 586:5047-5061.

Berry SH. Injectable anesthetics. In: Veterinary Anesthesia and Analgesia: The Fifth Edition of Lumb and Jones ( $5^{\text {th }}$ edn.). Grimm KA, Lamont LA, Tranquilli WJ, Greene SA, Robertson SA (eds.). Wiley-Blackwell, Ames, USA. 2015; pp. 277-296.

Bettschart-Wolfensberger R, Bettschart RW, Vanio O, Marlin D, Clarke K. Cardiopulmonary effects of a two hour medetomidine infusion and its antagonism by atipamezole in horses and ponies. J Vet Anaesth 1999; 26:8-12. 
Bettschart-Wolfensberger R, Freeman SL, Bowen IM, Aliabadi FS, Weller R, Huhtinen M, Clarcke KW. Cardiopulonary effects and pharmacokinetics of i.v. dexmedetomidine in ponies. Eq Vet J 2005; 37:60-64.

Boyd RE. $\alpha_{2}$-Adrenergic agonists as analgesic agents. Exp Opin Ther Patents 2000; 10:1741-1748. Brodbelt DC, Blissitt KJ, Hammond RA, Neath PJ, Young LE, Pfeiffer DU, Wood JLN. Vet Anaesth Analg 2008; 35:365-373.

Brosnan R, Steffey P. Inhalant anesthetics. In: Veterinary Pharmacology and Therapeutics $\left(10^{\text {th }}\right.$ edn.). Riviere JE, Papich MG (eds.). Wiley-Blackwell, Hoboken, USA. 2018; pp. 216-246.

Bylund DB. Subtypes $\alpha_{2}$-adrenoceptors: pharmacological and molecular biological evidence converge. Trends Pharmacol Sci 1988; 9:356-361.

Campbell T. Kinetics of onset of rate-dependent effects of Class I antiarrhythmic drugs are important in determining their effects on refractoriness in guinea-pig ventricle, and provide a theoretical basis for their subclassification. Cardiov Res 1983; 17:344-352.

Catterall WA, Mackie K. Local Anesthetics. In: Goodman And Gilman The Pharmacological Basis of Therapeutics. (14th Edn.). Brunton LL, Hilal-dandan R, Knollman B (Eds). McGraw-Hill Education, New York, USA. 2017; pp. 405-419.

Caulfield MP, Birdsall NJM. International union of pharmacology. XVII. Classification of muscarinic acetylcholine receptors. Pharmacol Rev 1998; 50:279-290.

Cepiel A, Noszczyk-Nowak A, Janiszewski A, Pasławski R, Pasławska U. Effect of xylazine, medetomidine and dexmedetomidine on cardiac conduction in pigs. Med Weter 2018; 73:187-192. 
Chandler JC, Monnet E, Staat AJ. Comparison of acute hemodynamic effects of lidocaine and procainamide for postoperative ventricular arrhythmias in dogs. J Am Anim Hosp Assoc $2006 ; 42: 262-268$.

Chen CY, Chen KS, Chang KM, Lee WM, Chang SC, Wang HC. Dexmedetomidine related bradycardia leading to cardiac arrest in a dog. Pak Vet J 2012; 32:635-636.

Cheng JW. Nebivolol: a third-generation beta-blocker for hypertension. Clin Ther 2009; 31:447462.

Chin KJ. Atrioventricular conduction block induced by low-dose atropine. Anesth 2005; 60:935936

Clineschimidt BV, Pettibone DJ, Lotti VJ, Hucker HB, Sweeney BM, Reiss DR, Lis EV, Huff JR, Vacca J. A peripherally acting alpha-2 adrenoceptor antagonist: L-659,066. J Pharmacol Exp Ther 1988; 245:32-40.

Cobbe SM. Clinical usefulness of the Vaughan Williams classification system. Eur Heart J 1987; 8:65-69.

Doyle DJ, Mark PWS. Reflex bradycardia during surgery. Can J Anaesth 1990; 37:219-222.

Dowing R, Gaynor JS. Chronic pain cases. In: Handbook of Veterinary Pain Management (3 ${ }^{\text {rd }}$ edn). Gaynor JS, Muir WW (eds.). Elsevier, St. Louis, USA. 2014; pp. 472-492.

Duke-Novakovski T, Carr A. Perioperative blood pressure control and management. Vet Clin Small Anim Pract 2015; 45:965-981.

Eason BD, Fine DM, Leeder D, Stauthammer C, Lamb K, Tobias AH. Influence of beta blockers on survival in dogs with severe subaortic stenosis. J Vet Int Med 2014; 28:857-862. 
Ergul Y, Unsal S, Ozyilmaz I, Ozturk E, Carus H, Guzeltas A. Electrocardiographic and electrophysiologic effects of dexmedetomidine on children. Pacing Clin Electrophysiol $2015 ; 38: 632-687$.

Eschenhagen T. Treatment of Ischemic Heart Disease. In: Goodman \& Gilman's: The Pharmacological Basis of Therapeutics (13 ${ }^{\text {th }}$ edn.). Brunton LL, Hilal-Dandan R, Knollmann BC (eds.). McGraw-Hill Education, New York, USA. 2017; pp. 489-506.

Eurell JA. Muscle. In: Dellmann's Textbook of Veterinary Histology (6 ${ }^{\text {th }}$ edn.). Eurell JA, Frappier BL (eds.). Blackwell, Ames, USA. 2006; pp. 79-90.

Fischer JR, Lane IF, Cribb AF. Urethral pressure profile and hemodynamic effects of phenoxybenzamine and prazosin in non-sedated male beagle dogs. Can J Vet Res 2003; 67:30-38.

Fisher B, Zornow MH, Yaksh TL, Peterson BM. Antinociceptive properties of intrathecal dexmedetomidine in rats. Eur J Pharmacol 1991; 192:221-225.

Flacke WE, Flacke JW, Blow KD, McIntee DF, Bloor BC. Effect of dexmedetomidine, an a 2 agonist, in the isolated heart. J Cardiothorac Vasc Anesth 1992; 6:418-423.

Francis AJ, Johnson MJS, Culshaw GC, Corcoran BM, M. Martin WS, French AT. Outcome in 55 dogs with pulmonic stenosis that did not undergo balloon valvuloplasty or surgery. $\mathrm{J}$ Small Animal Practice 2011; 52:282-288.

Fries R, Saunders AB. Use of procainamide for conversion of acute onset AF following pericardiocentesis in a dog. J Am Anim Hosp Assoc 2012; 48:429-433.

Gerlach A, Murphy C. Dexmedetomidine-associated bradycardia progressing to pulseless electrical activity: case report and review of the literature. Pharmacotherapy 2009; 29:392398. 
Goodchild CS. GABA receptors and benzodiazepines. Br J Anaesth 1993; 71:127-133.

Granholm M, McKusick BC, Westerholm FC, Aspegrén JC. Evaluation of the clinical efficacy and safety of intramuscular and intravenous doses of dexmedetomidine and medetomidine in dogs and their reversal with atipamezole. Vet Rec 2007; 160:891-897.

Grasso SC, Ko JC, Weil AB, Paranjape V, Constable PD. Hemodynamic influence of acepromazine or dexmedetomidine premedication in isoflurane-anesthetized dogs. J Am Vet Med Assoc 2015; 24:754-764.

Gilmour RF, Moïse NS. The electrocardiogram and cardiac arrhythmias. In: Dukes' Physiology of Domestic Animals (13 ${ }^{\text {th }}$ edn.). Reece WO, Erickson HH, Goff JP, Uemura EE (eds.). Wiley-Blackwell, Ames, USA. 2015; pp. 315-326.

Hall JE. Cardiac Muscle - The Heart as a Pump and Function of the Heart Valves. In: Guyton \& Hall Textbook of Medical Physiology (13 ${ }^{\text {th }}$ edn.). Hall JE (ed.). Elsevier, Philadelphia, USA. 2016a; pp. 109-122.

Hall JE. Rhythmical excitation of the heart. In: Guyton \& Hall Textbook of Medical Physiology (13 ${ }^{\text {th }}$ edn.). Hall JE (ed.). Elsevier, Philadelphia, USA. 2016b; pp. 75-88.

Hall JE. Contraction of Skeletal Muscle. In: Guyton \& Hall Textbook of Medical Physiology $\left(13^{\text {th }}\right.$ edn.). Hall JE (ed.). Elsevier, Philadelphia, USA. 2016c; pp. 123-129.

Hall JE. Excitation of skeletal muscle: neuromuscular transmission and excitation-contraction coupling. In: Guyton \& Hall Textbook of Medical Physiology (13 ${ }^{\text {th }}$ edn.). Hall JE (ed.). Elsevier, Philadelphia, USA. 2016d; pp. 89-96.

Hall JE. Excitation and contraction of smooth muscle. In: Guyton \& Hall Textbook of Medical Physiology (13 ${ }^{\text {th }}$ edn.). Hall JE (ed.). Elsevier, Philadelphia, USA. 2016e; pp. 97-105. 
Hayashi Y, Sumikawa K, Maze M, Yamatodani A, Kamibayashi T, Kuro M, Yoshiya I. Dexmedetomidine prevents epinephrine-induced arrhythmias through stimulation of central $\alpha_{2}$ adrenoceptors in halothane-anesthetized dogs. Anesthesiology 1991; 75:113-117.

Herrera MA, Mehl ML, Kass PH, Pascoe PJ, Feldman EC, Nelson RW. Predictive factors and the effect of phenoxybenzamine on outcome in dogs undergoing adrenalectomy for pheochromocytoma. J Vet Intern Med 2008; 22:1333-1339.

Honkavaara JM, Raekallio MR, Kuusela EK, Hyvärinen ES, Vainio OM. The effects of L659,066 , a peripheral $\alpha 2$-adrenoceptor antagonist, on dexmedetomidine-induced sedation and bradycardia in dogs. Vet Anaesth Analg 2008; 35:409-413.

Honkavaara JM, Raekallio MR, Syrja PM, Pypendop BH, Knych HK, Kallio-Kujalaa IJ, Vainio OM. Concentrations of medetomidine enantiomers and vatinoxan, an $\alpha_{2}$-adrenoceptor antagonist, in plasma and central nervous tissue after intravenous coadministration in dogs Vet Anesth Analg 2020; 47:47-52.

Hope RR, Scherlag BJ, El-Sherif N, Lazzara R. Hierarchy of ventricular pacemakers. Circ Res $1976 ; 39: 883-888$.

Hopkins PM. Skeletal muscle physiology. Cont Educ Anaesth Crit Care Pain 2006; 6:1-6.

Imai Y, Satoh K, Taira N. Role of the peripheral vasculature in changes in venous return caused by isoproterenol, norepinephrine, and methoxamine in anesthetized dogs. Circ Res 1978; $43: 553-561$

Jackson BL, Adin DB, Lehmkuhl LB. Effect of atenolol on heart rate, arrhythmias, blood pressure, and dynamic left ventricular outflow tract obstruction in cats with subclinical hypertrophic cardiomyopathy. J Vet Cardiol 2015; 17:29-305.

James TN. Anatomy of the sinus node of the dog. Anat Rec 1962; 143:251-265. 
Johnson MS, Martin M, Smith P. Cardioversion of supraventricular tachycardia using lidocaine in five dogs. J Vet Intern Med 2006; 20:272-276.

Jones DJ, Stehling LC, Zauder HL. Cardiovascular response to diazepam and midazolam maleate in the dog. Anesthesiology 1979; 51:430-434.

Josephson IR. Lidocaine blocks $\mathrm{Na}, \mathrm{Ca}$ and $\mathrm{K}$ currents of chick ventricular myocytes. J Mol Cell Cardiol 1988; 20:593-604.

Josephson ME, Kastor JA, Kitchen JG. Lidocaine in Wolff-Parkinson-White Syndrome with atrial fibrillation. Ann Intern Med 1976; 84:44-45.

Karas AZ. Sedation and chemical restraint in the dog and cat. Clin Tech Small Anim Pract 1999; $14: 15-26$.

Kasten JI, Messenger KM, Campbell NB. Sedative and cardiopulmonary effects of buccally administered detomidine gel and reversal with atipamezole in dogs. Am J Vet Res 2018; $12: 1253-1260$.

Katz AM. The Cardiac Action Potential. In: Physiology of the Heart (5 ${ }^{\text {th }}$ edn.). Katz AM (ed.). Wolters Kluwer/Lippincott Williams \& Wilkins, Philadelphia, USA. 2011a; pp. 369-398.

Katz AM. The Heart as a Muscular Pump. In: Physiology of the Heart (5 $5^{\text {th }}$ edn.). Katz AM (ed.). Wolters Kluwer/Lippincott Williams \& Wilkins, Philadelphia, USA. 2011b; pp. 297-312.

Knollmann BC, Roden DM. Antiarrhythmic Drugs. In: Goodman \& Gilman's: The Pharmacological Basis of Therapeutics (13 ${ }^{\text {th }}$ edn.). Brunton LL, Hilal-Dandan R, Knollmann BC (eds.). McGraw-Hill Education, New York, USA. 2017; pp. 547-572.

Kraus MS, Gelzer ARM, Moïse S. Treatment of Cardiac Arrhythmias and Conduction Disturbances in: Manual of Canine and Feline Cardiology (4th edn). Tilley L, Smith F, Oyama M, Sleeper M (eds.). Saunders/Elsevier, St. Louis, USA. 2018; pp. 315-331. 
Klein BG. Electrical activity of the heart. In: Cunningham's Textbook of Veterinary Physiology, ( $5^{\text {th }}$ edn.). Klein BG (ed.). Elsevier-Saunders, St. Louis, USA. 2013a; pp. 171-187.

Klein BG. The physiology of muscle. In: Cunningham's Textbook of Veterinary Physiology. $\left(5^{\text {th }}\right.$ edn.). Klein BG (ed.). Elsevier-Saunders, St. Louis, USA. 2013b; pp. 68-76.

Klein BG. The synapse. In: Cunningham's Textbook of Veterinary Physiology (5 ${ }^{\text {th }}$ edn.). Klein BG (ed.). Elsevier-Saunders, St. Louis, USA. 2013c; pp. 61-67.

Klein BG. The Heart as a pump. In: Cunningham's Textbook of Veterinary Physiology ( $5^{\text {th }}$ edn.). Klein BG (ed.). Elsevier-Saunders, St. Louis, USA. 2013d; pp. 200-212.

Klein SW, Sutherland RIL, Morch J. Hemodynamic effects of intravenous lidocaine in man. Can Med Ass J 1968; 99: 472-475.

Kline DD, Hasse EM, Heesch CM. Regulatiom of the heart. In: Dukes' Physiology of Domestic Animals (13 ${ }^{\text {th }}$ edn.). Reece WO, Erickson HH, Goff JP, Uemura EE (eds.). Wiley-Blackwell, Ames, USA. 2015; pp. 341-351.

Ko JC, McGrath CJ. Effects of atipamezole and yohimbine on medetomidine-induced central nervous system depression and cardiorespiratory changes in lambs. Am J Vet Res 1995; $56: 629-632$.

KuKanich B, Wiese A. Opioids. In: Veterinary Anesthesia and Analgesia: The Fifth Edition of Lumb and Jones ( $5^{\text {th }}$ edn.). Grimm KA, Lamont LA, Tranquilli WJ, Greene SA, Robertson SA (eds.). Wiley-Blackwell, Ames, USA. 2015 pp. 207-226.

Kuusela E, Raekallio M, Hietanen H, Huttula J, Vainio O. 24-hour holter moitoring in the perianethetic period in dogs premedicated with dexmedetomidine. Vet J 2002; 164:235-239. 
Kuusela E, Vainio O, Kaistinen A, Kobylin S, Raekallio M. Sedative, analgesic, and cardiovascular effects of levomedetomidine alone and in combination with dexmedetomidine in dogs. Am J Vet Res 2001; 62:616-621.

Langer SZ. Presynaptic regulation of catecholamine release. Biochem Pharmacol 1974; 23:17931800.

Lei M, Wu L, Terrar DA, Huang CL. Modernized classification of cardiac antiarrhythmic drugs. Circulation 2018; 138:1879-1896.

Lemke KA. Electrocardiographic and cardiopulmonary effects of intramuscular administration of glycopyrrolate and romifidine in conscious beagle dogs. Vet Anaest Analg 2001; 28:75-86.

Lerche P. Anticholinergics. In: Veterinary Anesthesia and Analgesia: The Fifth Edition of Lumb and Jones $\left(5^{\text {th }}\right.$ edn.). Grimm KA, Lamont LA, Tranquilli WJ, Greene SA, Robertson SA (eds.). Wiley-Blackwell, Ames, USA. 2015; pp. 178-182.

Levy JK, Bard KM, Tucker SJ, Diskant PD, Dingman PA. Perioperative mortality in cats and dogs undergoing spay or castration at a high-volume clinic. Vet J 2017; 224:11-15.

Lieberman NA, Harris RS, Katz RI, Lipschutz HM, Dolgin M, Fisher V. The effects of lidocaine on the electrical and mechanical activity of the heart. Am J Cardiol 1968; 22:375-380.

Liu P, Feldman HS, Covino BM, Giasi R, Covino BG. Acute cardiovascular toxicity of intravenous amide local anesthetics in anesthetized ventilated dogs. Anesth Analg 1982; 61:317-322.

Llorca-Torralba M, Borges G, Neto F, Mico JA, Berrocoso E. Noradrenergic locus coeruleus pathways in pain modulation. Neuroscience 2016; 338:93-113.

Ludders JW, Reitan JA, Martucci R, Fung DL, Steffey EP. Blood Pressure response to phenylephrine infusion in halothane-anesthetized dogs given acetylpromazine maleate. Am J Vet Res 1983; 44:996-999. 
Marks SL, Straeter-Knowlen IM, Moore M, Speth R, Rishniw M, Knowlen GG. Effects of acepromazine maleate and phenoxybenzamine on urethral pressure profiles of anesthetized, healthy, sexually intact male cats. Am J Vet Res 1996; 57:1497-1500.

Martin-Flores M, Sakai DM, Honkavaara J, Campoy L. Hemodynamic effects of low-dose atipamezole in isoflurane-anesthetized cats receiving an infusion of dexmedetomidine. J Fel Med Surg 2018; 20:571-577.

Mavropoulou A. Pathogenesis and Classification of Arrhythmias. In: Guide to Canine and Feline Electrocardiography. Willis R, Oliveira P, Mavropoulou A (eds.). John Wiley \& Sons, Chichester, UK. 2018; pp. 67-77.

Mavropolou A. Ventricular rhythms. In: Guide to Canine and Feline Electrocardiography.Willis R, Oliveira P, Mavropoulou A (eds.). John Wiley \& Sons, Chichester, UK. 2018; pp. 169187.

Mazzafero E, Wagner AE. Hypotension during anesthesia in dogs and cats: recognition, causes, and treatment. Compend Contin Educ Pract Vet 2001; 23:728-737.

McMurphy RM, Davis EG, Rankin AJ, Artzer MA, Lutjemeier BJ, Kenney MJ. Cholinergic Pharmacology: Autonomic Drugs. In: Veterinary Pharmacology and Therapeutics $\left(10^{\text {th }}\right.$ edn.). Riviere JE, Papich MG (eds.). Wiley-Blackwell, Hoboken, USA. 2018; pp. 151-164.

Merin RG, Bernard JM, Doursout MF, Cohen M, Chell JE. Comparison of the effects of isoflurane and desflurane on cardiovascular dynamics and regional blood flow in the chronically instrumented dog. Anesthesiology 1991; 74:568-574.

Meurs KM, Riviere JE. Antiarrhythmic agents. In: Veterinary Pharmacology and Therapeutics (10 ${ }^{\text {th }}$ edn.). Riviere JE, Papich MG (eds.). Wiley-Blackwell, Hoboken, USA. 2018; pp. 537551. 
Meyer EC, Sommers DK. Possible mechanisms of anti-cholinergic drug-induced bradycardia. Eur J Clin Pharmacol 1988; 35:503-506.

Miller DE, Gleason WL, Whalen RE, Morris JJ, McIntosh HD. Effect of ventricular rate on the cardiac output in the dog with chronic heart block. Circ Res 1962; 10:658-663.

Miller JM, Tomaselli GF, Zipes DP. Therapy for cardiac arrhythmias. In: Braunwald's Heart Disease: a textbook of cardiovascular medicine ( $11^{\text {th }}$ edn.). Zipes DP, Libby P, Bonow RO, Mann DL, Tomaselli GF (eds.). Elsevier, Philadelphia, USA. 2019; pp. 670-729.

Mitchell B, Peel S. Primary tissues 3: muscle tissue. In: Histology: an illustrated colour text. Mitchell B, Peel S (eds.). Elsevier, New York, USA. 2009; pp. 26-32.

Moïse NS, Moon PF, Flahive WJ, Brittain D, Pride P, Lewis B, Zipes DP, Lee RJ, Gilmour RF. Phenylephrine-induced ventricular arrhythmias in dogs with inherited sudden death. J Cardiovasc Electrophysiol 1996; 7:217-22.

Moïse NS, Pariaut R, Gelzer ARM, Kraus MS, Jung SW. Cardioversion with lidocaine of vagally associated atrial fibrillation in two dogs. J Vet Cardiol 2005; 7:143-148.

Monteiro ER, Neto FJT, Castro VB, Campagnol D. Effects of acepromazine on the cardiovascular actions of dopamine in anesthetized dogs. Vet Anaesth Analg 2007; 34:312-321.

Monteiro ER, Souza JFF, Baiotto GC, Figueiro GM, Rangel JPP, Coelho CS. Influence of acepromazine on the cardiovascular actions of dobutamine in isoflurane-anesthetized horses. Cienc Rural 2011; 41:470-475.

Moraes AN, Mirakhur K, McDonell W, O'Grady M, Kerr C. Modification of the cardiopulmonary response to medetomidine in isoflurane anesthetized dogs following treatment with glycopyrrolate. Vet Anaesth Analg 2004b; 31:13-14. (Abstract) https://doi.org/10.1111/j.1467-2995.2004.00220a.x 
Moraes AN, O'Grady M, McDonell W, Kerr C, Mirakhur K. The echocardiographic effects of glycopyrrolate pretreatment on the response to medetomidine in dogs anesthetized with isoflurane. Vet Anaesth Analg 2004a; 31:14. (Abstract) https://doi.org/10.1111/j.14672995.2004.00220a.x

Murrell JC. Adrenergic agents. In: Veterinary Anesthesia and Analgesia: The Fifth Edition of Lumb and Jones ( $5^{\text {th }}$ edn.) Grimm KA, Lamont LA, Tranquilli WJ, Greene SA, Robertson SA (eds.). Wiley-Blackwell, Ames, USA. 2015; pp. 183-195.

Murrell JC, Hellebrekers LJ. Medetomidine and dexmedetomidine: A review of cardiovascular effects and antinociceptive properties in the dog. Vet Anaesth Analg 2005; 32:117-127.

Noble MM, Trenchard D, Guz A. Effects of changing heart rate on cardiovascular function in the conscious dog. Circulation 1966; 19:206-213.

Nunes de Moraes A, Dyson DH, O’Grady MR, McDonell WN, Holmberg DL. Plasma concentrations and cardiovascular influence of lidocaine infusions during isoflurane anesthesia in healthy dogs and dogs with subaortic stenosis. Vet Surg 1998; 27:486-497.

Oberhauser V, Schwertfeger E, Rutz T, Beyersdorf F, Rump LC. Acetylcholine release in human heart atrium: influence of muscarinic autoreceptors, diabetes, and age. Circulation 2001; 103:1638-1643.

Oliveira P. Junctional rhythms. In: Guide to Canine and Feline Electrocardiography. Willis R, Oliveira P, Mavropoulou A (eds.). John Wiley \& Sons, Chichester, UK. 2018; pp. 147-167. Olgin JE, Zipes DP. Specific arrhythmias: diagnosis and treatment. In: Braunwald's Heart Disease: a textbook of cardiovascular medicine ( $11^{\text {th }}$ edn.). Zipes DP, Libby P, Bonow RO, Mann DL, Tomaselli GF (eds.). Elsevier, Philadelphia, USA. 2019; pp. 748-797. 
Olschewski A, Bräu ME, Olschewski H, Hempelmann G, Vogel W. ATP-Dependent potassium channel in rat cardiomyocytes is blocked by lidocaine: possible impact on the antiarrhythmic action of lidocaine. Circulation 1996; 93:656-659.

Olshansky B, Chung M, Pogwizd S, Goldshlager N. Bradyarrhythmias - conduction system abnormalities. In: Arrhythmias Essentials ( $2^{\text {nd }}$ edn.). Olshansky B, Chung M, Pogwizd S, Goldshlager N (eds.). Elsevier, Philadelphia, USA. 2016; pp. 28-86.

Pagel PS, Kampine JP, Schmeling WT, Waltier DC. Comparison of the systemic and coronary hemodynamics actions of desflurane, isoflurane, halothane and enflurane in the chronically instrumented dog. Anesthesiology 1991; 74:539-551.

Pagel PS, Proctor LT, Devcic A, Hettrick DA, Kersten JR, Tessmer JP, Farber NE, Schmeling WT, Waltier DC. A novel alpha2-adrenoceptor antagonist attenuates the early, but preserves the late cardiovascular effects of intravenous dexmedetomidine in conscious dogs. J Cardiothorac Vasc Anesth 1998; 12:429-434.

Pascoe PJ. The cardiopulmonary effects of dexmedetomidine infusions in dogs during isoflurane anesthesia. Vet Anaesth Analg 2015; 42:360-368.

Pendleton RG, Bendesky LRJ, Cook PG. Effects of atropine upon various components mediating postprandial gastric acid secretion in dogs. J Pharm Exp Therap 1986; 240:396-399.

Pertovaara A, Kauppila T, Tukeva T. The effect of medetomidine, an $\alpha_{2}$-adrenoceptor agonist, in various pain tests. Eur J Pharmacol 1990; 179:323-328.

Perego M, Ramera L, Santilli RA. Isorhythmic atrioventricular dissociation in Labrador retrievers. J Vet Intern Med 2012; 26:320-325. 
Pypendop BH, Ahokoivu H, Honkavaara J. Effects of dexmedetomidine, with or without vatinoxan (MK-467), on minimum alveolar concentration of isoflurane in cats. Vet Anaesth Analg 2019; 46:443-451.

Pypendop BH, Honkavaara J, Ilkiw JE. Cardiovascular effects of dexmedetomidine, with or without MK-467, following intravenous administration in cats. Vet Anaesth Analg 2017; 44:52-62.

Posner LP. Sedatives and Tranquilizers in: Veterinary Pharmacology and Therapeutics ( $10^{\text {th }}$ edn. $)$. Riviere JE, Papich MG (eds). Wiley- Blackwell, Ames, USA. 2018; pp. 324-368.

Proakis AG, GB Harris. Comparative penetration of glycopyrrolate and atropine across the bloodbrain and placental barriers in anesthetized dogs. Anesthesiology 1978; 48:339-344.

Racker DK. Atrioventricular node and input pathways: a correlated gross anatomical and histological study of the canine atrioventricular junctional region. Anat Rec 1989; 224:336354.

Rankin DC. Sedatives and tranquilizers. In: Veterinary Anesthesia and Analgesia: The Fifth Edition of Lumb and Jones ( $5^{\text {th }}$ edn.) Grimm KA, Lamont LA, Tranquilli WJ, Greene SA, Robertson SA (eds.). Wiley-Blackwell, Ames, USA. 2015; pp. 196-206.

Reece WO. Physiology of skeletal muscle. In: Dukes' Physiology of Domestic Animals (13 ${ }^{\text {th }}$ edn.). Reece WO, Erickson HH, Goff JP, Uemura EE (eds.). Wiley-Blackwell, Ames, USA. 2015; pp. 263-273.

Rendich A, Robertson JD, Willingham T. The use of specific opioid agonists and antagonists to delineate the vagally mediated antinociceptive and cardiovascular effects of intravenous morphine. Brain Res 1993; 603:186-200. 
Restitutti F, Raekallio M, Vainionpää M, Kuusela E, Vainio O. Plasma glucose, insulin, free fatty acids, lactate and cortisol concentrations in dexmedetomidine-sedated dogs with or without MK-467: a peripheral $\alpha-2$ adrenoceptor antagonist. Vet J 2012; 193:481-485.

Rioja E, Kerr C, Enouri Saad, McDonell W. Sedative and cardiopulmonary effects of medetomidine hydrochloride and xylazine hydrochloride and their reversal with atipamezole hydrochloride in calves. Am J Vet Res 2008; 3:319-329.

Riedesel DH. Mechanical activity of the heart in: Dukes' Physiology of Domestic Animals (13 ${ }^{\text {th }}$ edn.). Reece WO, Erickson HH, Goff JP, Uemura EE (eds.). Wiley-Blackwell, Ames, USA. 2015; pp. 327-340.

Richards DLS, Clutton RE, Boyd C. Electrocardiographic findings following intravenous glycopyrrolate to sedated dogs: a comparison with atropine. J Ass Vet Anaesth 1989; 16:4650.

Roberts F, Freshwater-Turner D. Pharmacokinetics and anaesthesia. Cont Ed Anaesth Crit Care Pain 2007; 7:25-29.

Robertson HA, Leslie RA. Noradrenergic alpha 2 binding sites in vagal dorsal motor nucleus and nucleus tractus solitarius: autoradiographic localization. Can J Physiol Pharmacol 1985; 63:1190-1194.

Rosen MR, Schwartz PJ. The 'Sicilian Gambit' - A new approach to the classification of antiarrhythmic drugs based on their actions on arrhythmogenic mechanisms. Eur Heart $\mathrm{J}$ $1991 ; 12: 1112-1131$.

Rosati M, Dyson D, Sinclair M, Sears W. Response of hypotensive dogs to dopamine hydrochloride and dobutamine hydrochloride during deep isoflurane anesthesia. Am J Vet Res 2007; 68:483-494. 
Ruetsch YA, Böni T, Borgeat A. From cocaine to ropivacaine: the history of local anesthetic drugs. Curr Top Med Chem 2001; 1:175-182.

Santilli R, Moïse NS, Pariaut R, Perego M. Bradyarrhythmias. In: Electrocardiography of the Dog and Cat - Diagnosis of Arrhythmias (2 $2^{\text {nd }}$ edn.). Santilli R, Moïse NS, Pariaut R, Perego M (eds.). Edra, Milano, Italy. 2018; pp. 252-269.

Schulman JM, Strichartz GR. Local Anesthetic Pharmacology. In: Principles of Pharmacology The Pathophysiologic Basis of Drug Therapy ( $3^{\text {rd }}$ edn.). Golan DE, Tashjian AH, Armstrong EJ, Armstrong AW (eds.). Lippincott Williams \& Wilkins, Philadelphia, USA. 2011; pp. $147-162$.

Schwartz DD, Clarck TP. Selectivity of atipamezole, yohimbine and tolazoline for alpha-2 adrenergic receptor subtypes: Implication for clinical reversal of alpha-2 adrenergic receptor mediated sedation in sheep. J Vet Pharmacol Therap 1998; 21:342-347.

Schwinn M, Schwenn DA. The locus coeruleus site of hypnotic actions of $\alpha 2$-adrenoceptor agonists? Anesthesiology 1992; 76:873-875.

Seagard JL, Elegbe EO, Hopp FA, Bosnjak ZJ, Colditz JH, Kalbfleisch JH, Kampine JP. Effects of isoflurane on the baroreceptor reflex. Anesthesiology 1983; 59:511-520.

Shih HT. Anatomy of the action potential in the heart. Molecular and Cellular Cardiology 1994; 21:30-41.

Shi H, Wang H, Wang Z. Identification and characterization of multiple subtypes of muscarinic acetylcholine receptors and their physiological functions in canine heart. Molec Pharmac 1999; 55:497-507.

Silva JF. Anti-arrhythmic drugs. In: Guide to Canine and Feline Electrocardiography. Willis R, Oliveira P, Mavropoulou A (eds.). John Wiley \& Sons, Chichester, UK. 2018; pp. 241-254. 
Sigel E, Ernst. M. The benzodiazepine binding sites of GABAA receptors. Trends Pharmacol Sci $2018 ; 39: 659-671$.

Sinclair MD, Dyson DH. The impact of acepromazine on the efficacy of crystalloid, dextran or ephedrine treatment in hypotensive dogs under isoflurane anesthesia. Vet Anaesth Analg $2012 ; 39: 563-573$.

Sinclair MD, McDonell WN, O’Grady M, Pettifer G. The cardiopulmonary effects of romifidine in dogs with and without prior or concurrent administration of glycopyrrolate. Vet Anaesth Analg 2002; 29:1-13.

Simon BT, Scallan EM, Sicaruca C, Henderson A, Sleeper MM, Menzies MPL. Effects of acepromazine or methadone on midazolam-induced behavioral reaction in dogs. Can Vet $\mathrm{J}$ $2014 ; 55: 875-885$

Steffey EP, Mama KR, Brosnan R. Inhalantion anesthetics. In: Veterinary Anesthesia and Analgesia: The Fifth Edition of Lumb and Jones ( th $^{\text {th }}$ edn.) Grimm KA, Lamont LA, Tranquilli WJ, Greene SA, Robertson SA (eds.). Wiley-Blackwell, Ames, USA. 2015; pp. 297-331

Sugimoto T, Schaal SF, Dunn NM, Wallace A. Electrophysiologic effects of lidocaine in awake dogs. J Pharmacol Exp Ther 1968; 166:146-150.

Sundnes J, Lines GT, Cai X, Nielsen BF, Mardal KA, Tveito A. Physiological background. In: Computing the Electrical Activity in the Heart. Springer, New York, USA. 2006; pp. 1-19.

Takahashi Y, Ishikawa Y, Ohmura H. Treatment of recent-onset atrial fibrillation with quinidine and flecainide in thoroughbred racehorses: 107 cases (1987-2014). J Am Vet Med Assoc $2018 ; 252: 1409-1414$ 
Taylor SS, Sparkes AH, Briscoe K, Carter J, Sala SC, Jepson RE, Reynolds BS, Scansen BA. ISFM Consensus Guidelines on the Diagnosis and Management of Hypertension in Cats. J Fel Med S 2017; 19:288-303.

Tobias JD, Chrysostomou C. Dexmedetomidine: antiarrhythmic effects in the pediatric cardiac patient. Pediatr Cardiol 2013; 34:779-785.

Trepanier LA. Medical Management of Hyperthyroidism. Clin Tech Small Anim Pract 2006; $21: 22-28$

Vainionpää MH, Raekallio MR, Pakkanen SA, Ranta-Panula V, Rinne VM, Scheinin M, Vainio OM. Plasma drug concentrations and clinical effects of a peripheral alpha-2-adrenoceptor antagonist, MK-467, in horses sedated with detomidine. Vet Anesth Analg 2013; 40:257264.

Valverde A. Alpha-2 agonists as pain therapy in horses. Vet Clin North Am Equine Pract 2010; 26:515-532.

Valverde A, Cantwell S, Hernandéz J, Brotherson C. Effects of acepromazine on the incidence of vomiting associated with opioid administration in dogs. Vet Anaesth Analg 2004; 31:40-45.

Valverde A, Guiguère S, Sanchez C, Shih A, Ryan C. Effects of dobutamine, norepinephrine, and vasopressin on cardiovascular function in anesthetized neonatal foals with induced hypotension. Am J Vet Res 2006; 67:1730-1737.

Vaughan Williams EM. Classification of antidysrhythmic drugs. Pharmac Therap 1975; 1:115138.

Vaughan Williams EM. Classifying antiarrhythmic actions: by facts or speculation. J Clin Pharmacol 1992; 32:964-977.

Vaughan Williams EM. Subgroups of Class I antiarrythmic drugs. Eur Heart J 1984; 5:96-98. 
Vincent JL. Understanding cardiac output. Crit Care 2008; 12:1-3.

Virtanen R, Savola JM, Saano V, Nyman L. Characterization of the selectivity, specificity and potency of medetomidine as an $\alpha_{2}$-adrenoceptor agonist. Eur J Pharmacol 1988; 150:9-14.

Virtanen R, Savola JM, Saano V. Highly selective and specific antagonism of central and peripheral alpha 2-adrenoceptors by atipamezole. Arch Int Pharmacodyn Therap 1989; 297:190-204.

Wellington D, Mikaelian I, Singer L. Comparison of ketamine-xylazine and ketaminedexmedetomidine anesthesia and intraperitoneal tolerance in rats. J Am Assoc Lab Anim Sci $2013 ; 52: 481-487$.

Willis R. Sinus rhythms. In: Guide to Canine and Feline Electrocardiography. Willis R, Oliveira P, Mavropoulou A (eds.). John Wiley \& Sons, Chichester, UK. 2018; pp. 57-66.

Willis R. Bradyarrhythmias and conduction disturbances. In: Guide to Canine and Feline Electrocardiography. Willis R, Oliveira P, Mavropoulou A (eds.). John Wiley \& Sons, Chichester, UK. 2018; pp. 79-107.

Wilson DV, Shih AC. Anesthetic emergencies and resuscitation. In: Veterinary Anesthesia and Analgesia: The Fifth Edition of Lumb and Jones (5 $5^{\text {th }}$ edn.). Grimm KA, Lamont LA, Tranquilli WJ, Greene SA, Robertson SA (eds.). Wiley-Blackwell, Ames, USA. 2015; pp. $114-129$.

Yamashita K, Muir III WW, Tsubakishita S, Abrahamsen E, Lerch P, Hubbell JAE, Bednarski RM, Skarda RT, DMV, Izumisawa Y, Kotani T. Clinical comparison of xylazine and medetomidine for premedication of horses. J Am Vet Med Assoc 2002; 221:1144-1149. 
Zatroch KK, Sakai DM, Parry S, Campoy L, Martin-Flores M. Evaluation of atipamezole as a treatment for dexmedetomidine-induced cardiovascular depression in anesthetized cats. Am J Vet Res 2019; 80:455-460. 
CHAPTER 2

USE OF INTRAVENOUS LIDOCAINE TO TREAT DEXMEDETOMIDINE-INDUCED

BRADYCARDIA IN SEDATED AND ISOFLURANE-ANESTHETIZED DOGS 


\subsection{SUMMARY}

Objective - To assess cardiorespiratory function in sedated and anesthetized dogs administered intravenous (IV) dexmedetomidine and subsequently administered IV lidocaine to treat the dexmedetomidine-induced bradycardia.

Study Design- Prospective, randomized, crossover experimental trial.

Animals- Six purpose-bred female beagles, weighing $9.1 \pm 0.6 \mathrm{~kg}$ (mean \pm standard deviation).

Methods- Dogs were randomly assigned to one of three treatments: dexmedetomidine (10 $\mu \mathrm{g} \mathrm{kg}^{-}$ ${ }^{1}$ IV) administered to conscious (groups SED1 and SED2) or isoflurane-anesthetized (ISO) dogs (FE'Iso: $1.19 \pm 0.04 \%$ ). Thirty minutes later, a lidocaine bolus ( $\mathrm{L} ; 2 \mathrm{mg} \mathrm{kg}^{-1} \mathrm{IV}$ ) was administered in groups SED1 and ISO, followed 20 minutes later by a second bolus of lidocaine ( $2 \mathrm{mg} \mathrm{kg}^{-1} \mathrm{IV}$ ) and a 30 minute constant rate infusion (L-CRI) at 50- (SED1) or $100 \mu \mathrm{g} \mathrm{kg}^{-1}$ minute-1 (ISO). In group SED2, L (2 mg kg-1) and the 30-minutes L-CRI (50 $\mu \mathrm{g} \mathrm{kg}^{-1}$ minute-1) was administered 5 minutes after dexmedetomidine. Cardiorespiratory measurements were obtained after dexmedetomidine, after lidocaine bolus, during the CRI and 30 minutes after discontinuation of the CRI. A mixed linear model $(p<0.05)$ was used for comparisons within groups. 
Results- L and L-CRI significantly increased heart rate and cardiac index, decreased mean blood pressure, systemic vascular resistance index and oxygen extraction ratio, and did not affect stroke volume index in all groups, when administered after a bolus of dexmedetomidine.

Conclusion and clinical relevance: Lidocaine was an effective treatment for dexmedetomidineinduced bradycardia in healthy research dogs.

Keywords bradycardia, dexmedetomidine, lidocaine, dog. 


\subsection{INTRODUCTION}

Dexmedetomidine is an alpha-2 agonist commonly used in small animals for its sedative and analgesic effects (Kuusela et al. 2001). Alpha-2 agonists, including dexmedetomidine, often produce some undesirable cardiovascular effects, including marked bradycardia, hypertension, reduced cardiac output, and arrhythmias, such as atrioventricular blocks and ventricular premature complexes (Ko et al. 2000; Enouri et al. 2008a; Enouri et al. 2008b; Pascoe 2014). Most of these changes are the result of an increase in peripheral vascular resistance, which triggers a vagal mediated bradycardia due to a baroreceptor reflex from the resultant hypertension, and a decrease in cardiac output (Pascoe 2014), since cardiac output is the product of heart rate and stroke volume (Kumada et al. 1967).

The use of dexmedetomidine and other alpha- 2 agonists prior to inhalant anesthesia is common in veterinary practice to decrease the minimum alveolar concentration (MAC) of the inhalational anesthetic required to maintain an optimal anesthetic plane (Ewing et al. 1993; Aantaa et al. 1997; Greene et al. 2003; Lerche \& Muir 2006; Gómez-Villamandos et al. 2008; Escobar et al. 2011; Gozalo-Marcilla et al. 2012). A decrease in MAC can offset the cardiovascular impact of inhalational anesthetics, such as hypotension and decreased cardiac output (Merin et al. 1991), but the effects of dexmedetomidine are more profound than those of inhalational anesthetics and do not necessarily improve cardiovascular function when used in balanced anesthetic techniques (Weitz et al. 1991; Keegan et al. 1995; Gómez-Villamandos et al. 2006).

The bradycardia induced by alpha- 2 agonists has been treated with anticholinergics or alpha-2 antagonists. Pre-emptive use of an anticholinergic, either before or in combination with the administration of alpha- 2 agonists used for sedation exacerbates the hypertension and increases myocardial work, which further reduces cardiac output, and is therefore not recommended (Alibhai 
et al. 1996; Ko et al. 2001; Sinclair et al. 2003; Congdon et al. 2011). Similar effects are seen if anticholinergics are used under inhalational anesthesia in the presence of alpha-2 agonists despite the vasodilatory effects of the inhalational anesthetic (Moraes et al. 2004a; Moraes et al. 2004b). Alpha-2 antagonists do not completely reverse adverse cardiovascular effects of alpha-2 agonists as heart rate can remain significantly decreased, despite reversing the beneficial sedative and analgesic effects (Granholm et al. 2007; Rankin 2015).

Lidocaine is a local anesthetic that has gained popularity as a systemic intravenous (IV) analgesic in dogs under inhalant anesthesia. The analgesia and central depression of the CNS caused by systemic lidocaine allows for a reduction in MAC (Valverde et al. 2004; Moran-Muñoz et al. 2017a), and has also been associated with other positive effects including; antiarrhythmic, prokinetic, anti-endotoxic, and anti-inflammatory properties (Fletcher \& Ramwell 1978; Cook et al. 2009; Torfs et al. 2009). Lidocaine is a class IB antiarrhythmic with a fast speed of association/dissociation with the cardiac sodium channel receptor (Singh \& Hauswirth 1974). The antiarrhythmic properties of lidocaine have mostly been applied to ventricular tachyarrhythmias because it acts mainly on the His-Purkinje system (Josephson et al. 1972) and no significant action results on atrial tissue, including the atrioventricular node, which limits its use for supraventricular arrhythmias (Rosen et al. 1970; Josephson et al. 1972; Indik \& Woosley 2010)

The effects of lidocaine on supraventricular arrhythmias are less understood. In a study in dogs, IV lidocaine did not affect heart rate under normal autonomic conditions; however, in the presence of increased vagal activity, heart rate increases due to a vagolytic effect of lidocaine (Lieberman et al. 1968) and it is also able to convert atrial fibrillation to normal sinus rhythm in dogs with induced arrhythmias under increased vagal tone (David et al. 1990), in dogs with naturally occurring vagally associated atrial fibrillation (Moïse et al. 2005) and in humans with 
sinus bradycardia associated with acute myocardial infarction (Rydén et al. 1972).

In the clinical setting, the authors have observed that IV lidocaine used to provide intraoperative analgesia as a constant rate infusion in anesthetized dogs that had received dexmedetomidine in their premedication and were exhibiting bradycardia and atrioventricular blocks, produced an increase in heart rate and normalize their rhythm after the initial loading dose of lidocaine. This beneficial response has not been described in the literature.

The primary objective of the current study was to assess cardiovascular function in sedated and anesthetized dogs that have received dexmedetomidine and are treated with IV lidocaine. A secondary objective was to determine if there are differences in the response to lidocaine between sedated and isoflurane-anesthetized dogs administered dexmedetomidine, since vascular resistance is lower in anesthetized dogs due to the effects of isoflurane, which may attenuate the effects of dexmedetomidine on vascular resistance and prevent an increase in vagal tone. It was hypothesized that administration of lidocaine to counteract the bradycardia from dexmedetomidine in dogs under sedation or isoflurane anesthesia can improve cardiac output by increasing heart rate without affecting systemic vascular resistance and/or blood pressure. 


\subsection{MATERIALS AND METHODS}

\subsubsection{Animals}

The study used 6 purpose-bred female Beagles 18 months of age and weighing 8.2 to $10.5 \mathrm{~kg}$, $(9.1 \pm 0.6 \mathrm{~kg}$ mean \pm standard deviation). All dogs were confirmed to be healthy by determining complete blood cell count, serum biochemical analysis and physical examination before they were included in the study. The Institutional Animal Care and Use Committee of the University of Guelph approved animal usage protocol for this study and followed the Canadian Council on Animal Care guidelines.

\subsubsection{Study design}

Dogs were randomized in a crossover block design to three treatment groups with a washout period of at least 1-week between treatments to ensure that each week two dogs were assigned to each group. Treatments consisted of the administration of dexmedetomidine (Dexdomitor; Orion Pharma, Espoo, Finland) to conscious dogs (groups SED1 and SED2) and to anesthetized dogs (ISO) followed by lidocaine (Lidocaine; Teligent, Tallinn, Estonia).

\subsubsection{Anesthesia and instrumentation}

Dogs were fasted for 12 hours and general anesthesia was induced by delivering $5 \%$ isoflurane (Aerrane; Baxter Corporation, Mississauga, Ontario) in oxygen at $4 \mathrm{~L}$ minute $^{-1}$ via facemask. The trachea was intubated and dogs allowed to breathe spontaneously while maintained with isoflurane in oxygen for instrumentation, using a circle system with an oxygen flow of $150 \mathrm{~mL} \mathrm{~kg}^{-1}$ minute $^{-1}$ at an end-tidal isoflurane (FE'Iso) concentration of 1.2\% measured from the endotracheal tube with an infrared gas analyzer from a multiparameter monitor (Datex-Ohmeda S/5 Anesthesia Monitor; GE 
Healthcare Finland, Helsinki, Finland), calibrated before each experiment with a standardized calibration gas mixture designed for the analyzer (755571-HEL, Calibration gas mixture, GE Healthcare Finland Oy, Helsinki, Finland). Dogs were positioned in right or left lateral recumbency and 22-gauge, 1-inch $(2.54 \mathrm{~cm})$ catheters (BD Insyte-W, Beckton Dickinson Infusion Therapy Systems Inc. Sandy, UT, USA) were placed in the cephalic vein and dorsal pedal artery. A central vein $7 \mathrm{Fr}$, 8-inch $(20 \mathrm{~cm})$ catheter was placed in the uppermost jugular vein (SA7FD20, Mila International Inc. Florence, KY, USA) using the Seldinger technique and advanced close to the right atrium based on pressure waves generated by connecting the catheter, via non compliant extension tubing (Arterial Pressure Tubing, ICU Medical Inc., CA, USA) to an electronic transducer (DTX Plus DT-36, Becton Dickinson Infusion Therapy Systems Inc, Sandy, UT, USA). The transducer was zeroed at the level of the sternal manubrium and previously verified for accuracy at $100 \mathrm{mmHg}$ against a mercury manometer (Mercurial Sphygmomanometer; KBM, Japan) before each use. Dogs in the ISO group were maintained at 1.2\% FE'Iso and dogs in group SED1 and SED2 were first allowed to recover from anesthesia and display normal behavior before the start of the experiment and not instrumented until then. For instrumentation before cardiorespiratory measurements, all dogs had the central vein and arterial catheter connected to the multiparameter monitor for measurement of central venous pressure (CVP), direct arterial blood pressures of systolic (SAP), mean (MAP) and diastolic (DAP), and also for continuous electrocardiogram, heart rate (HR), rectal temperature (RT) and end-tidal $\mathrm{CO} 2$ partial pressure $\left(\mathrm{PE}^{\prime} \mathrm{CO}_{2}\right)$. RT was maintained within reference range $\left(37.5-39^{\circ} \mathrm{C}\right)$ by use of a hot air heating device (Lancaster; Trileaf Distribution, Toronto, Ontario) and blankets. The cephalic catheter was used to administer all drugs and an isotonic solution (Plasmalyte-A; Baxter Corporation, Mississauga, Ontario) at a rate of $5 \mathrm{~mL} \mathrm{~kg}^{-1}$ hour ${ }^{-1}$. 
A lithium chloride sensor (Flow through cell electrode assembly, LiDCO, London, UK) was also attached to the arterial catheter for the determination of cardiac output $(\mathrm{CO})$ using a three-way valve and from the sensor, an extension tubing from a blood collection bag (Disposable blood collection bag, LIDCO, London, UK) was compressed by a peristaltic pump(LiDCO Flow Regulator; LiDCO, London, UK) that bled the vessel into the collection bag at a flow of $4 \mathrm{~mL}$ minute ${ }^{-1}$ across the sensor. The arterial hemoglobin $(\mathrm{Hb})$ and sodium concentrations required by the LiDCO computer were determined by use of a blood gas analyzer (ABL90 Flex Blood Gas Analyzer, Radiometer, Brea, CA, USA) immediately before the measurement of CO. A dose of $0.006 \mathrm{mmol} \mathrm{kg}^{-}$ ${ }^{1}$ of lithium chloride (LiDCO chloride injection; LiDCO, London, UK) was parked into the infusion IV set (CONTINU-FLO Solution Set; Baxter Deerfield, USA) attached to the cephalic vein catheter and flushed with $6 \mathrm{~mL}$ of saline solution, 8 seconds after starting the injection phase on the LiDCO computer.

Dogs in groups SED1 and SED2 were instrumented in the same manner and scored for degree of sedation during the experiment, using a scale from 0 to 3 , with 0 - indicating no obvious sedation and 3- indicating profound sedation (Appendix 1).

\subsubsection{Cardiorespiratory measurements}

Dogs in group ISO were allowed to achieve stable cardiorespiratory function for at least 5 minutes after instrumentation in groups SED1 and SED 2 and at 1.2\% FE'Iso in group ISO, and baseline measurements recorded for lead II electrocardiogram (ECG), HR from the ECG and/or arterial pulse wave, $\mathrm{CO}$, SAP, DAP, MAP, CVP, respiratory rate $\left(f_{\mathrm{R}}\right), \mathrm{RT}$, arterial $\left(\mathrm{PaO}_{2}, \mathrm{PaCO}_{2}\right.$, $\left.\mathrm{SaO}_{2}\right)$ and central venous $\left(\mathrm{PcvO}_{2}, \mathrm{PcvCO}_{2}, \mathrm{ScvO}_{2}\right)$ partial pressures and hemoglobin $(\mathrm{Hb})$ saturations, electrolyte and lactate concentration, $\mathrm{FE}^{\prime}$ Iso and $\mathrm{PE}^{\prime} \mathrm{CO}_{2}$. Then all groups received 
dexmedetomidine at $10 \mu \mathrm{g} \mathrm{kg}^{-1} \mathrm{IV}$ over 60 seconds. In groups SED1 and ISO all variables, except arterial and venous blood gases were measured at 5, 10, 20, and 30 minutes post dexmedetomidine. Then lidocaine ( $\left.2 \mathrm{mg} \mathrm{kg}^{-1} \mathrm{IV}\right)$ was administered over 10 seconds and cardiorespiratory measurements repeated at 3, 10, and 20 minutes post lidocaine. Then lidocaine was repeated at the same dose in conjunction with a constant rate infusion (CRI) at $50 \mu \mathrm{g} \mathrm{kg}^{-1}$ minute-1 in group SED1 or $100 \mu \mathrm{g} \mathrm{kg}^{-1}$ minute $^{-1}$ in group ISO for 30 minutes and cardiorespiratory measurements repeated at $3,10,20$, and 30 minutes during the CRI. Then final measurements were repeated 30 minutes after discontinuation of the CRI. Arterial and venous samples for blood gases were collected at baseline, 10 minutes post dexmedetomidine, 10 minutes post lidocaine single dose, 10 and 30 minutes during the lidocaine CRI, and at 30 minutes after discontinuation of the CRI.

Dogs in group SED2 had cardiorespiratory measurements recorded at 5 minutes postdexmedetomidine, then lidocaine ( $\left.2 \mathrm{mg} \mathrm{kg}^{-1} \mathrm{IV}\right)$ was administered over 10 seconds and a CRI of 50 $\mu \mathrm{g} \mathrm{kg}^{-1}$ minute $^{-1}$ was administered immediately after for 30 minutes and measurements repeated at 3 , 10, 20, and 30 minutes during the CRI, and at 30 minutes post-discontinuation of the CRI. Arterial and venous samples for blood gases were collected at baseline, at 5 minutes post-dexmedetomidine, and at the same time intervals post lidocaine as for the other groups.

From the measured cardiorespiratory variables, cardiac index (CI), stroke volume index (SVI), systemic vascular resistance index (SVRI), arterial oxygen content $\left(\mathrm{CaO}_{2}\right)$, central venous oxygen content $\left(\mathrm{CcvO}_{2}\right)$, oxygen consumption $\left(\mathrm{VO}_{2}\right)$, oxygen delivery $\left(\mathrm{DO}_{2}\right)$, and oxygen extraction ratio $\left(\mathrm{ERO}_{2}\right)$ were calculated (Appendix 2). 


\subsubsection{Recovery from sedation/anesthesia}

Dogs were administered meloxicam (Metacam; Boehringer Ingelheim, Burlington, Ontario), $0.1 \mathrm{mg} \mathrm{kg}^{-1} \mathrm{IV}$ at the end of each study and all instrumentation was removed. Dogs in group ISO were allowed to recover from anesthesia and in all groups observed throughout the recovery period for adverse effects related to the treatment.

\subsubsection{Data analysis}

Data was collected for baseline (before dexmedetomidine administration) and after treatments (dexmedetomidine and lidocaine), but the data for baseline was excluded from the analysis because the effects of dexmedetomidine have already been described and the objective of the study was to assess the effect of lidocaine on those of dexmedetomidine. All data was tested for normality using Shapiro-Wilk, Kolmogorov-Smirnov, Cramer-von Mises, and AndersonDarlin procedures; UNIVARIATE and PLOT procedures were used to detect unequal variances, outliers, and other non-random patterns within the data for each group (Version 9.4; SAS Institute, Cary, North Carolina, USA). The effects of treatment and time on cardiovascular variables and blood values were analysed with a generalized mixed linear model allowing correlations and nonconstant variability for normal distributions (proc MIXED) and NPARIWAY if the assumptions of a normal distribution were not met. The error structure over time was selected based on the Akaike Information Criteria (AIC) among structures offered by SAS: $\operatorname{ar}(1)$, $\operatorname{arh}(1)$, toep(2-4), toeph(2-4), un(2-4), using for each treatment a random effect and a 2-factor (time and treatment)factorial design with repeated measurements over time. When appropriate, multiple pairwise comparisons were done by use of the Holm-Sidak test. Results were considered statistically significant if the value of $p<0.05$. Sedation scores for each group were compared with the different 
treatments using a Mann-Whitney test (MedCalc Statistical Software version 19.3.1, Ostend, Belgium; https://www.medcalc.org; 2020).

The number of dogs in this study was determined based on estimations to detect differences of 25 beats minute ${ }^{-1}$ in $\mathrm{HR}, 30 \mathrm{mmHg}$ in MAP, and $40 \mathrm{~mL}$ minute ${ }^{-1} \mathrm{~kg}^{-1}$ in $\mathrm{CI}$, for a Type I error $(\alpha)$ at 0.05 and a desired power of $90 \%$, which required six dogs. 


\subsection{RESULTS}

All six dogs completed the study without any complication. Cardiovascular values for the three groups are reported in Figures 2.1-2.3 and Tables 2.1-2.3. Sedation scores were of moderate to profound sedation in both of the sedated groups and dogs remained in lateral recumbency and did not interfere with the data collection throughout the experiment (Tables 2.1 and 2.2).

Time to instrumentation during anesthesia for all groups was $29 \pm 8$ minutes for SED1, 24 \pm 3 minutes for SED2 and $25 \pm 8$ minutes for ISO. Time to complete the experiment from collection of baseline data to the last set of data collected (30 minutes post CRI) was $154 \pm 15$ minutes for SED1, $102 \pm 6$ minutes for SED2 and $159 \pm 8$ minutes for ISO.

\subsubsection{Effects of lidocaine 30 minutes after dexmedetomidine in sedated dogs (SED1)}

Lidocaine significantly increased the slow HR caused by IV dexmedetomidine, both when lidocaine was administered as a single bolus and later as a bolus followed by a CRI and this effect persisted for 30 minutes after discontinuation of the CRI (Table 2.1, Figure 2.1). Second degree atrioventricular blocks post dexmedetomidine administration occurred in 5/6 dogs at 5 minutes, in 2/6 dogs at 10 minutes, and in 1/6 dogs at 20 and 30 minutes. Atrioventricular blocks persisted in 1/6 dogs at 3 minutes post lidocaine administration. SVRI and MAP also decreased significantly with both lidocaine treatments and after discontinuation of the CRI; however, CI only increased significantly during the lidocaine $\mathrm{CRI}$ and 30 minutes after discontinuation. $\mathrm{ERO}_{2}$ improved with lidocaine administration and after discontinuation of the CRI. Rectal temperature, SVI, $f_{\mathrm{R}}$, and lactate did not differ significantly throughout the study. Arterial $\mathrm{CO}_{2}$ was significantly elevated with lidocaine and during the washout period, and $\mathrm{PaO}_{2}$ was significantly higher 30 minutes after discontinuation of the CRI. 


\subsubsection{Effects of lidocaine 5 minutes after dexmedetomidine in sedated dogs (SED2)}

Lidocaine as a bolus and CRI significantly increased the slow HR caused by IV dexmedetomidine including 30 minutes after discontinuation of the CRI (Table 2.2, Figure 2.2). Second degree atrioventricular blocks post dexmedetomidine administration occurred in 5/6 dogs at 5 minutes and persisted in one of the dogs at 3,10, 20, and 30 minutes post lidocaine administration. This same dog and an additional dog also had atrioventricular blocks at 30 minutes post discontinuation of lidocaine. SVRI and MAP also decreased significantly with lidocaine and after discontinuation of the CRI. CI increased significantly with lidocaine and 30 minutes after discontinuation. $\mathrm{ERO}_{2}$ did not change with lidocaine administration but improved after discontinuation of the CRI. Rectal temperature, SVI, $f_{\mathrm{R}}$, and $\mathrm{PaO}_{2}$ did not change significantly throughout the study. Arterial $\mathrm{CO}_{2}$ was significantly increased during the washout period. Arterial lactate was significantly increased during the lidocaine treatment and returned to dexmedetomidine values after discontinuation of the CRI.

\subsubsection{Effects of lidocaine 30 minutes after dexmedetomidine in isoflurane-anesthetized dogs} (ISO)

The FE'Iso was $1.19 \pm 0.04 \%$. Lidocaine significantly increased the slow HR caused by IV dexmedetomidine, both when lidocaine was administered as a single bolus and later as a bolus followed by a CRI, but it was not different between dexmedetomidine and after discontinuation of the CRI (Table 2.3, Figure 2.3). Second degree atrioventricular block post dexmedetomidine administration occurred in 1/6 dogs at 5 minutes. SVRI and MAP also decreased significantly with both lidocaine treatments and after discontinuation of the CRI. CI increased significantly during 
both lidocaine treatments and 30 minutes after discontinuation of the CRI. $\mathrm{ERO}_{2}$ improved with lidocaine administration and after discontinuation of the CRI. Rectal temperature, SVI, $f_{\mathrm{R}}$, and $\mathrm{PaO}_{2}$ did not change significantly throughout the study. There was a statistically significant decrease in arterial $\mathrm{CO}_{2}$ during the washout period. There was a statistically significant decrease in arterial lactate during the lidocaine treatments. 


\subsection{DISCUSSION}

The results of this study support the use of lidocaine to improve the cardiovascular changes induced by the administration of dexmedetomidine in dogs, in both sedated and anesthetized conditions.

Dexmedetomidine was administered IV in this study to achieve a more homogenous plasma concentration among individual dogs and groups, and to decrease variability caused by differences in tissue perfusion between conscious and anesthetized dogs (Riviere 2018), which could have affected the bioavailability of dexmedetomidine if given by the intramuscular (IM) route. The bioavailability of dexmedetomidine in dogs after IM administration has not been reported; however, in cats it is approximately 52\% (range of 38 to $72 \%$ ) (Pypendop et al. 2017). In dogs, similar cardiovascular, analgesic and sedative scores were achieved by IV doses $25 \%$ lower than IM doses (15 versus $20 \mu \mathrm{g} \mathrm{kg}^{-1}$ ) (Granholm et al. 2007). The IM sedative dose range used for premedication in dogs is usually 15-20 $\mathrm{g} \mathrm{kg}^{-1}$ (Kuusela et al. 2000; Granholm et al. 2007) and a lower dose is recommended for IV use.

The IV dose of dexmedetomidine $\left(10 \mu \mathrm{g} \mathrm{kg}^{-1}\right)$ used in this study is in agreement with dexmedetomidine IV doses used in other studies (Kuusela et al. 2000; Granholm et al. 2007) and should have maintained the cardiorespiratory effects for the duration of the experiment, so that lidocaine's effects could be assessed. The administration of a single IV dose of lidocaine and the decline in plasma concentration over time can influence the effects of a single bolus (groups SED1 and ISO), since lidocaine was administered 30 minutes after dexmedetomidine. The elimination half-life of $10 \mu \mathrm{g} \mathrm{kg}^{-1}$ of IV dexmedetomidine is $39.6 \pm 10.8$ minutes in dogs and reaches peak plasma concentrations of approximately $15 \mathrm{ng} \mathrm{mL}^{-1}$ within 5 minutes and decline to $0.5 \mathrm{ng} \mathrm{mL}^{-1}$ over a two-hour period (Kuusela et al. 2000). These concentrations maintain consistent 
bradycardia, increased MAP and SVRI, and decreased CI for those two hours (Kuusela et al. 2000; Pascoe et al. 2006; Pascoe 2014); therefore, the effect of lidocaine in counteracting the cardiovascular effects induced by dexmedetomidine could still be determined from a single bolus administered 30 minutes after dexmedetomidine.

After a single dexmedetomidine IV bolus of $10 \mu \mathrm{g} \mathrm{kg}^{-1}$, HR decreases immediately after administration and remains at least $50 \%$ lower than baseline for 60 minutes, and only increases to $67 \%$ of its baseline by 120 minutes (Kuusela et al. 2000). The cardiovascular effects of dexmedetomidine are dose-dependent: lower doses result in less profound and shorter alterations as was demonstrated with three infusion rates of $0.1-, 0.5-$, and $3.0 \mu \mathrm{g} \mathrm{kg}^{-1}$ hour $^{-1}$ in dogs under isoflurane anesthesia, after IV loading doses of the same magnitude $\left(0.1,0.5\right.$, and $3.0 \mu \mathrm{g} \mathrm{kg}^{-1}$, respectively) (Pascoe et al. 2006, Pascoe 2014). Average serum concentrations of $0.198 \pm 0.081$ ng mL $\mathrm{mL}^{-1}$ and $1.903 \pm 0.621 \mathrm{ng} \mathrm{mL}^{-1}$ were measured for the 0.5 and $3.0 \mu \mathrm{g} \mathrm{kg}^{-1}$ hour ${ }^{-1}$ rates, but were not measurable for the low dose (Pascoe et al. 2006).

All groups in this study had their HR increased significantly by lidocaine, both as a single dose and/or during the CRI. In the SED1 and SED2 groups, the range of values for $95 \%$ confidence interval for HR increased to values of 55 to 70 beats $\mathrm{min}^{-1}$ from a range of 31 to 44 beats $\mathrm{min}^{-1}$; whereas in the ISO group the HR was higher ( 63 to 83 beats $\mathrm{min}^{-1}$ ) despite the administration of dexmedetomidine and significantly increased to 94 to 103 beats $\min ^{-1}$. The increase in HR is attributed to lidocaine's inhibition on the vagal reflex effect (Lieberman et al. 1968; Rydén et al. 1972) caused by the increase in vascular resistance from dexmedetomidine's action on alphaadrenergic receptors (Kuusela et al. 2001; Pascoe et al. 2006; Pascoe 2014), but has also been observed in isoflurane-anesthetized dogs administered lidocaine IV without prior bradycardia (Nunes de Moraes et al. 1998). Lidocaine is used for ventricular arrhythmias because of its 
negative chronotropic effect on automatic pacemakers of the ventricles (Lieberman et al. 1968). Although lidocaine decreases conduction time from the SA node to the His bundle, its effect on the atria is less, and conversely, under conditions of increased vagal activity, such as stimulation of the peripheral end of the vagus nerve, it can increase heart rate (Lieberman et al. 1968). Lidocaine is considered safe in patients with high degrees of atrioventricular nodal block and in patients with impulse formation disturbances at this level, but not in patients with intraventricular conduction defects because it can exacerbate the conduction disturbance (Roos \& Dunning 1975).

The elimination half-life of $2 \mathrm{mg} \mathrm{kg}^{-1}$ of IV lidocaine is $68 \pm 10.9$ minutes (Ngo et al. 1997) and for $6 \mathrm{mg} \mathrm{kg}^{-1} \mathrm{IV}$ is $47 \pm 17.6$ minutes (Wilcke et al. 1983) in awake dogs, and 99 minutes in halothane-anesthetized dogs administered $2 \mathrm{mg} \mathrm{kg}^{-1}$ minute ${ }^{-1}$ over 20 minutes (Burney \& DiFazio 1976). The effects of a single bolus of $2 \mathrm{mg} \mathrm{kg}^{-1} \mathrm{IV}$ are short lasting due to a sharp decline from peak plasma maximum concentrations of approximately $6 \mu \mathrm{g} \mathrm{mL}-1$ shortly after injection to aproximately $1.2 \mu \mathrm{g} \mathrm{mL}^{-1}$ at 30 minutes (Ngo et al. 1997; Vickroy 2018). Therapeutic plasma concentrations for analgesic, antiarrhythmic and innocuous cardiovascular effects are associated with levels of 1.2 to $5.5 \mu \mathrm{g} \mathrm{mL}{ }^{-1}$ (Gianelly et al. 1967; Kunkel et al. 1974; Collinsworth et al. 1974; Estes et al. 1989; Nunes de Moraes et al. 1998; Valverde et al. 2004; Daykin 2017). Therefore, measurements were obtained for only 20 minutes after the IV lidocaine in groups SED1 and ISO, and a second loading dose and CRI was started thereafter to maintain plasma concentrations within therapeutic levels. The effects of lidocaine on cardiorespiratory parameters were maintained with this treatment in both groups and persisted after discontinuation of the lidocaine CRI when values were measured once again after 30 minutes. At this time, the dogs had received the dexmedetomidine dose 110 minutes before and plasma concentrations were still expected to be at least $0.5 \mathrm{ng} \mathrm{mL}$, which are associated with cardiorespiratory effects of dexmedetomidine 
(Kuusela et al. 2000). The disposition of lidocaine is similar after a single dose or a short duration CRI, based on infusions of less than 12 hours in humans and monkeys (Benowitz et al. 1974) and infusions of 2 hours in dogs (LeLorier et al. 1977).

Lidocaine IV did not result in detrimental changes to the cardiorespiratory system in healthy conscious and anesthetized dogs. Dogs anesthetized with IV pentobarbital or inhalational anesthesia (sevoflurane, isoflurane) administered a loading dose of lidocaine of $2 \mathrm{mg} \mathrm{kg}^{-1} \mathrm{IV}$ followed by CRIs of 50-200 $\mu \mathrm{g} \mathrm{kg}^{-1}$ minute ${ }^{-1}$ maintain their HR, CI, SV, MAP and SVRI within normal values (Nicodemus et al. 1981; Nunes de Moraes et al. 1998; Valverde et al. 2004; MoranMuñoz et al. 2017b). Similarly, single loading doses of lidocaine $\leq 3 \mathrm{mg} \mathrm{kg}^{-1}$ in pentobarbitalanesthetized dogs also caused minimal changes in those same cardiovascular variables (Liu et al. 1982). In conscious dogs, doses of $2 \mathrm{mg} \mathrm{kg}^{-1}$ followed by increasing CRI doses of up to $100 \mu \mathrm{g}$ $\mathrm{kg}^{-1}$ minute ${ }^{-1}$ did not affect HR and MAP (MacDougall et al. 2009). Based on these findings, one of the hypotheses of this study was that administration of lidocaine to counteract the bradycardia from dexmedetomidine in dogs under sedation or isoflurane anesthesia would improve CI by increasing HR without negatively affecting SVRI and/or MAP.

In this study, as HR increased with lidocaine, all groups had a concomitant decrease in MAP and SVRI, and CI was increased but not significantly in SED1 and significantly in the SED2 and ISO groups. These changes are attributed to a different effect of lidocaine under the conditions of increased vagal tone and vascular resistance induced by dexmedetomidine. Values for these variables were considered to have improved from the administration of dexmedetomidine, since both HR and CI increased, conditions of increased afterload were less and MAP was still maintained within recommended ranges. The changes caused by lidocaine in those cardiovascular variables were considered ideal and more desirable than those caused by anticholinergic drugs 
used to treat bradycardia associated with alpha-2 agonists or the use of antagonists such as atipamezole. Anticholinergics further increase MAP and decrease CI when administered to sedated or anesthetized dogs administered alpha-2 agonists (Alibhai et al. 1996; Ko et al. 2001; Sinclair et al. 2003; Moraes et al. 2004a; Moraes et al. 2004b; Congdon et al. 2011). In this study, $\mathrm{ERO}_{2}$ and lactate levels remained within clinical normal levels or improved with lidocaine administration, reflecting a stable cardiorespiratory state. The use of atipamezole is not always effective in increasing HR and CI and can also decrease MAP (Granholm et al. 2007; Zatrock et al. 2019) and can also result in reversal of the sedative and analgesic effects (Granholm et al. 2007).

No statistical comparison was carried out between the different groups in this study, since the conditions were different for each of them. One of the objectives of this study was to determine if there were differences in the response to lidocaine between sedated and isoflurane-anesthetized dogs administered dexmedetomidine and it was apparent that SVRI was lower in the ISO group, most likely due to the vasodilatory effect of isoflurane (Newberg et al. 1984; Merin et al. 1991; Mutoh et al. 1997). The vasodilation of inhalational anesthetics seems to attenuate the increase in vascular resistance caused by dexmedetomidine, since studies in conscious or anesthetized dogs with similar doses of dexmedetomidine resulted in increases of greater magnitude in SVRI in conscious compared to anesthetized dogs (Flacke et al. 1993; Pagel et al. 1998). It is also likely that as a result of the lower SVRI in the ISO group, HR was also higher than for the other groups and the incidence of atrioventricular blocks caused by dexmedetomidine was also lower.

Lidocaine was effective in improving cardiovascular variables in the SED2 group, which presented the most drastic conditions to assess the effects of lidocaine, since lidocaine was administered as a bolus and CRI, 5 minutes after IV dexmedetomidine. The CRI used in this group 
of $50 \mu \mathrm{g} \mathrm{kg}^{-1}$ minute ${ }^{-1}$ is within recommended doses for conscious dogs (Garcia 2015; Pariaut 2015), and lower than the CRI used in the ISO group of $100 \mu \mathrm{g} \mathrm{kg}^{-1}$ minute $^{-1}$, which is also within the recommended range of 50-200 $\mathrm{g} \mathrm{kg}^{-1}$ minute $^{-1}$ for a MAC-sparing effect in anesthetized patients (Valverde et al. 2004; Acevedo-Arcique et al. 2014; Moran-Muñoz et al. 2017a).

The pitfalls of this study include that it is possible that the cardiovascular improvement was not only the result of IV lidocaine, but also from recovery of the cardiovascular system from clearance of dexmedetomidine plasma concentrations over the duration of the experiments. The duration of action of the $10 \mu \mathrm{g} \mathrm{kg}^{-1} \mathrm{IV}$ dose of dexmedetomidine on cardiovascular variables can persist for up to 120 minutes and has been associated with plasma concentrations (Kuusela et al. 2000), which allows for the assessment of lidocaine to counteract those effects. However, the effects of lidocaine were facilitated over time because as dexmedetomidine plasma concentrations were decreasing, lidocaine concentrations were sustained by the CRI. In addition, it is likely that the washout period of 30 minutes from the lidocaine CRI discontinuation was also insufficient, despite the fact that the concentrations of lidocaine were most likely below the steady-state plasma concentrations. If $97 \%$ of a drug is eliminated in five half-lives (Toutain \& Bousquet-Mélou 2004), it would require 5.7 hours for lidocaine (68 \pm 10.9 minutes; Ngo et al. 1997) and 3.3 hours for dexmedetomidine (39.6 \pm 10.8 minutes; Kuusela et al. 2000) to be cleared almost completely.

A CRI of dexmedetomidine was not used in this study, which would have maintained more steady plasma concentrations while lidocaine was administered. In sevoflurane-anesthetized dogs, a CRI of lidocaine (100 $\mu \mathrm{g} \mathrm{kg}^{-1} \mathrm{~min}^{-1}$; loading dose of $\left.2 \mathrm{mg} \mathrm{kg}-1\right)$ and dexmedetomidine $\left(2 \mu \mathrm{g} \mathrm{kg}^{-}\right.$ ${ }^{1} \mathrm{~h}^{-1}$; loading dose of $2 \mu \mathrm{g} \mathrm{kg}^{-1}$ ) was slightly better at preventing a decrease in HR than the same CRI of dexmedetomidine alone (36\% versus 41\%) (Moran-Muñoz et al. 2017b). It seems that in the presence of a CRI of dexmedetomidine and more steady plasma concentrations, the effects of 
lidocaine are diminished, since in that same study, SVRI and $\mathrm{ERO}_{2}$ increased and CI decreased in both groups by the same magnitude (Moran-Muñoz et al. 2017b).

In conclusion, IV lidocaine significantly improves the hemodynamics of dogs that had received a dexmedetomidine IV bolus while conscious or anesthetized, by increasing HR, decreasing SVRI, and improving CI. In addition, the presence of isoflurane attenuates the cardiovascular effects of dexmedetomidine. 


\subsection{REFERENCES}

Aantaa R, Jaakola ML, Kallio A, Kanto J. Reduction of the minimum alveolar concentration of isoflurane by dexmedetomidine. Anesthesiology 1997; 86:1055-1060.

Acevedo-Arcique CM, Ibancovichi JA, Chavez1 Jr, Gutierrez-Blanco E, Moran-Muõz R, Victoria-Mora JM, Tendillo-Cortijo F, Santos-González M, Sanchez-Aparicio P. Lidocaine, dexmedetomidine and their combination reduce isoflurane minimum alveolar concentration in dogs. Plos One 2014; 9:1-5.

Alibhai HI, Clarke KW, Lee YH, Thompson J. Cardiopulmonary effects of combinations of medetomidine hydrochloride and atropine sulphate in dogs. Vet Rec 1996; 138:11-13.

Benowitz N, Forsyth PR, Melmon KL, Rowland M. Lidocaine disposition kinetics in monkey and man. Part I. Prediction by a perfusion model. Clin Pharmacol Ther 1974; 16:87-98.

Burney RG, DiFazio CA. Hepatic clearance of lidocaine during $\mathrm{N}_{2} \mathrm{O}$ anesthesia in dogs. Anesth Analg 1976; 55:322-325.

Collinsworth KA, Kalman SM, Harrison DC. The clinical pharmacology of lidocaine as an antiarrhythymic drug. Circulation 1974; 50:1217-1230.

Congdon JM, Marquez M, Niyom S, Boscan P. Evaluation of the sedative and cardiovascular effects of intramuscular administration of dexmedetomidine with and without concurrent atropine administration in dogs. J Am Vet Med Assoc 2011; 239:81-89.

Cook VL, Jones Shults J, McDowell MR, Campbell NB, Davis JL, Marshall JF, Blikslager AT. Anti-inflammatory effects of intravenously administered lidocaine hydrochloride on ischemia-injured jejunum in horses. Am J Vet Res 2009; 70:1259-1268.

David D, Lang RM, Neumann A, Borow KM, Akselrod S, Mor-Avi V. Parasympathetically modulated antiarrhythmic action of lidocaine in atrial fibrillation. Am Heart J 1990; 
119:1061-1068.

Daykin H. The efficacy and safety of intravenous lidocaine for analgesia in the older adult: a literature review. Br J Pain 2017; 11:23-31.

Enouri SS, Kerr CL, McDonell WN, Dyson DH. Cardiopulmonary effects of anesthetic induction with thiopental, propofol, or a combination of ketamine hydrochloride and diazepam in dogs sedated with a combination of medetomidine and hydromorphone. Am J Vet Res 2008a; 69:586-595.

Enouri SS, Kerr CL, McDonell WN, O’Sullivan ML, Teixeira Neto FJ. Effects of peripheral $\alpha 2$ adrenergic-receptor antagonist on the hemodynamic changes induced by medetomidine administration in conscious dogs. Am J Vet Res 2008b; 69:728-736.

Estes $3^{\text {rd }} \mathrm{NA}$, Manolis AS, Greenblatt DJ, Garan H, Ruskin JN. Therapeutic serum lidocaine and metabolite concentrations in patients undergoing electrophysiologic study after discontinuation of intravenous lidocaine infusion. Am Heart J 1989; 117:1060-1064.

Ewing KK, Mohammed HO, Scarlett JM, Short CE. Reduction of isoflurane anesthetic requirement by medetomidine and its restoration by atipamezole in dogs. Am J Vet Res $1993 ; 54: 294-299$.

Flacke WE, Flacke JW, Bloor BC, McIntee DF, Sagan M. Effects of dexmedetomidine on systemic and coronary hemodynamics in the anesthetized dog. J Cardiothorac Vasc Anesth 1993; 7:41-49.

Fletcher JR, Ramwell PW. E. coli endotoxin shock in the dog; treatment with lidocaine or indomethacin. Br J Pharmacol 1978; 64:185-191. 
ER. Local Anesthetics. In: Veterinary Anesthesia and Analgesia: The Fifth Edition of Lumb and Jones ( $5^{\text {th }}$ edn.) Grimm KA, Lamont LA, Tranquilli WJ, Greene SA, Robertson SA (eds.). Wiley-Blackwell, Ames, USA. 2015;pp. 332-354.

Gianelly R, Von der Groeben JO, Spivack AP, Harrison DC. Effect of lidocaine on ventricular arrhythmias in patients with coronary heart disease. New Eng J Med 1967; 277:1215-1219. Gómez-Villamandos RJ, Palacios C, Benítez A, Granados MM, Domínguez JM, Estepa JC, Ruiz I, Aguilera E, Santisteban JM. Effect of medetomidine infusion on the anaesthetic requirements of desflurane in dogs. Res Vet Sci 2008; 84:68-73.

Gómez-Villamandos RJ, Palacios C, Benítez A, Granados MM, Domínguez JM, López I, Ruiz I, Aguilera E, Santisteban JM. Dexmedetomidine or medetomidine premedication before propofol-desflurane anasthesia in dogs. J Vet Pharmacol Therap 2006; 29:157-163.

Gozalo-Marcilla, M, Hopster K, Gasthuys F, Hatz L, Krajewski AE, Schauvliege S. Effects of a constant-rate infusion of dexmedetomidine on the minimal alveolar concentration of sevoflurane in ponies. Equine Vet J 2012; 45:204-208.

Granholm M, McKusick BC, Westerholm FC, Aspegrén JC. Evaluation of the clinical efficacy and safety of intramuscular and intravenous doses of dexmedetomidine and medetomidine in dogs and their reversal with atipamezole. Vet Rec 2007; 160:891-897.

Greene SA, Tranquilli WJ, Benson J, Grimm KA. Effect of medetomidine administration on bispectral index measurements in dogs during anesthesia with isoflurane. Am J Vet Res $2003 ; 64: 316-320$.

Indik JH, Woosley RL. Pharmacokinetics/pharmacodynamics of antiarrhythmic drugs. Card Electrophysiol Clin 2010; 2:341-358. 
Josephson ME, Caracta AR, Lau SH, Gallagher JJ, Damato AN. Effects of lidocaine on refractory periods in man. Am Heart J 1972; 84:778-786.

Keegan RD, Green SA, Bagley RS, Moore MP, Weil AB, Short CE. Effects of medetomidine administration on intracranial pressure and cardiovascular variables of isofluraneanesthetized dogs. Am J Vet Res 1995; 56:193-198.

Ko JC, Fox SM, Mandsager RE. Sedative and cardiorespiratory effects of medetomidine, medetomidine-butorphanol, and medetomidine-ketamine in dogs. J Am Vet Med Assoc $2000 ; 216: 1578-1583$.

Ko JC, Fox SM, Mandsager RE. Effects of preemptive atropine administration on incidence of medetomidine-induced bradycardia in dogs. J Am Vet Med Assoc 2001; 218:52-58.

Kumada M, Azuma T, Matsud K. Cardiac output-heart rate relationship under different conditions. Japan J Physiol 1967; 17:538-555.

Kunkel F, Rowland M, Scheinman MM. The electrophysiologic effects of lidocaine in patients with intraventricular conduction defects. Circulation 1974; 49:894-899.

Kuusela E, Raekallio M, Anttila M, Falck I, Mölsä S, Vanio O. Clinical effects and pharmacokinetics of medetomidine and its enantiomers in dogs. J Vet Pharmacol Therap $2000 ; 23: 15-20$.

Kuusela E, Vainio O, Kaistinen A, Kobylin S, Raekallio M. Sedative, analgesic, and cardiovascular effects of levomedetomidine alone and in combination with dexmedetomidine in dogs. Am J Vet Res 2001; 62:616-621.

LeLorier J, Moisan R, Gagné J, Caillé G. Effect of the duration of infusion on the disposition of lidocaine in dogs. J Pharmacol Exp Ther 1977; 203:507-511. 
Lerche P, Muir III WW. Effect of medetomidine on respiration and minimum alveolar concentration in halothane- and isoflurane-anesthetized dogs. Am J Vet Res 2006; 67:782789.

Lieberman NA, Harris RS, Katz RI, Lipschutz HM, Dolgin M, Fisher VJ. The effects of lidocaine on the electrical and mechanical activity of the heart. Am J Cardiol 1968; 22:375-380.

Liu PL, Feldman HS, Covino BM, Giasi R, Covino BG. Acute cardiovascular toxicity of intravenous amide local anesthetics in anesthetized ventilated dogs. Anesth Analg 1982; 61:317-322.

MacDougall LM, Hethey JA, Livingston A, Clark C, Shmon CL, Duke-Novakoski T. Antinociceptive, cardiopulmonary, and sedative effects of five intravenous rates of lidocaine in conscious dogs. Vet Anaesth Analg 2009; 36:512-522.

Merin RG, Bernard JM, Doursout MF, Cohen M, Chelly JE. Comparison of the effects of isoflurane and desflurane on cardiovascular dynamics and regional blood flow in the chronically instrumented dog. Anesthesiology 1991; 74:568-574.

Moïse NS, Pariaut R, Gelzer ARM, Kraus MS, Jung SW. Cardioversion with lidocaine of vagally associated atrial fibrillation in two dogs. J Vet Cardiol 2005; 7:143:148.

Moraes AN, Mirakhur K, McDonell W, O'Grady M, Kerr C. Modification of the cardiopulmonary response to medetomidine in isoflurane anesthetized dogs following treatment with glycopyrrolate (abstract). Vet Anaesth Analg 2004a; 31:13-14. https://doi.org/10.1111/j.1467-2995.2004.00220a.x.

Moraes A, O’Grady M, McDonell W, Kerr C, Mirakhur K. The echocardiographic effects of glycopyrrolate pretreatment on the response to medetomidine in dogs anesthetized with 
isoflurane (abstract). Vet Anaesth Analg 2004b; 31:14. https://doi.org/10.1111/j.14672995.2004.00220a.x

Moran-Muñoz R, Ibanovichi JA, Gutierrez-Blanco E, Acevedo-Arcique CM, Victoria Mora JM, Tendillo FJ, Yamashita K. Effects of lidocaine, dexmedetomidine or their combination on the minimum alveolar concentration of sevoflurane in dogs. J Vet Med Sci 2017a; 76:847853.

Moran-Muñoz R, Valverde A, Ibancovichi JA, Acevedo-Arcique CM, Recillas-Morales S, Sanchez-Aparicio P, Osorio-Avalos J, Chavez-Monteagudo JR. Cardiovascular effects of constant rate infusions of lidocaine, lidocaine and dexmedetomidine, and dexmedetomidine in dogs anesthetized at equipotent doses of sevoflurane. Can Vet J 2017b; 58:729-734.

Mutoh T, Nishimura R, Kim HY, Matsunaga S, Sasaki N. Cardiopulmonary effects of sevoflurane, compared with halothane, enflurane, and isoflurane, in dogs. Am J Vet Res 1997; 58:88590.

Newberg LA, Milde JH, Michenfelder JD. Systemic and cerebral effects of isoflurane-induced hypotension in dogs. Anesthesiology 1984; 60:541-546.

Ngo LY, Tam YK, Tawfik S, Coutts RT, Gray MR. Effects of intravenous infusion of lidocaine on its pharmacokinetics in conscious instrumented dogs. J Pharmac Sci 1997; 86:944-952.

Nicodemus HF, Chaney RD, Herold R. Hemodynamic effects of inotropes during hypothermia and rapid rewarming. Crit Care Med 1981; 9;325-328.

Nunes de Moraes A, Dyson DH, O’Grady M, McDonell WN, Holmberg DL. Plasma concentrations and cardiovascular influence of lidocaine infusions during isoflurane anesthesia in healthy dogs and dogs with subaortic stenosis. Vet Surg 1998; 27:486-497. 
Pagel PS, Proctor LT, Devcic A, Hettrick DA, Kersten JR, Tessmer JP, Farber NE, Schmeling WT, Wartier DC. A novel alpha2-adrenoceptor antagonist attenuates the early but preserves the late cardiovascular effects of intravenous dexmedetomidine in conscious dogs. J Cardiothorac Vasc Anesth 1998; 12:429-434.

Pariaut R. Ventricular tachyarrhythmias. In: Small animal critical care medicine ( $\left.2^{\text {nd }} e d n.\right)$. Silverstein DC, Hopper K (eds.). Elsevier, St. Louis, USA, 2008 pp. 255-259.

Pascoe PJ. The cardiopulmonary effects of dexmedetomidine infusions in dogs during isoflurane anesthesia. Vet Anaesth Analg 2014; 42:360-368.

Pascoe PJ, Raekallio M, Kuusela E, McKusick B, Granholm M. Changes in the minimum alveolar concentration of isoflurane and some cardiopulmonary measurements during three continuous infusion rates of dexmedetomidine in dogs. Vet Anaest Analg 2006; 33:97-103.

Pypendop BH, Honkavaara J, Ilkiw JE. Pharmacokinetics of dexmedetomidine, MK-467 and their combination following intramuscular administration in male cats. Vet Anaesth Analg 2017; 44:823-831.

Rankin DC. Sedatives and tranquilizers. In: Veterinary Anesthesia and Analgesia: The Fifth Edition of Lumb and Jones ( $5^{\text {th }}$ edn.) Grimm KA, Lamont LA, Tranquilli WJ, Greene SA, Robertson SA (eds.). Wiley-Blackwell, Ames, USA. 2015;pp. 196-206.

Riviere JE. Absorption, distribution, metabolism and elimination. In: Veterinary Pharmacology and Therapeutics (10 ${ }^{\text {th }}$ edn.). Riviere JE, Papich MG (eds.). Wiley-Blackwell, Hoboken, USA. 2018;pp. 8-40.

Roos JC, Dunning AJ. Effects of lidocaine on impulse formation and conduction defects in man. Am Heart J 1975; 89:686-699.

Rosen KM, Lau SH, Weiss MB, Damato AN. The effect of lidocaine on atrioventricular and 
intraventricular conduction in man. Am J Cardiol 1970; 25:1-5.

Rydén L, Cullhed I, Wasir H. Effect of lignocaine on heart rate in patients with sinus bradycardia associated with proven or suspected acute myocardial infarction. Cardiovasc Res 1972; 6:664-870.

Sinclair MD, O'Grady MR, Kerr CL, McDonell WN. The echocardiographic effects of romifidine in dogs with and without prior or concurrent administration of glycopyrrolate. Vet Anaest Analg 2003; 30:211-219.

Singh \& Hauswirth 1974. Comparative mechanisms of action of antiarrhythmic drugs. Am Heart J 1974; 87:367-382.

Skelding A, Valverde A, Aguilera R, Moens N, Sinclair M, Thomason JJ. Comparison of 3 blind brachial plexus block techniques during maintenance of anesthesia and postoperative pain scores in dogs undergoing surgical procedures of the thoracic limb. Can J Vet Res 2019; 83:197-205.

Torfs S, Delesalle C, Dewulf J, Devisscher L, Deprez P. Risk factors for equine postoperative ileus and effectiveness of prophylactic lidocaine. J Vet Intern Med 2009; 23:606-611.

Toutain PL, Bousquet-Mélou A. Plasma terminal half-life. J Vet Pharmacol Therap 2004; 27:427439.

Valverde A, Doherty TJ, Hernández J, Davies W. Effect of lidocaine on the minimum alveolar concentration of isoflurane in dogs. Vet Anaesth Analg 2004; 31:264-271.

Valverde A, Gianotti G, Rioja E, Hathway E. Effects of high-volume and rapid-fluid therapy on cardiovascular function and hematological values during isoflurane-induced hypotension in healthy dogs. Can J Vet Res 2012; 76:99-108. 
Vickroy TW. Local Anesthetics. In: Veterinary Pharmacology and Therapeutics $\left(10^{\text {th }}\right.$ edn.). Riviere JE, Papich MG (eds.). Wiley-Blackwell, Hoboken, USA. 2018;pp. 369-386.

Wilcke JR, Davis LE, Neff-Davis CA, Koritz D. Pharmacokinetics of lidocaine and its active metabolites in dogs. J Vet Pharmacol Ther 1983; 6:49-58.

Zatroch KK, Sakai DM, Parry S, Campoy L, Martin-Flores M. Evaluation of atipamezole as a treatment for dexmedetomidine-induced cardiovascular depression in anesthetized cats. Am J Vet Res 2019; 80:455-460. 


\subsection{APPENDIX 1}

\section{Sedation score}

$0 \quad$ Bright and alert, no apparent sedation and/or excitable-dysphoric

(excited, anxious, difficult to restrain in recumbency, very interactive and responsive, vocalizing, reactive to voice and touch)

1 Calm, minimal sedation (quiet but still alert and aware of surroundings, mild resistance to restraint for lateral recumbency, moderate response to voices and touch; mild resistance to catheterization)

2 Very calm, with moderate sedation (quiet, relaxed, minimal restraint required for lateral recumbency, mild response to voices or touch; no resistance to catheterization)

3 Profound sedation (quiet, very relaxed, no restraint necessary for lateral recumbency, does not respond to voice or touch)

Modified from Skelding et al. (2019). 


\subsection{APPENDIX 2}

\section{Variable}

CI (mL kg ${ }^{-1}$ minute $\left.^{-1}\right)$

$\mathrm{SV}\left(\mathrm{mL}\right.$ beat $\left.^{-1}\right)$

SVI ( $\mathrm{mL}$ beat $\left.{ }^{-1} \mathrm{~kg}^{-1}\right)$

SVRI (dynes seconds $\mathrm{cm}^{-5} \mathrm{~kg}^{-1}$ )

$\mathrm{CaO}_{2}\left(\mathrm{~mL} \mathrm{dL}^{-1}\right)$

$\mathrm{CcvO}_{2}\left(\mathrm{~mL} \mathrm{dL}^{-1}\right)$

$\mathrm{VO}_{2}\left(\mathrm{~mL} \mathrm{O}_{2} \mathrm{~kg}^{-1} \mathrm{~min}^{-1}\right)$

$\mathrm{DO}_{2}\left(\mathrm{~mL} \mathrm{O}_{2} \mathrm{~kg}^{-1} \mathrm{~min}^{-1}\right)$

$\mathrm{ERO}_{2}(\%)$

\section{Formula}

$$
\frac{\mathrm{CO}\left(\mathrm{L} \mathrm{min}^{-1}\right)}{\mathrm{BW}(\mathrm{kg})} \times 1000
$$

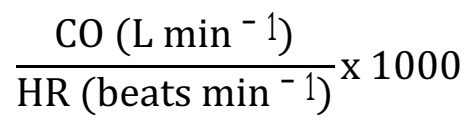

$\underline{\mathrm{SV}\left(\mathrm{mL} \text { beat }^{-1}\right)}$

$$
\text { BW (kg) }
$$

$$
\frac{\mathrm{MAP}(\mathrm{mmHg})-\mathrm{CVP}(\mathrm{mmHg})}{\mathrm{CI}\left(\mathrm{mL} \mathrm{kg}^{-1} \text { minute }^{-1}\right)} \times 80
$$

$\left[\mathrm{Hb}\left(\mathrm{g} \mathrm{dL}^{-1}\right) \times \mathrm{SaO}_{2}(\%) \times 1.34\right]+0.0031 \times \mathrm{PaO}_{2}(\mathrm{mmHg})$

$\left[\mathrm{Hb}\left(\mathrm{g} \mathrm{dL}^{-1}\right) \times \mathrm{ScvO}_{2}(\%) \times 1.34\right]+0.0031 \times \mathrm{PcvO}_{2}(\mathrm{mmHg})$

$$
\frac{\left(\mathrm{CaO}_{2}-\mathrm{CcvO}_{2}\right) \times \mathrm{CI}}{100}
$$

$$
\frac{\mathrm{CaO} 2 \times \mathrm{CI}}{100}
$$

$$
\frac{\mathrm{VO}_{2}}{\mathrm{DO}_{2}} \times 100
$$

$\mathrm{CI}=$ Cardiac index $; \mathrm{CO}=$ Cardiac output $\mathrm{BW}=$ Bodyweight $\mathrm{SV}=$ Stroke volume; $\mathrm{HR}=$ Heart rate; $\mathrm{SVI}=$ Stroke volume index; $\mathrm{SVRI}=$ Systemic vascular resistance index; $\mathrm{MAP}=\mathrm{Mean}$ arterial pressure; $\mathrm{CVP}=$ Central venous pressure; $\mathrm{CaO}_{2}=$ Arterial oxygen content; $\mathrm{Hb}=$ Hemoglobin; $\mathrm{SaO}_{2}=$ Arterial oxygen saturation; $\mathrm{PaO}_{2}=$ Arterial partial pressure of oxygen; $\mathrm{CcvO}_{2}=$ Central venous oxygen content; $\mathrm{PcvO}_{2}=$ Central venous partial pressure of oxygen; 
$\mathrm{ScvO}_{2}=$ Saturation of hemoglobin in central-venous blood; $\mathrm{VO}_{2}=$ Oxygen consumption; $\mathrm{DO}_{2}=$ Oxygen delivery; $\mathrm{ERO}_{2}=$ Oxygen extraction ratio. (Valverde et al. 2012). 

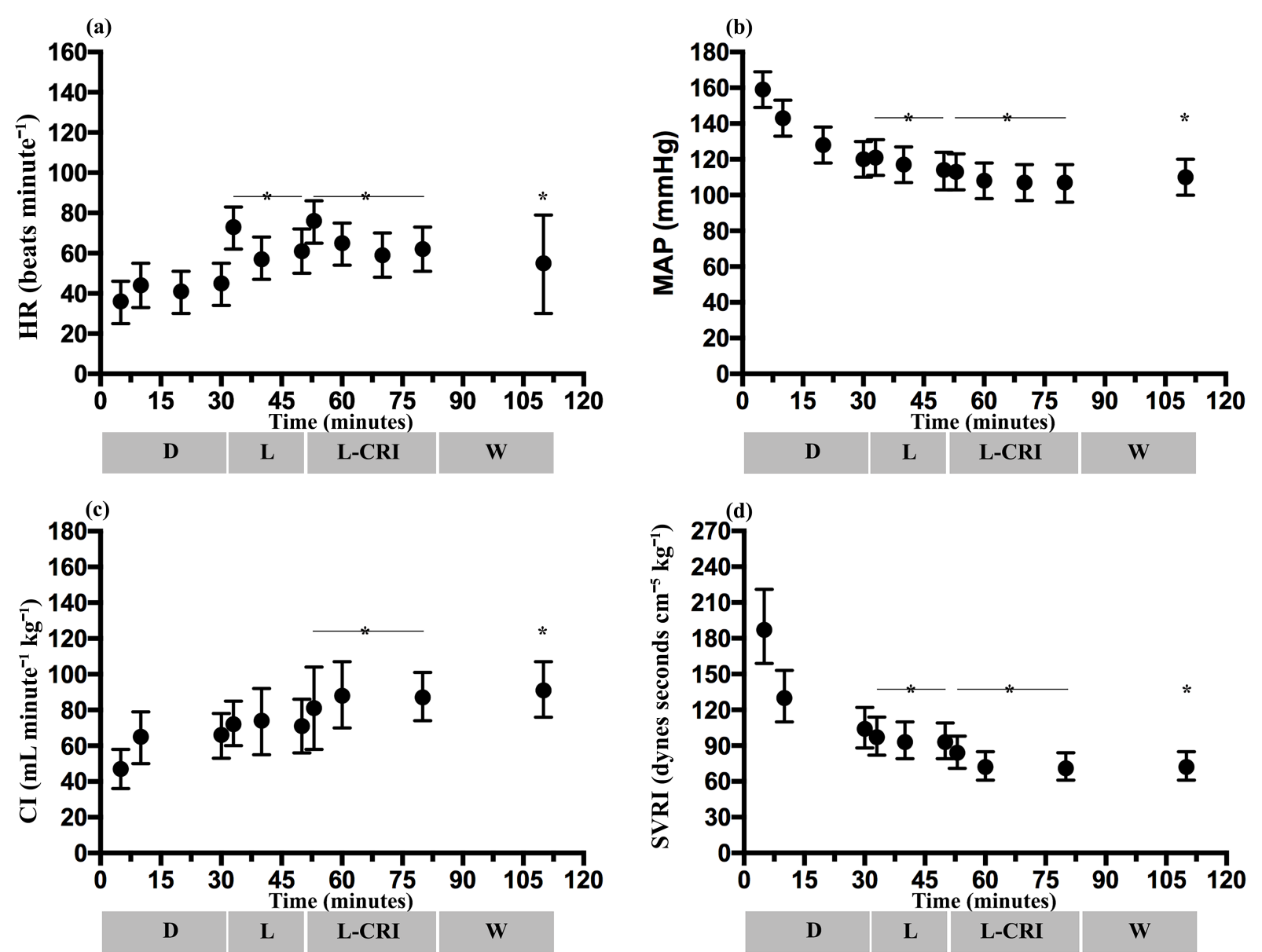

Figure 2.1 (a) Heart rate (HR), (b) mean arterial pressure (MAP), (c) cardiac index (CI) and (d) systemic vascular resistance index (SVRI) in conscious dogs administered IV dexmedetomidine (D; $\left.10 \mu \mathrm{g} \mathrm{kg}^{-1}\right)$, followed by an IV lidocaine bolus (L;2 $\left.\mathrm{mg} \mathrm{kg}^{-1}\right)$ after 30 minutes, and a second lidocaine bolus and constant rate infusion 20 minutes later (L-CRI, $2 \mathrm{mg} \mathrm{kg}{ }^{-1}+50 \mu \mathrm{g} \mathrm{kg}^{-1} \mathrm{minute}^{-}$ ${ }^{1}$ for 30 minutes), followed by a washout period (W) of 30 minutes (group SED1). Data expressed as mean \pm standard deviation. *Significantly different from $\mathrm{D}(p<0.05)$. Horizontal line indicates all values during that period of assessment were significantly different from D. 

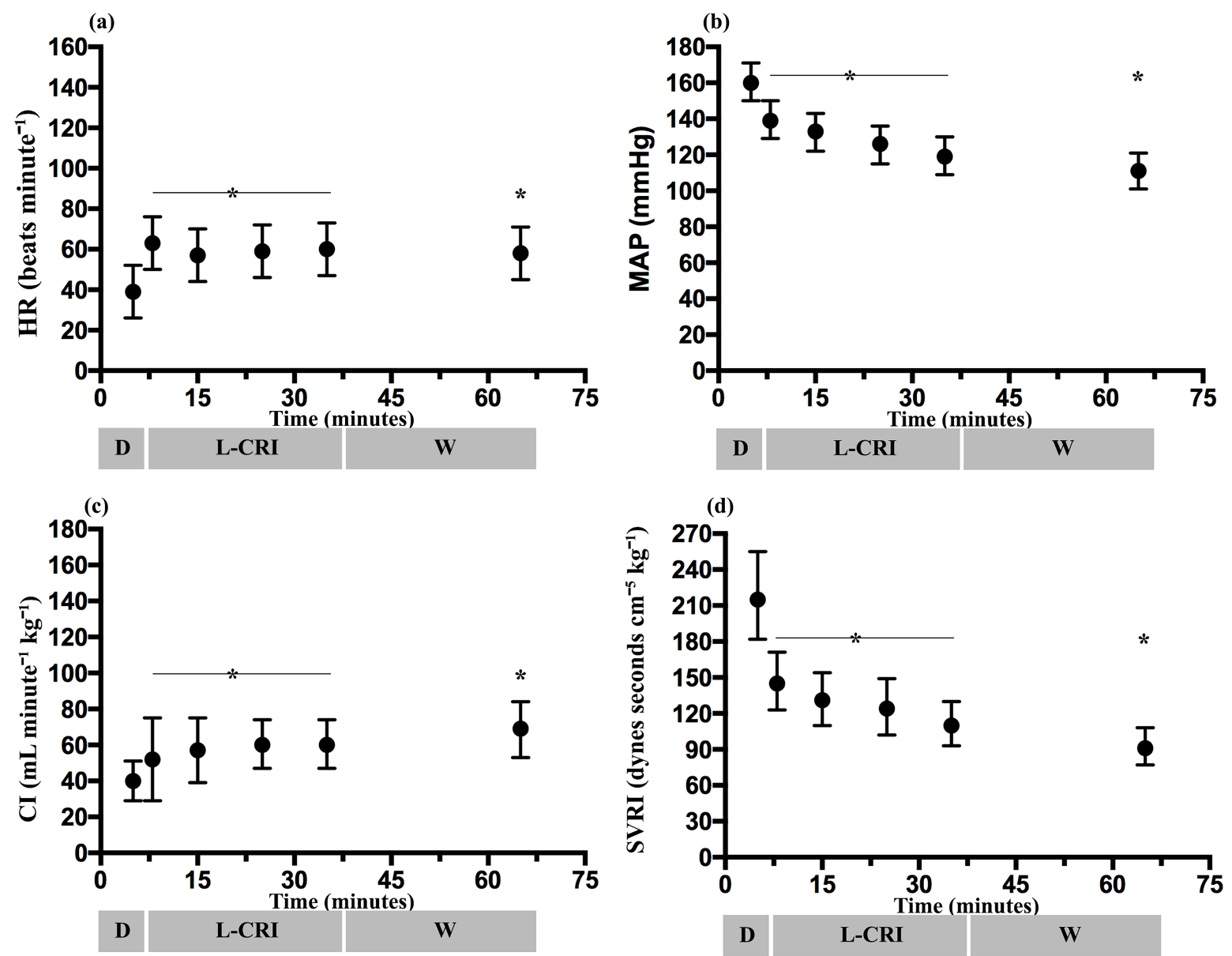

Figure 2.2 (a) Heart rate (HR), (b) mean arterial pressure (MAP), (c) cardiac index (CI) and (d) systemic vascular resistance index (SVRI) in conscious dogs administered IV dexmedetomidine (D; $10 \mu \mathrm{g} \mathrm{kg}^{-1}$ ), followed by an IV lidocaine bolus and constant rate infusion 5 minutes later (LCRI, $2 \mathrm{mg} \mathrm{kg}{ }^{-1}+50 \mu \mathrm{kg}^{-1}$ minute-1 for 30 minutes), followed by a washout period (W) of 30 minutes (group SED2). Data expressed as mean \pm standard deviation. *Significantly different from D $(p<0.05)$. Horizontal line indicates all values during that period of assessment were significantly different from D. 

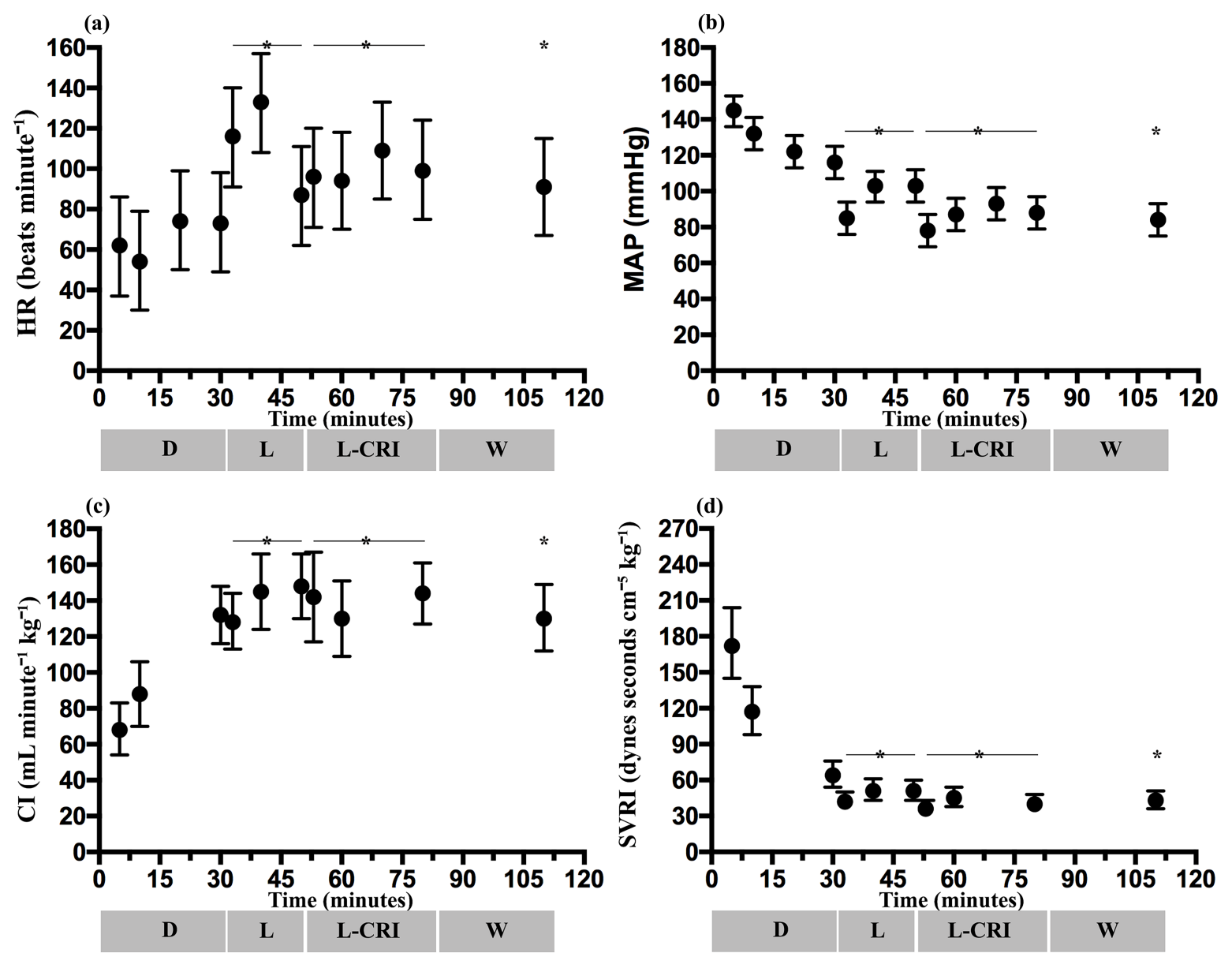

Figure 2.3 (a) Heart rate (HR), (b) mean arterial pressure (MAP), (c) cardiac index (CI) and (d) systemic vascular resistance index (SVRI) in isoflurane-anesthetized dogs administered IV dexmedetomidine (D; $10 \mu \mathrm{g} \mathrm{kg}^{-1}$ ), followed by an IV lidocaine bolus (L; $2 \mathrm{mg} \mathrm{kg}{ }^{-1}$ ) after 30 minutes, and a second lidocaine bolus and constant rate infusion 20 minutes later (L-CRI, $2 \mathrm{mg}$ $\mathrm{kg}^{-1}+100 \mu \mathrm{g} \mathrm{kg}^{-1}$ minute ${ }^{-1}$ for 30 minutes), followed by a washout period (W) of 30 minutes (group ISO). Data expressed as mean \pm standard deviation. * Significantly different from $\mathrm{D}(p<0.05)$. Horizontal line indicates all values during that period of assessment were significantly different from D. 
Table 2.1. Temperature and cardiorespiratory variables in conscious dogs administered IV dexmedetomidine (10 $\left.\mathrm{g} \mathrm{kg}^{-1}\right)$, followed by an IV lidocaine bolus $\left(2 \mathrm{mg} \mathrm{kg}^{-1}\right)$ after 30 minutes, and a second lidocaine bolus and constant rate infusion (CRI) 20 minutes later $\left(2 \mathrm{mg} \mathrm{kg}^{-1}+50 \mu \mathrm{g} \mathrm{kg}^{-1}\right.$ minute $^{-1}$ for 30 minutes), followed by a washout period of 30 minutes (group SED1).

\begin{tabular}{|c|c|c|c|c|}
\hline Variable & $\begin{array}{l}\text { Dexmedetomidine } \\
\text { post administration }\end{array}$ & $\begin{array}{c}\text { Lidocaine bolus } \\
\text { post administration }\end{array}$ & $\begin{array}{l}\text { Lidocaine bolus and CRI } \\
\text { post administration }\end{array}$ & Washout \\
\hline $\begin{array}{l}\text { Heart rate } \\
\text { (beats minute }^{-1} \text { ) }\end{array}$ & $\begin{array}{l}41 \pm 7^{\mathrm{a}} \\
(38,44)\end{array}$ & $\begin{array}{l}63 \pm 13^{\mathrm{b}} \\
(57,70)\end{array}$ & $\begin{array}{l}61 \pm 11^{\mathrm{b}} \\
(55,66)\end{array}$ & $\begin{array}{l}53 \pm 9^{b} \\
(43,63)\end{array}$ \\
\hline (beats minute $\mathrm{e}^{-1}$ ) & & $p<0.0001$ & $p<0.0001$ & $p=0.0015$ \\
\hline Mean arterial pressure & $126 \pm 16^{\mathrm{a}}$ & $106 \pm 5^{\mathrm{b}}$ & $96 \pm 5^{\mathrm{b}}$ & $99 \pm 8^{b}$ \\
\hline (mmHg) & $(119,133)$ & $(103,108)$ & $(94,98)$ & $(90,108)$ \\
\hline & & $p<0.0001$ & $p<0.0001$ & $p=0.006$ \\
\hline Cardiac index & $69 \pm 15^{\mathrm{a}}$ & $82 \pm 12^{\mathrm{a}}$ & $98 \pm 17^{b}$ & $101 \pm 19^{\mathrm{b}}$ \\
\hline (mL minute ${ }^{-1} \mathbf{k g}^{-1}$ ) & $(61,76)$ & $(75,88)$ & $(87,109)$ & $(81,122)$ \\
\hline & & & $p=0.0001$ & $p=0.0003$ \\
\hline Systemic vascular & $143 \pm 47^{\mathrm{a}}$ & $95 \pm 17^{\mathrm{b}}$ & $73 \pm 13^{b}$ & $72 \pm 8^{\mathrm{b}}$ \\
\hline resistance index & $(119,166)$ & $(87,104)$ & $(64,81)$ & $(64,81)$ \\
\hline (dynes second $\mathrm{cm}^{-5} \mathrm{~kg}^{-1}$ ) & & $p=0.0003$ & $p<0.0001$ & $p=0.0016$ \\
\hline Stroke volume index & $1.7 \pm 0.4^{\mathrm{ab}}$ & $1.3 \pm 0.2^{\mathrm{a}}$ & $1.6 \pm 0.3^{\mathrm{a}}$ & $1.9 \pm 0.2^{\mathrm{b}}$ \\
\hline$\left(\mathrm{mL}\right.$ beat $\left.^{-1} \mathrm{~kg}^{-1}\right)$ & $(1.5,1.8)$ & $(1.2,1.5)$ & $(1.4,1.8)$ & $(1.7,2.1)$ \\
\hline Oxygen extraction ratio & $49 \pm 2^{\mathrm{a}}$ & $43 \pm 6^{\mathrm{b}}$ & $34 \pm 5^{c}$ & $34 \pm 6^{c}$ \\
\hline
\end{tabular}


(\%)

47,52)

$(37,49)$

$p=0.039$

$13 \pm 6^{\mathrm{a}}$

$(10,15)$

(breaths minute ${ }^{-1}$ )

$\mathrm{PaO}_{2}$

(mmHg)

$94 \pm 6^{\mathrm{a}}$

$(87,102)$

$31 \pm 2^{\mathrm{a}}$

$(29,33)$

(mmHg)

Temperature

$\left({ }^{\circ} \mathrm{C}\right)$

Lactate

(mmol/L)
$37.4 \pm 0.5^{\mathrm{a}}$

$(37.0,37.7)$

$1.3 \pm 0.2^{\mathrm{a}}$

$(1.2,1.5)$
$96 \pm 6^{\mathrm{a}}$

$(90,102)$

$10 \pm 3^{\mathrm{a}}$

$(8,11)$

$(9,10)$

$105 \pm 11^{\mathrm{a}}$

$(98,112)$

$35 \pm 4^{\mathrm{b}}$

$(33,36)$

$p=0.0088$

$37.3 \pm 0.7^{\mathrm{a}}$

$(36.7,38.0)$

$1.5 \pm 0.2^{\mathrm{a}}$

$(1.3,1.6)$

$34 \pm 3^{b}$

$(33,35)$
$(31,38)$

$p<0.0001$

$p=0.0005$

$11 \pm 2^{\mathrm{a}}$

$(9,13)$

$111 \pm 12^{\mathrm{b}}$

$(98,124)$

$p=0.0204$

$34 \pm 5^{\mathrm{b}}$

$(32,36)$

$p=0.0039$

$p=0.0281$

Data expressed as mean \pm standard deviation (95\% confidence intervals) and represents the pooled data from figure 2.1. * Median and 95\% confidence interval. Different letters indicate significant difference with dexmedetomidine post administration. 
Table 2.2. Temperature and cardiorespiratory variables in conscious dogs administered IV dexmedetomidine $\left(10 \mu \mathrm{g} \mathrm{kg}^{-1}\right)$, followed by an IV lidocaine bolus $\left(2 \mathrm{mg} \mathrm{kg}^{-1}\right)$ and constant rate infusion (CRI) 5 minutes later ( $2 \mathrm{mg} \mathrm{kg}^{-1}+50 \mu \mathrm{g} \mathrm{kg}^{-1}$ minute ${ }^{-1}$ for 30 minutes), followed by a washout period of 30 minutes (group SED2).

\begin{tabular}{|c|c|c|c|}
\hline Variable & $\begin{array}{l}\text { Dexmedetomidine } \\
\text { post administration }\end{array}$ & $\begin{array}{c}\text { Lidocaine bolus and CRI } \\
\text { post administration }\end{array}$ & Washout \\
\hline $\begin{array}{l}\text { Heart rate } \\
\text { (beats minute }{ }^{-1} \text { ) }\end{array}$ & $\begin{array}{l}37 \pm 5^{\mathrm{a}} \\
(31,43)\end{array}$ & $\begin{array}{c}61 \pm 13^{\mathrm{b}} \\
(55,67) \\
p=0.0002\end{array}$ & $\begin{array}{c}55 \pm 7^{b} \\
(48,62) \\
p=0.0005\end{array}$ \\
\hline $\begin{array}{l}\text { Mean arterial pressure } \\
(\mathrm{mmHg})\end{array}$ & $\begin{array}{l}147 \pm 6^{a} \\
(141,153)\end{array}$ & $\begin{array}{c}116 \pm 9^{\mathrm{b}} \\
(111,120) \\
p<0.0001\end{array}$ & $\begin{array}{c}98 \pm 3^{\mathrm{c}} \\
(95,101) \\
p<0.0001\end{array}$ \\
\hline $\begin{array}{l}\text { Cardiac index } \\
\left(\mathrm{mL} \text { minute }{ }^{-1} \mathrm{~kg}^{-1}\right)\end{array}$ & $\begin{array}{l}50 \pm 6^{\mathrm{a}} \\
(44,56)\end{array}$ & $\begin{array}{c}68 \pm 13^{\mathrm{b}} \\
(62,75) \\
p=0.0033\end{array}$ & $\begin{array}{c}79 \pm 4^{b} \\
(74,83) \\
p<0.0001\end{array}$ \\
\hline $\begin{array}{l}\text { Systemic vascular } \\
\text { resistance index }\end{array}$ & $\begin{array}{l}213 \pm 29^{\mathrm{a}} \\
(183,244)\end{array}$ & $\begin{array}{l}125 \pm 28^{b} \\
(111,138)\end{array}$ & $\begin{array}{l}90 \pm 7^{\mathrm{b}} \\
(82,97)\end{array}$ \\
\hline (dynes second $\mathrm{cm}^{-5} \mathrm{~kg}^{-1}$ ) & & $p<0.0001$ & $p<0.0001$ \\
\hline $\begin{array}{l}\text { Stroke volume index } \\
\left(\mathrm{mL} \text { beat }{ }^{-1} \mathrm{~kg}^{-1}\right)\end{array}$ & $\begin{array}{l}1.4 \pm 0.2^{\mathrm{ab}} \\
(1.2,1.6)\end{array}$ & $\begin{array}{l}1.1 \pm 0.4^{\mathrm{a}} \\
(1.0,1.3)\end{array}$ & $\begin{array}{l}1.5 \pm 0.2^{\mathrm{b}} \\
(1.3,1.6)\end{array}$ \\
\hline Oxygen extraction ratio & $41 \pm 10^{\mathrm{a}}$ & $41 \pm 9^{\mathrm{a}}$ & $36 \pm 4^{\mathrm{b}}$ \\
\hline
\end{tabular}




\section{Respiratory rate}

(breaths minute ${ }^{-1}$ )

$\mathrm{PaO}_{2}$

(mmHg)

$\mathrm{PaCO}_{2}$

(mmHg)
$15 \pm 7^{\mathrm{a}}$

$(8,23)$

$95 \pm 14^{\mathrm{a}}$

$(80,109)$

$30 \pm 7^{\mathrm{a}}$

$(27,33)$
$10 \pm 4^{\mathrm{a}}$

$(8,11)$

$96 \pm 7^{\mathrm{a}}$

$(90,101)$

$31 \pm 3^{\mathrm{a}}$

$(30,32)$
$10 \pm 2^{\mathrm{a}}$

$103 \pm 6^{\mathrm{a}}$

$(97,109)$

$34 \pm 1^{\mathrm{b}}$

$(33,34)$

$p=0.0092$

$37.6 \pm 0.5^{\mathrm{a}}$

$37.5 \pm 0.6^{\mathrm{a}}$

$(37.2,37.9)$

$(36.9,38.1)$

$(36.9,38.0)$

$1.6 \pm 0.3^{b}$

$1.2 \pm 0.3^{\mathrm{ab}}$

$(1.2,1.9)$

$(1.0,1.5)$

$p<0.0267$

$3.0^{\mathrm{b}}$

$3.0^{\mathrm{ab}}$

$(3.0,3.0)$

$(2.0,3.0)$

$$
(1.0,3.0)
$$

$p<0.0472$

Data expressed as mean \pm standard deviation ( $95 \%$ confidence intervals) and represents the pooled data from figure 2.2. *Median and 95\% confidence interval. Different letters indicate significant difference with dexmedetomidine post administration. 
Table 2.3. Temperature and cardiorespiratory variables in isoflurane-anesthetized dogs administered IV dexmedetomidine ( $\left.10 \mu \mathrm{g} \mathrm{kg}^{-1}\right)$, followed by an IV lidocaine bolus $\left(2 \mathrm{mg} \mathrm{kg}^{-1}\right)$ after 30 minutes, and a second lidocaine bolus and constant rate infusion (CRI) 20 minutes later ( $2 \mathrm{mg}$ $\mathrm{kg}^{-1}+100 \mu \mathrm{g} \mathrm{kg}^{-1}$ minute${ }^{-1}$ for 30 minutes), followed by a washout period without of 30 minutes (group ISO).

\begin{tabular}{|c|c|c|c|c|}
\hline Variable & $\begin{array}{l}\text { Dexmedetomidine } \\
\text { post administration }\end{array}$ & $\begin{array}{c}\text { Lidocaine bolus } \\
\text { post administration }\end{array}$ & $\begin{array}{c}\text { Lidocaine bolus and CRI } \\
\text { post administration }\end{array}$ & Washout \\
\hline $\begin{array}{l}\text { Heart rate } \\
\text { (beats } \text { min }^{-1} \text { ) }\end{array}$ & $\begin{array}{l}73 \pm 23^{\mathrm{a}} \\
(63,83)\end{array}$ & $\begin{array}{c}99 \pm 9^{b} \\
(94,103) \\
p=0.0001\end{array}$ & $\begin{array}{c}94 \pm 8^{\mathrm{b}} \\
(90,97) \\
p=0.0009\end{array}$ & $\begin{array}{l}86 \pm 9^{\mathrm{ab}} \\
(77,95)\end{array}$ \\
\hline $\begin{array}{l}\text { Mean arterial pressure } \\
(\mathrm{mmHg})\end{array}$ & $\begin{array}{l}113 \pm 13^{\mathrm{a}} \\
(107,119)\end{array}$ & $\begin{array}{c}81 \pm 11^{\mathrm{b}} \\
(76,87) \\
p<0.0001\end{array}$ & $\begin{array}{c}71 \pm 11^{\mathrm{c}} \\
(66,75) \\
p<0.0001\end{array}$ & $\begin{array}{c}69 \pm 10^{c} \\
(59,79) \\
p<0.0001\end{array}$ \\
\hline $\begin{array}{l}\text { Cardiac index } \\
\left(\mathrm{mL} \text { minute }^{-1} \mathbf{k g}^{-1}\right)\end{array}$ & $\begin{array}{l}80 \pm 31^{a} \\
(65,96)\end{array}$ & $\begin{array}{l}125 \pm 21^{\mathrm{b}} \\
(114,135)\end{array}$ & $\begin{array}{l}123 \pm 28^{b} \\
(109,137)\end{array}$ & $\begin{array}{l}115 \pm 22^{b} \\
(91,138)\end{array}$ \\
\hline & & $p<0.0001$ & $p=0.0051$ & $p=0.0197$ \\
\hline Systemic vascular & $120 \pm 53^{\mathrm{a}}$ & $47 \pm 9^{b}$ & $42 \pm 13^{b}$ & $45 \pm 9^{b}$ \\
\hline resistance index & $(94,146)$ & $(43,52)$ & $(35,48)$ & $(36,54)$ \\
\hline (dynes second $\mathrm{cm}^{-5} \mathrm{~kg}^{-1}$ ) & & $p<0.0001$ & $p<0.001$ & $p=0.0025$ \\
\hline Stroke volume index & $1.2 \pm 0.2^{\mathrm{a}}$ & $1.3 \pm 0.2^{\mathrm{a}}$ & $1.3 \pm 0.3^{\mathrm{a}}$ & $1.4 \pm 0.3^{\mathrm{a}}$ \\
\hline$\left(\mathrm{mL}\right.$ beat $\left.{ }^{-1} \mathrm{~kg}^{-1}\right)$ & $(1.1,1.3)$ & $(1.1,1.4)$ & $(1.2,1.5)$ & $(1.1,1.7)$ \\
\hline
\end{tabular}




\begin{tabular}{|c|c|c|c|c|}
\hline Oxygen extraction ratio & $25 \pm 7^{\mathrm{a}}$ & $16 \pm 5^{b}$ & $14 \pm 4^{\mathrm{b}}$ & $13 \pm 3^{\mathrm{b}}$ \\
\hline \multirow[t]{2}{*}{$(\%)$} & $(17,33)$ & $(10,21)$ & $(11,17)$ & $(9,16)$ \\
\hline & & $p=0.0244$ & $p=0.0321$ & $p=0.0035$ \\
\hline Respiratory rate & $10 \pm 4^{\mathrm{a}}$ & $13 \pm 4^{\mathrm{a}}$ & $14 \pm 4^{\mathrm{a}}$ & $14 \pm 4^{\mathrm{a}}$ \\
\hline (breaths minute $^{-1}$ ) & $(9,12)$ & $(11,14)$ & $(12,16)$ & $(10,18)$ \\
\hline $\mathrm{PaO}_{2}$ & $508 \pm 24^{\mathrm{a}}$ & $525 \pm 17^{a}$ & $427 \pm 148^{a}$ & $460 \pm 21^{\mathrm{a}}$ \\
\hline (mmHg) & $(483,533)$ & $(506,543)$ & $(342,512)$ & $(438,483)$ \\
\hline $\mathrm{PaCO}_{2}$ & $51 \pm 16^{\mathrm{a}}$ & $49 \pm 10^{\mathrm{a}}$ & $48 \pm 6^{\mathrm{a}}$ & $46 \pm 7^{b}$ \\
\hline (mmHg) & $(46,55)$ & $(46,53)$ & $(46,49)$ & $(43,49)$ \\
\hline Temperature & $36.6 \pm 0.4^{\mathrm{a}}$ & $36.5 \pm 0.4^{\mathrm{a}}$ & $36.6 \pm 0.4^{\mathrm{a}}$ & $36.6 \pm 0.5^{\mathrm{a}}$ \\
\hline$\left({ }^{\circ} \mathrm{C}\right)$ & $(36.3,36.8)$ & $(36.1,37.0)$ & $(36.2,37.0)$ & $(36.0,37.1)$ \\
\hline Lactate & $1.3 \pm 0.1^{\mathrm{a}}$ & $0.9 \pm 0.1^{b}$ & $1.0 \pm 0.1^{\mathrm{b}}$ & $1.1 \pm 0.32^{\mathrm{ab}}$ \\
\hline$(\mathrm{mmol} / \mathrm{L})$ & $(1.1,1.4)$ & $(0.7,1.0)$ & $(1.1,1.4)$ & $(0.8,1.4)$ \\
\hline & & $p=0.0012$ & $p=0.0103$ & \\
\hline
\end{tabular}

Data expressed as mean \pm standard deviation (95\% confidence intervals) and represents the pooled data from figure 2.3. Different letters indicate significant difference with dexmedetomidine post administration. 
CHAPTER 3

GENERAL DISCUSSION AND FINAL CONCLUSIONS 


\subsection{GENERAL DISCUSSION}

The aim of this investigation was to evaluate the cardiorespiratory effects elicited by the administration of intravenous (IV) lidocaine to treat the vagal-mediated bradycardia that results from dexmedetomidine's actions on increasing systemic vascular resistance.

Dexmedetomidine is the most popular alpha-2 agonist in small animal practice. It provides sedative and analgesic effects, and is used to facilitate diagnostic and minor surgical procedures under heavy sedation, even in aggressive patients, or as premedication prior to general anesthesia. However, dexmedetomidine impacts the cardiovascular system profoundly by causing an increase in vascular resistance from vasoconstriction, and hypertension that triggers a baroreceptor reflex, in addition to direct central vagal stimulation, which results in bradycardia (Tobias \& Chrysostomou 2013; Cepiel et al. 2018). The effects of vagal stimulation result in an increase in the permeability to potassium, which hyperpolarizes the cell and reduces the rate of firing, resulting in bradycardia (Pinnell et al. 2007).

Dexmedetomidine also has a negative dromotropic effect and increases atrial effective refractory period in humans (Ergul et al. 2015). The decrease in heart rate can exceed 50\% and result in a reduction in cardiac output of similar magnitude (Granholm et al. 2007; Flaherty 2013); for this reason dexmedetomidine is mostly recommended in healthy patients that are able to tolerate these conditions, and avoided in compromised patients with concomitant pathologies, even subclinical, because it can result in a significant decrease in perfusion and cardiovascular collapse (Chen et al. 2012; Flaherty 2013).

Lidocaine has antiarrhythmic actions and is classified as a class IB antiarrhythmic, able to depress the fast inflow current of sodium during phase 0 of the action potential, present 
preferentially in atrial cells, the His-Purkinje system cells and ventricular cells, but less important in the SA and AV nodal cells, in which slow sodium-calcium channels are more relevant to generate the action potential (Pinnell et al. 2007; Katz 2011; Klein 2013; Hall 2016). Therefore, lidocaine is mostly indicated for ventricular arrhythmias, which have a distinct phase 0 of the cardiac cycle where the increased permeability to the inflow of sodium can predispose to depolarizations triggered by ectopic pacemaker activity. For this same reason, it is assumed that lidocaine is ineffective for most types of supraventricular arrhythmias because in contrast to the cardiac myocyte action potential, in the SA and $\mathrm{AV}$ nodal cells, a decrease in membrane permeability to potassium, a slow inward current because of calcium influx via calcium channels and an increased sodium current because of sodium-calcium exchange, are all part of phase 0 , and once the threshold potential is reached, L-type calcium channels open, calcium ions enter the cell, and depolarization occurs (Pinnell et al. 2007; Miller et al. 2018).

Interestingly, lidocaine has been shown to increase heart rate in dogs with increased vagal tone (Lieberman et al. 1968) and to convert atrial fibrillation to sinus rhythm in dogs with increased vagal stimulation in different studies (David et al. 1990; Moïse et al. 2005), which demonstrates that in specific supraventricular arrhythmias in which increased vagal tone is involved, lidocaine can have an effective antiarrhythmic action. However, cases should be selected under these conditions of increased vagal tone, because lidocaine can worsen the arrhythmia in cases of atrioventricular blocks and escape rhythms due to the possibility of inhibiting the rate of escape beats and could result in asystole, especially if the location of the block is lower in the His bundle (Aravindakshan et al. 1977).

In the clinical setting at the Ontario Veterinary College, the administration of IV lidocaine when used as a constant rate infusion (CRI) in anesthetized dogs to provide intraoperative 
analgesia, was noticed to increase the heart rate of bradycardic dogs, with or without atrioventricular blocks, that had received dexmedetomidine in their premedication and that were therefore under increased vagal tone. This effect of lidocaine against dexmedetomidine-induced bradycardia has not been described in the literature, which prompted the present investigation in order to assess lidocaine's effectiveness and influence on other cardiovascular variables that are also profoundly affected by dexmedetomidine, including mean arterial pressure, systemic vascular resistance, cardiac output, and tissue perfusion. It is also possible that the effects of lidocaine on counteracting dexmedetomidine-induced bradycardia could also be different between conscious and anesthetized dogs, since the decrease in vascular resistance caused by inhalational anesthetics can attenuate the increase caused by dexmedetomidine on this variable, which is the triggering factor for the bradycardia (Flacke et al. 1993; Pagel et al. 1998). Therefore, this study assessed the effects of lidocaine in conscious dogs sedated with IV dexmedetomidine and in isofluraneanesthetized dogs administered IV dexmedetomidine.

In this study, dexmedetomidine $\left(10 \mu \mathrm{g} \mathrm{kg}^{-1}, \mathrm{IV}\right)$ was administered to purpose-bred Beagle dogs in a randomized crossover study, where they received dexmedetomidine in two separate scenarios while conscious and sedated with dexmedetomidine, and once more while anesthetized with isoflurane. One of the sedated groups (SED1) received lidocaine (2 $\left.\mathrm{mg} \mathrm{kg}^{-1}, \mathrm{IV}\right) 20$ minutes after dexmedetomidine, and cardiorespiratory effects were assessed for 30 minutes on that single lidocaine dose; then, the lidocaine dose was repeated and a CRI started immediately at $50 \mu \mathrm{g} \mathrm{kg}^{-1}$ minute $^{-1}$ for 30 minutes, and cardiorespiratory effects assessed once again, and lastly, cardiorespiratory effects were assessed 30 minutes following cessation of the CRI. The other sedated group (SED2) did not receive the single dose alone of lidocaine and instead the single dose and CRI were administered 5 minutes after the dexmedetomidine and the cardiorespiratory effects 
assessed for 30 minutes and then again 30 minutes following cessation of the CRI. The isofluraneanesthetized group (ISO) was maintained at an end-tidal isoflurane concentration of $1.2 \%$ and then administered the dexmedetomidine, and cardiorespiratory measurements completed as for the first sedated group, except with a higher CRI of $100 \mu \mathrm{g} \mathrm{kg}^{-1} \mathrm{~min}^{-1}$.

The dose of dexmedetomidine used in this investigation was within the recommended range and allowed for homogeneous plasma concentrations after IV administration, with a duration of action appropriate for the assessment of its cardiorespiratory effects for the length of the experiments (Kuusela et al. 2000; Riviere 2018). Likewise, the dose of lidocaine and the treatment modalities were based on its duration of action and recommended doses used in conscious and anesthetized patients (Ngo et al. 1997; Nunes de Moraes et al. 1998; Valverde et al. 2004).

In this study, lidocaine was an effective treatment to counteract dexmedetomidine-induced bradycardia in all groups. Heart rate increased significantly, systemic vascular resistance index and mean arterial pressure decreased, and cardiac index improved, and all of these variables were considered to fall within recommended ranges for anesthetized or sedated scenarios. One of the goals of this study was to assess the effects of lidocaine in different scenarios common to anesthesia practice, and although no statistical comparison was carried out between the groups, systemic vascular resistance index and mean arterial pressure were lower in the isoflurane group than in the sedated groups, most likely due to the vasodilatory effects of isoflurane (Newberg et al. 1984; Merin et al. 1991; Mutoh et al. 1997). In this study, dexmedetomidine resulted in a range (95\% confidence interval) in systemic vascular resistance index and mean arterial pressure of 119 to 166 dynes second $\mathrm{cm}^{-5} \mathrm{~kg}^{-1}$ and 119 to $133 \mathrm{mmHg}$ in the SED1 group, respectively; of 183 to 244 dynes second $\mathrm{cm}^{-5} \mathrm{~kg}^{-1}$ and 141 to $153 \mathrm{mmHg}$ in the SED2 group, respectively; whereas the ISO group had a lower range of 94 to 146 dynes second $\mathrm{cm}^{-5} \mathrm{~kg}^{-1}$ and 107 to $119 \mathrm{mmHg}$, 
respectively, compared to lower ranges of 48 to 54 dynes second $\mathrm{cm}^{-5} \mathrm{~kg}^{-1}$ and 99 to $106 \mathrm{mmHg}$, respectively, in conscious dogs (Haskins et al. 2005) and mean \pm standard deviation values of 76 \pm 25 dynes second $\mathrm{cm}^{-5} \mathrm{~kg}^{-1}$ and $79 \pm 15 \mathrm{mmHg}$, respectively, in dogs kept anesthetized with an end-tidal concentration (FE'Iso) of 1.3\% (Valverde et al. 2012), similar to the concentration used in this study of $1.19 \%$.

Heart rate after dexmedetomidine administration was also higher in the ISO group (range of 63 to 83 beats $\min ^{-1}$ ) than in the SED1 ( 38 to 44 beats $\min ^{-1}$ ) and SED2 (31 to 43 beats $\min ^{-1}$ ) groups, because the lower vascular resistance present in the ISO group was less likely to elicit the baroreceptor reflex, and consequently less vagal stimulation results from it. Despite these differences, lidocaine was also effective at improving the cardiorespiratory changes caused by dexmedetomidine in isoflurane-anesthetized dogs. It was also apparent that in the sedated group that received the lidocaine bolus and CRI shortly after dexmedetomidine (SED2), the benefits of lidocaine in increasing heart rate and cardiac index, and decreasing systemic vascular resistance index and mean arterial pressure, were of a lower magnitude than for the other groups, most likely due to higher plasma concentrations of dexmedetomidine at the time of lidocaine administration.

The use of lidocaine to treat dexmedetomidine-induced bradycardia represents a viable alternative to the use of anticholinergic drugs or the reversal with its specific antagonist, atipamezole. The increase in heart rate is more physiological than that caused by anticholinergic drugs because the increase in heart rate is less pronounced, which if excessive, often results in hypertension and a lower cardiac index (Alibhai et al. 1996; Ko et al. 2001; Sinclair et al. 2003; Moraes et al. 2004a; Moraes et al. 2004b; Congdon et al. 2011). Lidocaine instead increases heart rate to values that are closer to those found in conscious dogs (range of 83 to 91 beats $\min ^{-1}$ ) (Haskins et al. 2005) and the degree of increase in heart rate allowed for an increase in cardiac 
output of up to $19 \%, 36 \%$ and $56 \%$ with the first lidocaine dose in the SED1, SED2 and ISO groups, respectively, and further increased from that value by $20 \%$ in the SED1 with the CRI and remained increased in the other two groups. The range in cardiac index after dexmedetomidine administration was 61 to $76 \mathrm{~mL}$ minute ${ }^{-1} \mathrm{~kg}^{-1}$ in the SED1 group and 44 to $56 \mathrm{~mL}$ minute ${ }^{-1} \mathrm{~kg}^{-1}$ in the SED 2 group, compared to values of 156 to $174 \mathrm{~mL}$ minute ${ }^{-1} \mathrm{~kg}^{-1}$ in conscious dogs (Haskins et al. 2005), and increased to a range of 75 to $109 \mathrm{~mL}$ minute ${ }^{-1} \mathrm{~kg}^{-1}$ in the SED1 group, and to 62 to $75 \mathrm{~mL}$ minute ${ }^{-1} \mathrm{~kg}^{-1}$ in the SED2 group after lidocaine administration. In the ISO group, cardiac index with dexmedetomidine was in the range of 65 to $96 \mathrm{~mL}$ minute ${ }^{-1} \mathrm{~kg}^{-1}$ and increased to 114 to $137 \mathrm{~mL}$ minute ${ }^{-1} \mathrm{~kg}^{-1}$ after lidocaine administration, to values that are closer to those observed in dogs kept anesthetized at $1.3 \% \mathrm{FE}^{\prime} \mathrm{Iso}$ (mean \pm standard deviation values of $159 \pm 35 \mathrm{~mL}^{\text {minute }}{ }^{-}$ ${ }^{1} \mathrm{~kg}^{-1}$ ) without the presence of any other anesthetic drugs (Valverde et al. 2012).

In addition, in these circumstances, lidocaine decreased systemic vascular resistance without compromising mean arterial pressure because it remained within recommended values in all groups, range of 94-108 $\mathrm{mmHg}$, of 111-120 $\mathrm{mmHg}$ and of 66-87 $\mathrm{mmHg}$ for the SED1, SED2 and ISO group, respectively, which are similar to reported values for conscious and anesthetized dogs (Haskins et al. 2005; Valverde et al. 2012). The other alternative to treat dexmedetomidine's bradycardia includes the use of the specific antagonist atipamezole, however its effects are inconsistent and it also reverses the analgesia and sedation (Granholm et al. 2007; Zatrock et al. 2019), whereas lidocaine's analgesic actions (Valverde et al. 2004) may enhance the overall level of analgesia.

One of the main limitations of this study was the use of a single dose of dexmedetomidine without a CRI. This could result in clearance of dexmedetomidine over time, which also allows for partial recovery of cardiorespiratory function, independent of lidocaine's effects. It is very 
likely that lidocaine's effects were favoured by this aspect of the study design; however, several studies have demonstrated that despite decreasing plasma concentrations of IV dexmedetomidine, the cardiorespiratory effects from $10 \mu \mathrm{g} \mathrm{kg}^{-1}$ are maintained for up to 120 minutes (Kuusela et al. 2000; Pascoe et al. 2006; Pascoe 2014), which were within the duration of the experiment at which lidocaine's effects were assessed in this study.

The other limitation of this investigation was the use of young adult healthy female research Beagles under controlled conditions, in which only specific drugs were included in the study (dexmedetomidine and lidocaine in sedated groups; dexmedetomidine, lidocaine and isoflurane in the anesthetized group). This scenario is different from many clinical situations, in which other pharmacological groups, such as opioids, benzodiazepines, and ketamine could be present and exert other cardiorespiratory effects that may counteract or facilitate the specific effects of drugs included in this study. 


\subsection{FINAL CONCLUSIONS}

This investigation demonstrated the following results:

1. Lidocaine was effective in treating the bradycardia induced by dexmedetomidine in research dogs and is a feasible and reliable alternative to the use of anticholinergics or reversal of dexmedetomidine with atipamezole.

2. The response to lidocaine can vary in its magnitude according to the anesthetic protocol (sedation or general anesthesia) in which it is assessed, according to the time of administration.

3. Inhalational anesthesia and the associated vasodilation attenuates the increase in vascular resistance caused by dexmedetomidine.

4. Cardiac index was improved after lidocaine administration to within acceptable values for sedation or general anesthesia.

5. Systemic vascular resistance index and mean arterial pressure were both decreased after lidocaine administration to values more accordingly to a dog at rest.

6. Lidocaine is a feasible treatment for dexmedetomidine-induced bradycardia. 


\subsection{REFERENCES}

Alibhai HI, Clarke KW, Lee YH, Thompson J. Cardiopulmonary effects of combinations of medetomidine hydrochloride and atropine sulphate in dogs. Vet Rec 1996; 138:11-13.

Aravindakshan V, Kuo Cs, Gette LS. Effect of lidocaine on escape rate in patients with complete atrioventricular block. Am J Cardiol 1977; 40:177-183.

Cepiel A, Noszczyk-Nowak A, Janiszewski A, Pasławski R, Pasławska U. Effect of xylazine, medetomidine and dexmedetomidine on cardiac conduction in pigs. Med Weter 2018; 74:187-192.

Chen CY, Chen KS, Chang KM, Lee WM, Chang SC, Wang HC. Dexmedetomidine related bradycardia leading to cardiac arrest in a dog. Pak Vet J 2012; 32:635-636.

Congdon JM, Marquez M, Niyom S, Boscan P. Evaluation of the sedative and cardiovascular effects of intramuscular administration of dexmedetomidine with and without concurrent atropine administration in dogs. J Am Vet Med Assoc 2011; 239:81-89.

David D, Lang RM, Neumann A, Borow KM. Parasympathetically modulated antiarrhythmic action of lidocaine in atrial fibrillation. Am Heart J 1990; 119:1061-1068.

Ergul Y, Unsal S, Ozyilmaz I, Ozturk E, Carus H, Guzeltas A. Electrocardiographic and electrophysiologic effects of dexmedetomidine on children. Pacing Clin Electrophysiol $2015 ; 38: 632-687$.

Flaherty D. Alpha2-adrenoceptor agonists in small animal practice. 1. Why they do what they do. In Practice 2013; 35:524-530.

Flacke WE, Flacke JW, Blow KD, McIntee DF, Bloor BC. Effect of dexmedetomidine, an a $\mathrm{a}_{2}$ agonist, in the isolated heart. J Cardiot Vasc Anest 1992; 6:418-423. 
Granholm M, McKusick BC, Westerholm FC, Aspegrén JC. Evaluation of the clinical efficacy and safety of intramuscular and intravenous doses of dexmedetomidine and medetomidine in dogs and their reversal with atipamezole. Vet Rec 2007; 160:891-897.

Hall JE. Rhythmical excitation of the heart. In: Guyton \& Hall Textbook of Medical Physiology (13 ${ }^{\text {th }}$ edn.). Hall JE (ed.). Elsevier, Philadelphia, USA. 2016; pp. 75-88.

Haskins S, Pascoe PJ, Ilkiw JE, Fudge J, Hopper K, Aldrich J. Reference cardiopulmonary values in normal dogs. Comp Med 2005; 55:156-161.

Katz AM. The Cardiac Action Potential. In: Physiology of the Heart (5 $5^{\text {th }}$ edn.). Katz AM (ed.). Lippincott Williams \& Wilkins, Philadelphia, USA. 2011; pp. 369-398.

Klein BG. Electrical activity of the heart. In: Cunningham's Textbook of Veterinary Physiology, (5 ${ }^{\text {th }}$ edn.). Klein BG (ed.). Elsevier-Saunders, St. Louis, USA. 2013; pp. 171-187.

Ko JC, Fox SM, Mandsager RE. Effects of preemptive atropine administration on incidence of medetomidine-induced bradycardia in dogs. J Am Vet Med Assoc 2001; 218:52-58.

Kuusela E, Raekallio M, Anttila M, Falck I, Mölsä S, Vanio O. Clinical effects and pharmacokinetics of medetomidine and its enantiomers in dogs. J Vet Pharmacol therap $2000 ; 23: 15-20$.

Lieberman NA, Harris RS, Katz RI, Lipschutz HM, Dolgin M, Fisher VJ. The effects of lidocaine on the electrical and mechanical activity of the heart. Am J Cardiol 1968; 22:375-380.

Merin RG, Bernard JM, Doursout MF, Cohen M, Chelly JE. Comparison of the effects of isoflurane and desflurane on cardiovascular dynamics and regional blood flow in the chronically instrumented dog. Anesthesiology 1991; 74:568-574.

Miller JM, Tomaselli GF, Zipes DP. Therapy for cardiac arrhythmias. In: Braunwald's Heart 
Disease: a textbook of cardiovascular medicine (1 $11^{\text {th }}$ edn.). Zipes DP, Libby P, Bonow RO, Mann DL, Tomaselli GF (eds.). Elsevier, Philadelphia, USA. 2018; pp. 670-729.

Moïse NS, Pariaut R, Gelzer ARM, Kraus MS, Jung SW. Cardioversion with lidocaine of vagally associated atrial fibrillation in two dogs. J Vet Cardiol 2005; 7:143-148.

Mutoh T, Nishimura R, Kim HY, Matsunaga S, Sasaki N. Cardiopulmonary effects of sevoflurane, compared with halothane, enflurane, and isoflurane, in dogs. Am J Vet Res 1997; 58:88590.

Newberg LA, Milde JH, Michenfelder JD. Systemic and cerebral effects of isoflurane-induced hypotension in dogs. Anesthesiology 1984; 60:541-546.

Ngo LY, Tam YK, Tawfik S, Coutts RT, Gray MR. Effects of intravenous infusion of lidocaine on its pharmacokinetics in conscious instrumented dogs. J Pharmac Sci 1997; 86:944-952.

Nunes de Moraes A, Dyson DH, O'Grady M, McDonell WN, Holmberg DL. Plasma concentrations and cardiovascular influence of lidocaine infusions during isoflurane anesthesia in healthy dogs and dogs with subaortic stenosis. Vet Surg 1998; 27:486-497.

Moraes AN, Mirakhur K, McDonell W, O'Grady M, Kerr C. Modification of the cardiopulmonary response to medetomidine in isoflurane anesthetized dogs following treatment with gltcopyrrolate. Vet Anaesth Analg 2004b; 31:13-14. (Abstract) https://doi.org/10.1111/j.1467-2995.2004.00220a.x

Moraes AN, O’Grady M, McDonell W, Kerr C, Mirakhur K. The echocardiographic effects of glycopyrrolate pretreatment on the response to medetomidine in dogs anesthetized with isoflurane. Vet Anaesth Analg 2004a; 31:14. (Abstract) https://doi.org/10.1111/j.14672995.2004.00220a.x 
Pagel PS, Proctor LT, Devcic A, Hettrick DA, Kersten JR, Tessmer JP, Farber NE, Schmeling WT, Waltier DC. A novel alpha2-adrenoceptor antagonist attenuates the early, but preserves the late cardiovascular effects of intravenous dexmedetomidine in conscious dogs. J Cardiothorac Vasc Anesth 1998; 12:429-434.

Pascoe PJ. The cardiopulmonary effects of dexmedetomidine infusions in dogs during isoflurane anesthesia. Vet Anaesth Analg 2014; 42:360-368.

Pascoe PJ, Raekallio M, Kuusela E, McKusick B, Granholm M. Changes in the minimum alveolar concentration of isoflurane and some cardiopulmonary measurements during three continuous infusion rates of dexmedetomidine in dogs. Vet Anaesth Analg 2006; 33:97-103.

Pinnell J, Turner S, Howell S. Cardiac muscle physiology. Continuing Education in Anaesthesia, Critical Care \& Pain 2007; 7:85-88.

Riviere JE. Absorption, distribution, metabolism and elimination. In: Veterinary Pharmacology and Therapeutics $\left(10^{\text {th }}\right.$ edn.). Riviere JE, Papich MG (eds.). Wiley-Blackwell, Hoboken, USA. 2018; pp. 8-40.

Sinclair MD, O'Grady MR, Kerr CL, McDonell WN. The echocardiographic effects of romifidine in dogs with and without prior or concurrent administration of glycopyrrolate. Vet Anaesth Analg 2003; 30:211-219.

Tobias JD, Chrysostomou C. Dexmedetomidine: antiarrhythmic effects in the pediatric cardiac patient. Pediatr Cardiol 2013; 34:779-785.

Valverde A, Gianotti G, Rioja E, Hathway E. Effects of high-volume and rapid-fluid therapy on cardiovascular function and hematological values during isoflurane-induced hypotension in healthy dogs. Can J Vet Res 2012; 76:99-108.

Valverde A, Doherty TJ, Hernández J, Davies W. Effect of lidocaine on the minimum alveolar 
concentration of isoflurane in dogs. Vet Anaesth Analg 2004; 31:264-271.

Zatrock KK, Sakai DM, Parry S, Campoy L, Martin-Flores M. Evaluation of atipamezole as a treatment for dexmedetomidine-induced cardiovascular depression in anesthetized cats. Am J Vet Res 2019; 80:455-460. 